PNL-4135

\title{
Aquifer Thermal Energy Storage Costs with a Seasonal Heat Source
}
R. W. Reilly
D. R. Brown
H. D. Huber

December 1981

Prepared for the U.S. Department of Energy under Contract DE-AC06-76RLO 1830

Pacific Northwest Laboratory Operated for the U.S. Department of Energy by Battelle Memorial Institute 
NO T I C E

This report was prepared as an account of work sponsored by the United States Government. Neither the United States nor the Department of Energy, nor any of their employees, nor any of their contractors, subcontractors, or their employees, makes any warranty, express or implied, or assumes any legal liability or responsibility for the accuracy, completeness or usefulness of any information, apparatus, product or process disclosed, or represents that its use would not infringe privately owned rights.

The views, opinions and conclusions contained in this report are those of the contractor and do not necessarily represent those of the United States Government or the United States Department of Energy.

\author{
PACIFIC NORTHWEST LABORATORY \\ operated by \\ BATTELLE \\ for the \\ UNITED STATES DEPARTMENT OF ENERGY \\ Under Contract DE-AC06-76RLO 1830
}

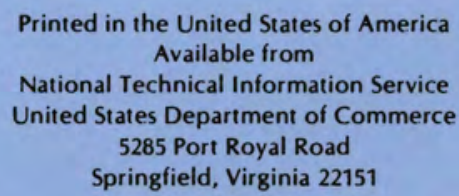

Price: Printed Copy \$ *; Microfiche $\$ 3.00$

NTIS

*Pages Selling Price

001-025 \$4.00

026-050 \$4.50

051-075 \$5.25

076-100 $\$ 6.00$

$101-125 \quad \$ 6.50$

126-150 \$7.25

$151-175 \quad \$ 8.00$

176-200 \$9.00

$201-225 \quad \$ 9.25$

226-250 \$9.50

$251-275 \quad \$ 10.75$

$276-300 \quad \$ 11.00$ 
R. W. Reilly

D. R. Brown

H. D. Huber

December 1981

Prepared for the U.S. Department of Energy under Contract DE-ACO6-76RLO 1830 


\section{SUMMARY}

Under the sponsorship of the Office of Energy Systems Research, U.S. Department of Energy, the cost of energy supplied by an aquifer thermal energy storage (ATES) system from a seasonal heat source was investigated. The work was performed in support of the Underground Energy Storage Program at the Pacific Northwest Laboratory (PNL).

This investigation considers only the storage of energy from a seasonal heat source. Cost estimates are based upon the assumption that all of the energy is stored in the aquifer before delivery to the end user. Systems with near-continuous heat sources would be able to supply some energy directly, and so only a portion of the energy would need to be stored underground. Delivery costs from such systems would be less than estimated here, since these systems would require less pumping energy, probably a reduction in pipe size and number of wells required, and potentially less heat loss within the aquifer.

Costs were estimated for point demand, residential development, and multidistrict city ATES systems using the computer code AQUASTOR. AQUASTOR was developed at PNL specifically for the economic analys is of ATES systems. In this analysis the cost effect of varying a wide range of technical and economic parameters was examined. Those parameters exhibiting a substantial influence on ATES costs were:

- Cost of purchased thermal energy

- Cost of capital

- Source temperature

- System size

- Transmission distance

- Aquifer efficiency

Purchased thermal energy cost is the major cost component of ATES delivered energy at purchase prices as low as $\$ 2 / M B T U$. The purchase price of thermal energy is magnified by price escalation and by thermal losses to the surroundings.

ATES systems are generally capital intensive projects. Thus, the cost of financing is important in determining a system's cost effectiveness. Municipalities offer financing possibilities at substantially lower interest than 
available from private entities. For this reason a municipality can consider a broader range of other system parameters as part of a potentially cost effective ATES system.

The source temperature deliverable to an ATES system plays an important role in system economics. Higher storage temperatures are expected to yield poorer thermal efficiencies due to tilting of the thermocline within the aquifer and conductive losses at the "bubble" interface. Despite the poorer thermal efficiency, a higher source temperature ultimately allows a higher deliverable temperature to the user, with more usable energy per pound of water. This higher energy density allows lower system fluid flow and directly reduces the amount of piping, pumping, well drilling, etc. required. Of course, higher temperature sources will probably command a higher purchase price. In this analysis, no attempt is made to differentiate between the cost of energy at various temperatures. Rather, the ATES costs estimated are based on examining a range of possible costs on a "what if" basis.

Significant economies of scale are available for ATES systems. In fact, fairly large systems are required to achieve cost effectiveness. For point demand systems costs are fairly constant for peak demands (at $25 \%$ load factor) 8 to $10 \mathrm{MW}$ and larger. Costs rise quickly for systems with peak demands less than 3 to $5 \mathrm{MW}$. Residential developments achieve the available economies of scale at larger system sizes due to the addition of extensive distribution piping networks.

Lengthy transmission distances can quickly result in prohibitive costs, especially for smaller (less than 5 MW) ATES systems. Extensive transmission systems can become a major portion of system capital cost as well as increasing the thermal loss to surroundings. Larger ATES systems are somewhat shielded from these cost effects due to large economies of scale available in piping systems.

The availability of a suitable aquifer is obviously of prime concern when considering an ATES installation. Potential site-specific availability of aquifers is not addressed here. This analysis assumes a (more or less) suitable aquifer exists and examines the cost effect of a range of possible thermal 
efficiencies. As expected, aquifer thermal efficiency is an important ATES cost parameter, especially with high purchased thermal energy costs.

ATES-delivered energy costs are compared with the costs of hot water generated from more conventional fuel sources in Figure 1 . Levelized costs for electrically heated water (at $5 \$ / \mathrm{kWh}$ and $7 \%$ annual escalation) and 011 heated water (at $\$ 1.00 /$ gallon and $8 \%$ annual escalation) are compared to costs for an ATES point demand configuration (at $10 \mathrm{MW}$ and $325^{\circ} \mathrm{F}$ source temperature). ATES costs are shown as a function of purchased thermal energy. Figure 1 shows both the potentially low delivered energy costs available from an ATES system and its strong cost dependence on the cost of purchased thermal energy.

Cost components are shown in Figure 2 for point demand and multi-district city ATES systems. Capital and thermal energy costs dominate. Capital costs, as a percentage of total costs, increase for the multi-district city due to the addition of a large distribution system. The proportion of total cost attributable to thermal energy would change dramatically if the cost of purchased thermal energy were varied.

ATES-delivered energy can be cost competitive with conventional energy sources under a number of economic and technical conditions. This investigation reports the cost of ATES under a wide range of assumptions concerning parameters important to ATES economics.

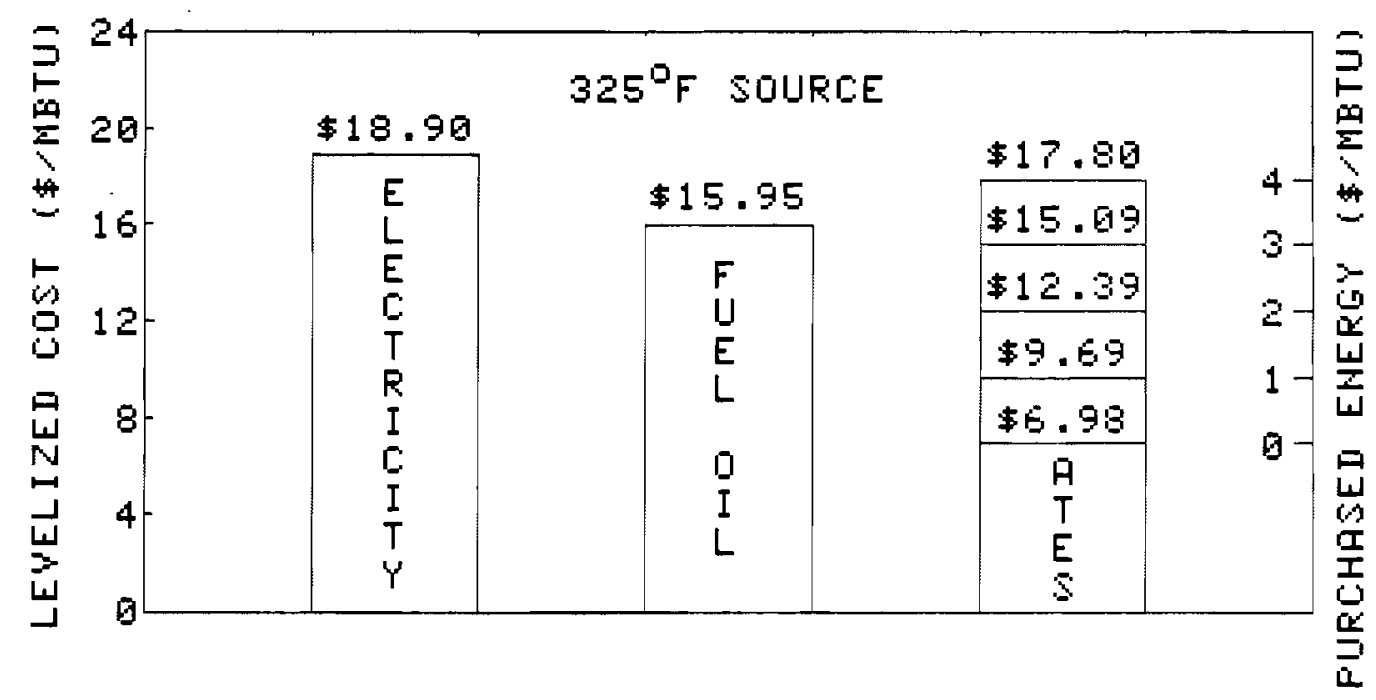

FIGURE 1. A Comparison of the Cost of ATES Against Conventiona 7 Technology 


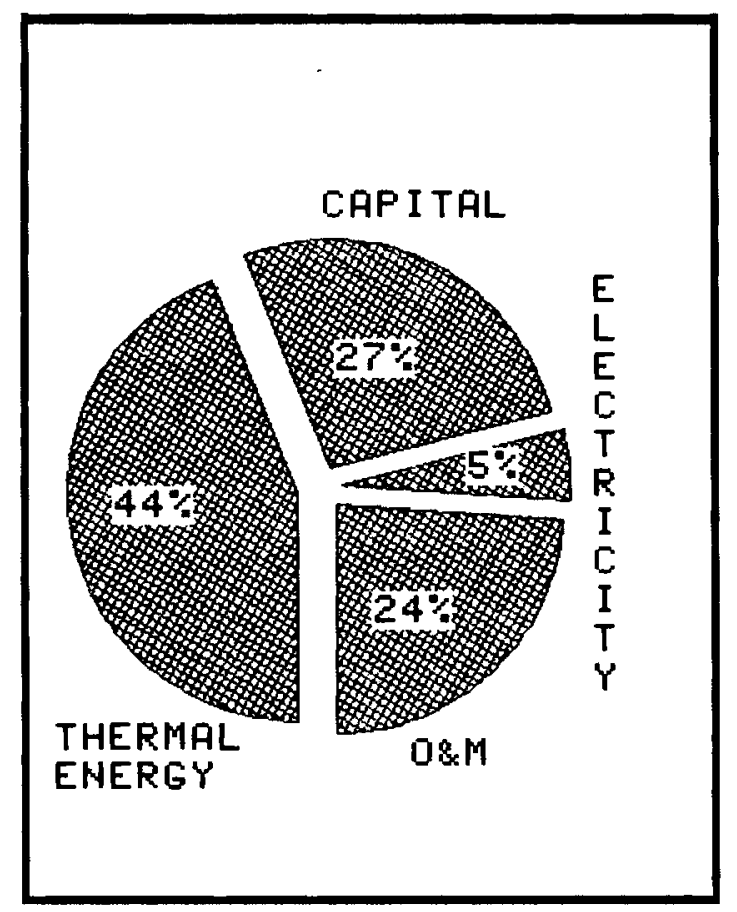

Point Demand System

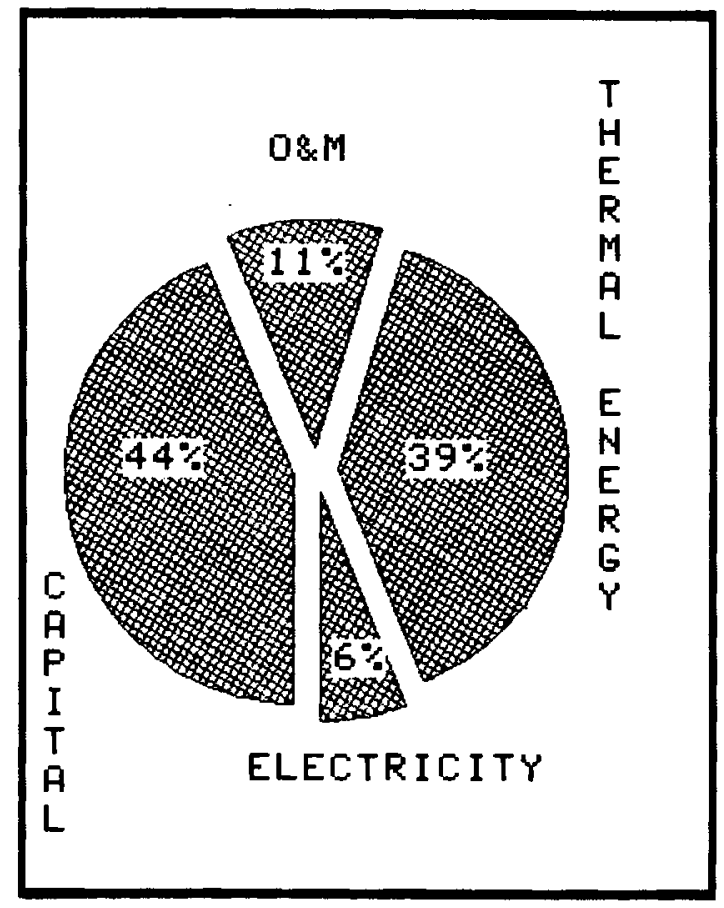

Multi-District City System

FIGURE 2. ATES Component Cost Breakdown 
SUMMARY

INTRODUCTION

THE TECHNOLOGY

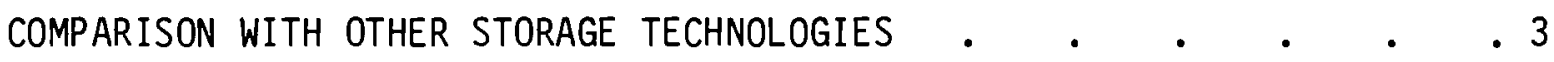

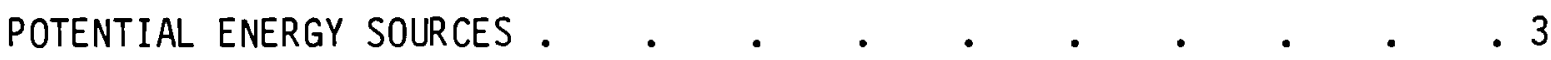

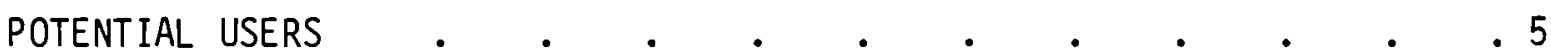

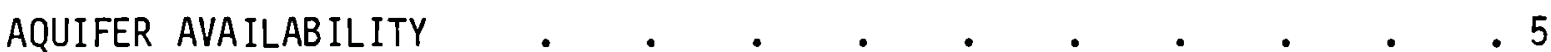

STATUS OF THE ATES TECHNOLOGY •

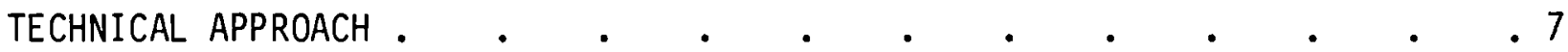

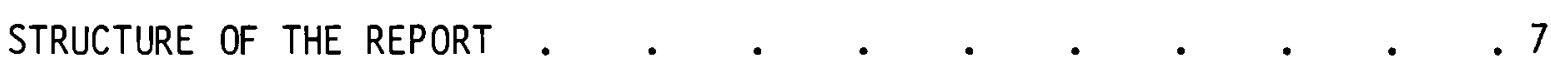

ECONOMIC METHODOLOGY

THE AQUASTOR CODE $\quad$ • $\quad$ • $\quad$ •

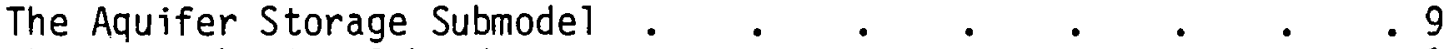

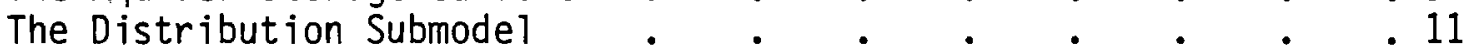

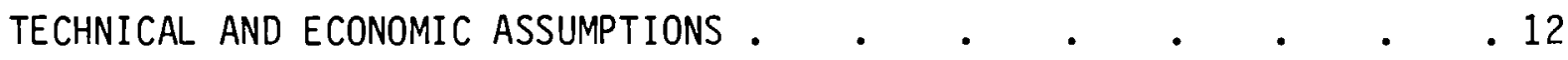

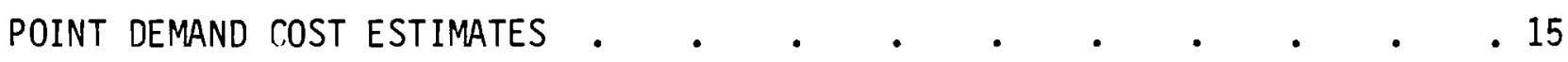

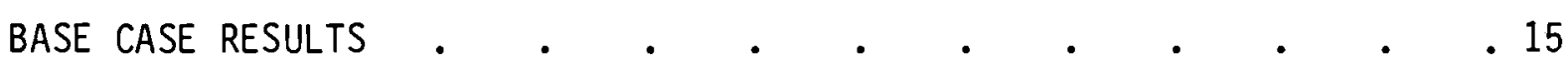

COMPONENT COST BREAKDOWN FOR ATES $\quad$ •

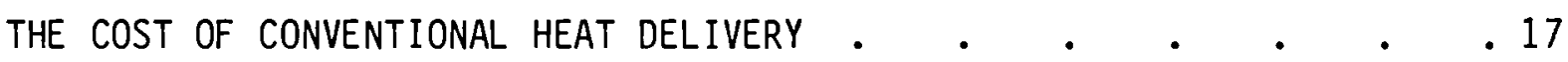

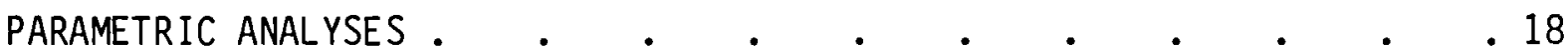

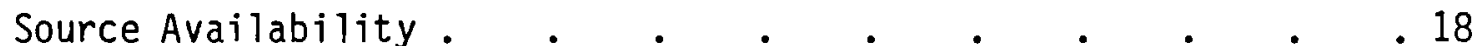

Well Parameters . . . . . . . . . . . . . 19

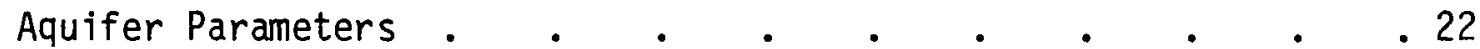

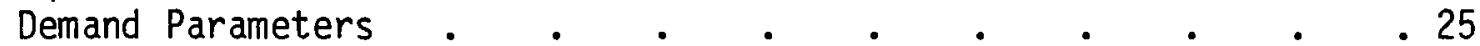

Economic Parameters . $. \quad . \quad . \quad . \quad . \quad . \quad . \quad . \quad 027$

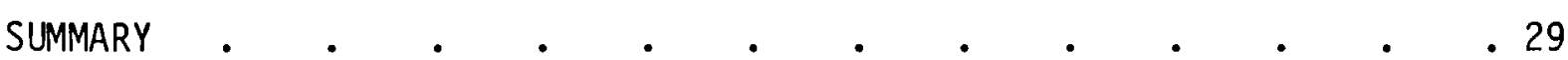

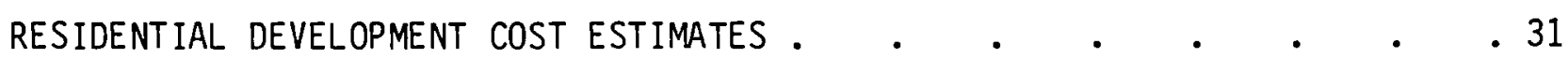




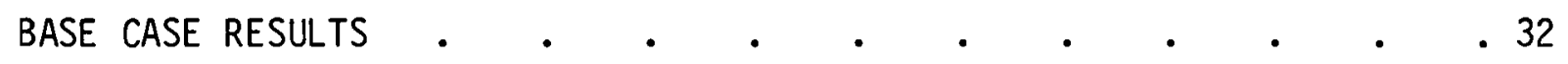

COMPONENT COST BREAKDOWN FOR RESIDENTIAL DEVELOPMENTS . . . . . 33

PARAMETRIC ANALYSES . . . . . . . . . . . . . . 34

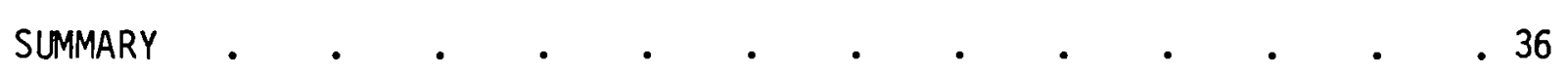

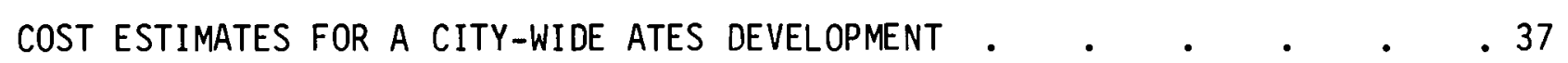

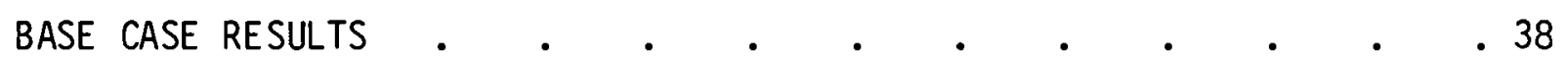

COMPONENT COST BREAKDOWN FOR CITY-WIDE ATES . $. \quad . \quad . \quad . \quad . \quad 38$

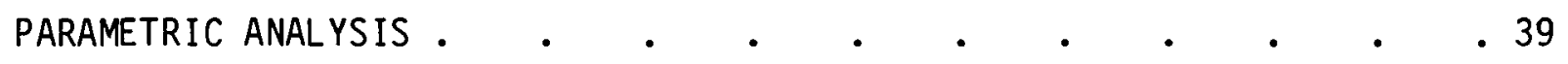

SUMMARY . . . . . . . . . . . . . . . . . . . 40

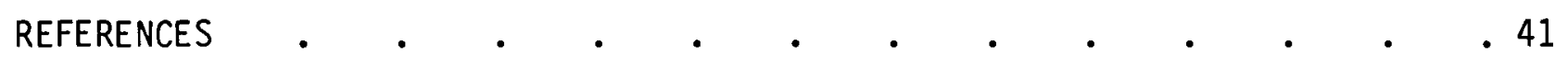

APPENDIX A - POINT DEMAND ATES COST ESTIMATES FOR $175^{\circ} \mathrm{F}$,

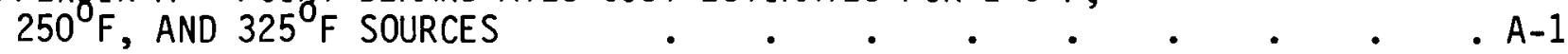

APPENDIX 8 - ${ }^{-R E S I D E N T I A L}$ DEVELOPMENT ATES COST ESTIMATES FOR
$175 \mathrm{~F}, 250^{\circ} \mathrm{F}$, AND $325^{\circ} \mathrm{F}$ SOURCES 


\section{FIGURES}

1 A Comparison of the Cost of ATES Against Conventional Technology . v

2 ATES Component Cost Breakdown . . . . . . . . . . vi

3 Aquifer Thermal Energy Storage . . . . . . . 2

4 System Modelled by Base Case . . . . . . . . . 15

5 Energy Cost as a Function of System Size . . . . . . 16

6 Cost Breakdown for the $325^{\circ} \mathrm{F}, 10 \mathrm{MW}$ ATES Base Case . . . 16

7 A Comparison of the Cost of ATES Against Conventional Technology . 17

8 Energy Cost as a Function of Source Availability . . . . 19

9 Energy Cost as a Function of Well Productivity . . . . 20

10 Energy Cost as a Function of Wel1 Cost . . . . . . 20

11 Energy Cost as a Function of Well Life . . . . . . . 21

12 Energy Cost as a Function of Aquifer Depth . . . . . 22

13 Energy Cost as a Function of Aquifer Performance . . . . 25

14 Energy Cost as a Function of Demand Load Factor a . . . 26

15 Energy Cost as a Function of Transmission Distance . . $\quad 27$

16 Energy Cost for a System with No User Heat Exchanger . . . 28

17 Energy Cost as a Function of the Cost of Electricity . . . 28

18 Energy Cost as a Function of the Cost of Purchased Thermal Energy 29

19 Energy Cost as a Function of Cost of Capital . . . . . 30

20 Base Case Results for Residential Developments . . . . 32

21 Cost Component Breakdown for Residential Developments . . . 33

22 Effect of Financing on Residential ATES Systems Seattle Single-Family Houses . . . . . . . . 34

23 Effect of Financing on Residential ATES Systems Minneapol is Single-Family Houses . . . . . . 
24 Effect of Financing on Residential ATES Systems -

Seattle Apartment Houses . . . . . . . . .

25 Effect of Financing on Residential ATES Systems -

Minneapolis Apartment Houses . . . . . . . . . 36

26 Layout of Heating Districts in Richland . • • • . . 37

27 Energy Cost as a Function of Cost of Capital -

City of Richland . . . . . . . . . . . . 38

28 Component Cost Breakdown for ATES - City of Richland . . . 39

29 Energy Cost as a Function of Transmission Distance -

City of Richland . . . . . . . . . . . 40

A-1 Energy Cost as a Function of Source Availability . . . . A.1

A-2 Energy Cost as a Function of Well Productivity . . . . A.2

A-3 Energy Cost as a Function of Well Cost . . . . . . A.3

A-4 Energy Cost as a Function of Well Life . . . . . . A.4

A-5 Energy Cost as a Function of Aquifer Depth . . . . . A.5

A-6 Energy Cost as a Function of Aquifer Performance . • . . A.6

A-7 Energy Cost as a Function of Demand Load Factor . . . . A.7

A-8 Energy Cost as a Function of Transmission Distance . . . A.8

A-9 Energy Cost as a Function of Electricity Cost . . . . . . A.9

A-10 Energy Cost as a Function of the
Price of Purchased Thermal Energy . A.10

A-11 Energy Cost as a Function of the Cost of Capital . . . . A.11

A-12 A Comparison of the Cost of ATES Against Conventional Technology A.12

B-1 Energy Cost as a Function of System Size

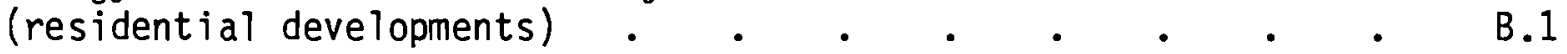

B-2 Energy Cost as a Function of Cost of Capital (residential development: Seattle houses) . . . . . B.2

B-3 Energy Cost as a Function of Cost of Capital (residential development: Minneapolis houses) . . . . B.3 
B-4 Energy Cost as a Function of Cost of Capital

(residential developments: Minneapolis apartments) . . . B.4

B-5 Energy Cost as a Function of Cost of Capital

(residential development: Seattle apartments) . . . . B.5

\section{TABLES}

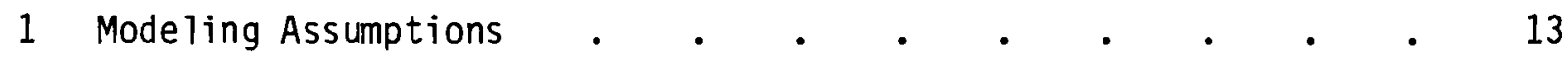

2 Cost Ranges for Selected Elements of ATES Systems _ . • 14 


\section{INTRODUCTION}

This document reports cost estimates for energy supplied by an aquifer thermal energy storage (ATES) system coupled to a seasonal heat source. The work was performed in support of the Underground Energy Storage Program at the Pacific Northwest Laboratory (PNL), DOE's lead laboratory for underground energy storage. Funding was provided by the Office of Energy Systems Research, U.S. Department of Energy under contract number DE-ACO6-76RLO 1830.

\section{THE TECHNOLOGY}

Seasonal storage of thermal energy in aquifers has the potential to make a significant contribution towards national energy conservation and fuel substitution goals. ATES can increase the overall thermodynamic efficiency of energy generation, while enabling waste heat and energies of opportunity to be substituted for scarce, costly fuels such as oil and natural gas.

An ATES installation in its simplest form is composed of a pair of ordinary water wells drilled into an aquifer (Figure 3). During operation, the ground water is withdrawn from the supply we11, heated (or chilled) in a heat exchanger, and then returned to the same aquifer through the storage we 11. (The two wells are horizontally separated to ensure that the storage bubble is unaffected by operations at the supply we11.) Thermal energy is stored in the aquifer until needed. At recovery the storage well is pumped, and the hot (or chilled) water is circulated through a heat exchanger to recapture the stored energy and then returned to the aquifer through the supply we11. The thermal energy can then be employed for space or process heating (cooling), thus reducing the need for generation of primary energy. The concept is simple, inexpensive, and relatively efficient.

Like any other energy storage technology, however, ATES is characterized by a net energy 10ss. Only about 50 to $90 \%$ of the input energy can be recovered for beneficial use, depending upon system design and aquifer characteristics. The remainder is dissipated to the surroundings.

The key to ATES's effectiveness is that the recovered energy is energy that would have been wasted or unavailable without seasonal storage, generally 
SEASONAL THERMAL ENERGY STORAGE

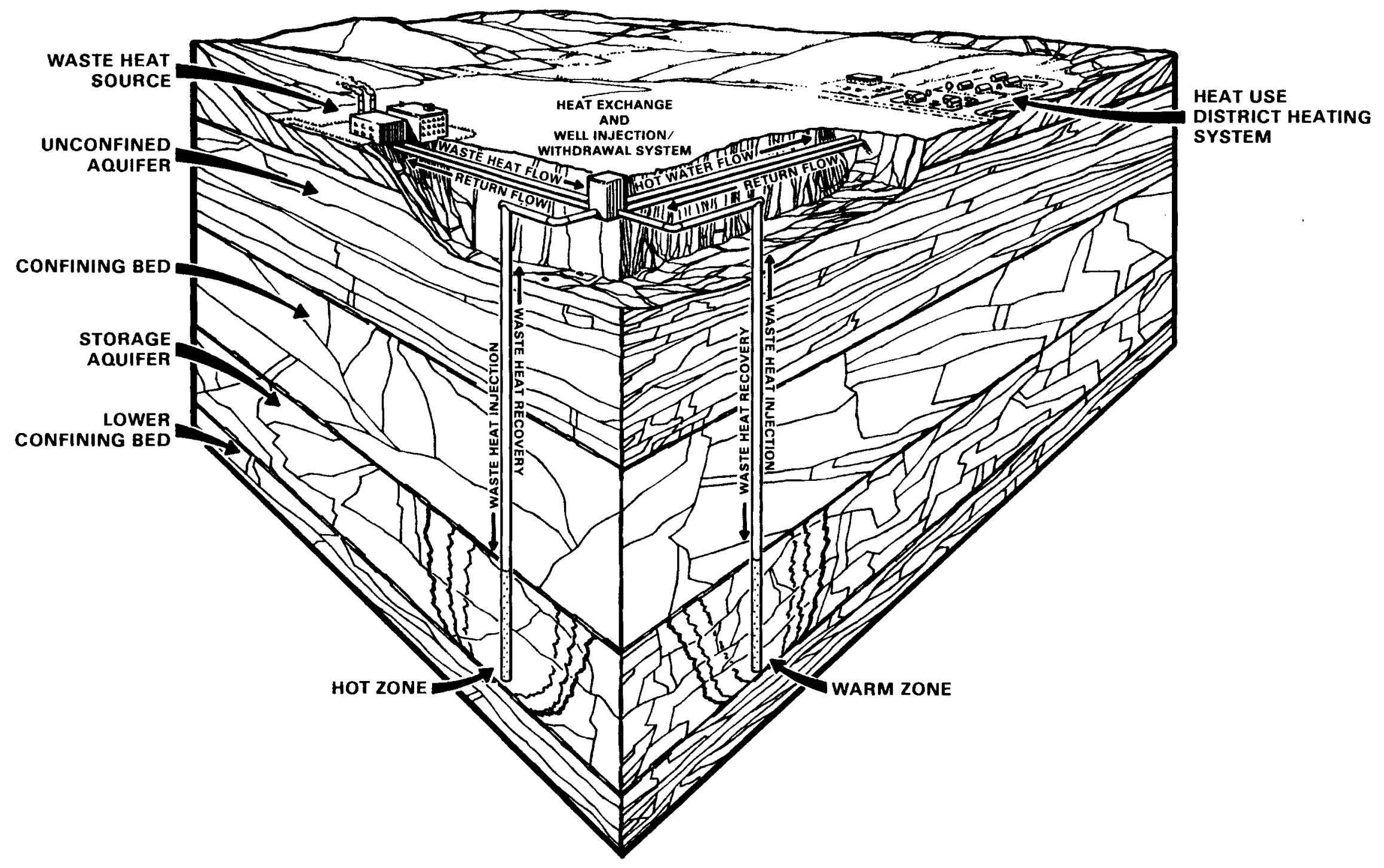

FIGURE 3. Aquifer Therma1 Energy Storage 
because no demand existed for it at the time of availability. This mismatch of energy supply and demand over time is the pervasive condition that makes ATES attractive.

\section{COMPARISON WITH OTHER STORAGE TECHNOLOGIES}

ATES is only one of many seasonal storage concepts under investigation. It appears to be competitive with, and probably superior to, other modes of longterm thermal storage for a number of reasons:

- Storage costs are not directly related to the total amount of energy stored because use of the aquifer is essentially free. Rather, storage costs are proportional to the rate of energy storage or retrieval. It is the rate of water injection and withdrawal that determines the number of wells, and well-related costs constitute the largest portion of the capital cost for a typical ATES installation.

- Energy is stored as heat or chill. Most waste energy and energies of opportunity exist in this same form of thermal energy, and many of the ultimate uses for the stored energy are in the form of heat or chill. Avoiding a transformation between energy forms (such as from thermal to electrical and back to thermal) eliminates the losses inherent in such transformations.

- Water is an inexpensive, widely available storage medium with a very high heat capacity. It is safe, and the technologies for its control are well developed.

- The water is not consumed by the storage process, but instead is available for continuous cycling (or for other uses).

- Aquifers provide natural thermal insulation.

- Aquifers provide safe containment for high-temperature, pressurized water.

- Aquifers are readily available over most of the nation.

- ATES readily permits the superposition of short-term storage cycles over the seasonal cycle. This characteristic makes ATES very flexible and suitable for a wide range of applications.

\section{POTENTIAL ENERGY SOURCES}

ATES, like any storage technology, can be effective only if there is a relatively inexpensive source of energy available. In general three major sources 
of thermal energy will be available for storage: cogenerated heat, climaterelated energy, and industrial waste heat.

Cogeneration is the simultaneous production of electricity and heat in the same facility, generally in constant proportions. It is a desirable mode of energy production because of its high efficiency: about $85 \%$ of the fuel's energy content is made available as electricity and hot water, as compared to an overall generation efficiency of about $33 \%$ in conventional electric plants. Despite this gain in efficiency, cogeneration is not widely practiced because the heat is generated according to electrical demand (electricity is usually the primary product), which seldom coincides with the demand for heat. Hence, there is the continuous problem of too little or too much heat to meet the demand, making the technology impractical for many applications. The availability of an efficient form of long-term storage for large amounts of heat (such as ATES) can make cogeneration attractive for many uses. Even if a storage coefficient of only $60 \%$ is available, the overall efficiency of the cogeneration/storage installation would be about $60 \%$, a considerable improvement over conventional modes of power generation. (1)

The second class of mismatched supply and demand is the use of climate energies of opportunity for heating and cooling of buildings. Winter chill is readily available in the form of snow, cold air, or cold surface water. Seasonal storage can make this energy available for surmer air conditioning. Likewise, summer heat can be captured for winter heating. In higher latitudes, where winter daylight is limited in duration and intensity, seasonal storage provides the only means of employing solar energy for significant amounts of space heating. In lower latitudes it may facilitate the cost-effective use of solar energy by reducing or eliminating backup systems normally required for solar installations.

Industrial waste heat is the third class of energy that is available for seasonal storage utilization. Seasonal storage of this year-round supply would extend its possible applications, and simultaneously reduce the need for expensive heat dissipation equipment at the plant site. 
POTENTIAL USERS

The market for thermal energy withdrawn from ATES systems is extensive, limited only by the economics of application. The market falls naturally into three segments: space heating and cooling, industrial process heat, and agriculture (including aquaculture). Total national energy consumption in 1977 was 75.8 quads. Space heating and cooling of residential and commercial sectors (including hot water for sanitary purposes) accounted for 19 quads or $25 \%$ of total consumption. Process steam and direct heat in the industrial sector totaled 15.4 quads or 20.3\%. Agriculture consumed about $2 \%$ (1.5 quads), chiefly in the form of liquified natural gas for the drying of grain, crop curing, and space heating.

Various investigations estimate that up to $55 \%$ of the nation's space heating and cooling demand could be economically provided by conventional hot water district heating/cooling systems. (2) It is unclear how many existing installations could benefit from the added reliability and reduced system cost offered by ATES systems, but it is likely that this number is significant. Likewise, about $5-10 \%$ of the nation's total energy consumption could be provided by ATES process heat systems, based on technical evaluations. (3) Finally, agriculture and aquaculture appear to hold unlimited potential for the utilization of waste heat, at least from a technical viewpoint. Numerous pilot operations have demonstrated the ability of properly applied waste heat to increase the yield of existing crops and to enable cultivation of crops in areas previously too cold for those particular crops. Whether cost-effective operation can be demonstrated for agriculture using seasonally-stored energy remains to be seen.

\section{AQUIFER AVAILABILITY}

One factor governing market penetration for ATES will be the availability of a suitable aquifer. In general, this will not seriously constrain ATES on a national basis, since roughly $2 / 3$ of the nation is underlain by aquifers. (4) All aquifers are not suited to the ATES technology, however, and each potential installation will need to demonstrate the existence of a suitable geologic formation. 


\section{STATUS OF THE ATES TECHNOLOGY}

The Department of Energy, Office of Energy Systems Research, under the Thermal and Mechanical Energy Storage Program, maintains an ambitious research program to accelerate the commercialization of the ATES concept. The Pacific Northwest Laboratory, operated for DOE by Battelle Memorial Institute, is the lead laboratory for ATES research. At PNL, the Underground Energy Storage (UES) Program is undertaking a wide range of investigations aimed at commercialization of the ATES concept. These activities include field test facilities to investigate the response of aquifer systems to hot water injection, mathematical modelling of aquifer storage systems, environmental and institutional assessment of the ATES technologies, and economic assessment. Additionally, a number of ancillary activities have been undertaken to support the acceleration of the technology, including development of an extensive library on ATES and related technologies. 


\section{TECHNICAL APPROACH}

STRUCTURE OF THE REPORT

The purpose of this report is to provide cost estimates for thermal energy delivered by aquifer thermal energy storage systems coupled to a seasonal heat source. The most important factors contributing to the cost of ATES are identified, and the effect of these parameters on cost is assessed through a systematic sensitivity analysis. Three types of loads are investigated: point demands, residential developments, and a multi-district city. The point demand investigation estimates the cost of ATES-supplied process heat for an industrial user, or space conditioning heat for an entity with an existing hot water distribution system, such as an airport or university. The residential systems investigated are homogeneous developments of (1) single family homes and (2) high-rise apartment buildings, under two climatic conditions - a cold climate as typified by Minneapolis, Minnesota, and a moderately cool climate as typified by Seattle, Washington. The multi-district city investigated is Richland, Washington, with a climate midway between that of Seattle and Minneapolis.

This investigation considers only the storage of energy from a seasonal heat source. Hence, equipment and operating cost estimates are based upon the assumption that all of the energy is stored in the aquifer before delivery to the end user. Systems with near-continuous heat sources would be able to supply some energy directly, and so only a portion of the energy would need to be stored underground. Delivery costs from such systems would be less than estimated here, since these systems would require less pumping energy, probably a reduction in pipe size and number of wells required, and potentially less heat loss within the aquifer. The estimates presented here can be considered a ceiling for the cost of energy from continuous (or near-continuous) heat sources linked to an ATES system.

This report focuses solely upon economic assessment. Technical feasibility and institutional issues are not included here, but are treated in other publications issued by the Underground Energy Storage Program. 


\section{ECONOMIC METHODOLOGY}

The figure of merit for this cost analysis is the unit cost of delivered energy, expressed in dollars per million British thermal units ( $\$ / M B t u)$. This cost is the price that must be charged to the end user to recover all costs of production, including capital investment, purchased thermal energy, operating expenses, and taxes, as well as a specified rate of return on investment. This unit of cost can be directly compared to a per-unit cost of heat delivery from more conventional sources such as electric furnaces.

The unit cost of energy developed is a levelized cost, expressed in constant 1980 price levels. It is calculated in a discounted cash flow analysis, using the basic equation presented below. The complete life cycle of the ATES system is considered in the analysis, including exploration of the aquifer, installation of the storage and transmission systems, and a 30-year operating life.

$$
\$ / M B t u=\frac{\sum_{n=1, n y}\left[P W_{n} \times\left(C_{n}+E_{n}+T_{n}\right)\right]}{\sum_{n=1, n y}\left[P W_{n} \times B t u_{n}\right]}
$$

where:

$$
\begin{aligned}
\$ / M B t u & =\text { levelized unit cost of energy } \\
n y & =\text { operating life } \\
P W_{n} & =\text { present worth factor for year } n \\
C_{n} & =\text { capital expenditures in year } n \\
E_{n} & =\text { expenses in year } n \\
T_{n} & =\text { taxes paid in year } n \\
B t u_{n} & =\text { energy sold in year } n
\end{aligned}
$$

System design, cost estimation, cash flow analysis, and calculation of the levelized cost of energy delivery were all performed through use of a technoeconomic computer code called AQUASTOR. 
THE AQUASTOR CODE

AQUASTOR is a computer model for systematic investigation of the cost of energy from an Aquifer Thermal Energy Storage (ATES) system. AQUASTOR is extremely flexible, and can simulate heating systems (using stored hot water) or cooling systems (with stored chilled water). There is also the provision for cooling systems that employ stored hot water and absorption chillers. AQUASTOR combines system design functions with a detailed cash flow simulation routine to estimate the cost of ATES energy delivery. The code provides the flexibility to individually or collectively evaluate the impact of varying economic and technical assumptions and uncertainties on the cost of energy delivery.

The model consists of two parts: an aquifer storage submodel, and a distribution submodel. The storage submodel calculates the life cycle cost of energy production by simulating the exploration, development, and operation of an ATES storage system and the construction and operation of a transmission pipeline for delivering the energy to a distribution center. The distribution submodel calculates the life-cycle cost of energy delivery by simulating cash flows for construction and operation of a distribution system. Each of the submodel systems is considered to be its own operating entity with a tailored financial configuration, including its own tax rates and incentives, capital structure, and depreciation schedule. The code can simulate a two entity system (a private company selling stored energy to a municipal distribution system, for instance) or a single entity (by using the same financial structure for both sets of inputs).

\section{The Aquifer Storage Submodel}

The storage submodel employs energy source characteristics, aquifer efficiency characteristics and peak/annual flow requirements to design the storage and transmission systems. It uses a triple set of nested iterations to design heat exchangers, pipelines, and wellfields, balancing mass and thermal flows between the supply and demand portions of the system. These iterations take into account water and heat losses (gains) in both aquifer systems and in all pipelines. 
The storage submodel assumes that thermal energy is purchased from an external source on a \$/MBTU basis, and that the heat is delivered through a liquid medium (water). The code designs a shell and tube heat exchanger for extracting the energy, and calculates the pump size and pumping power required for operation of both sides of the heat exchanger.

AQUASTOR does not attempt to simulate fluid or thermal flow within the aquifer. Rather, it captures the relevant aquifer characteristics in three input parameters: fluid recovery fraction, thermal storage efficiency, and discovery aquifer temperature. The fluid recovery fraction is simply the ratio of the water volume recovered from the storage wellfield to the previously injected volume. It can vary from a fraction to greater than one, depending upon the nature of the aquifer being simulated, the temperature differential between the injected water and the in-situ water, and heating system response to temperature degradation. (Some users may shut down when the temperature of the recovered water starts to degrade; others may be able to continue operation by increasing flow rates, or by employing supplemental energy sources.) The thermal storage efficiency is similarly the ratio of the energy recovered to energy injected, both defined with respect to the discovery (natural) water temperature of the aquifer. Defining storage efficiency in this manner isolates aquifer storage efficiency from the characteristics of the above-ground equipment. The storage and supply wellfields may have different thermal efficiency factors (because of different injection temperatures and water recovery ratios); they will usually have different fluid recovery factors, the one being the reciprocal of the other.

The code employs a simple enthalpy balance to determine the average temperature of water recovered from the storage aquifer, once the injection temperature, natural aquifer temperature, and fluid and thermal recovery parameters have been specified. The wellfield and transmission pipline systems are designed based upon this average temperature.

The storage submodel operates on an average-year performance basis. In an actual ATES development, aquifer efficiency is expected to rise dramatically over the first several years of operation as the aquifer is conditioned to the temperature of storage by lost thermal energy, and it is expected to approach a 
steady state thereafter. In the present configuration of AQUASTOR, only the steady state situation is modelled.

A typical ATES system contains both "storage" and "supply" aquifer reservoirs. It is important to note that in most cases, both are actually thermal storage units. (Only if the injection temperature into the supply aquifer is equal to the discovery aquifer temperature will heat losses not occur. This will generally not be the case, given the range of natural aquifer temperatures, and typical rejection temperatures from heating devices.) Thermal losses in the supply aquifer can constitute a significant portion of the total cost of delivery.

The aquifer submodel estimates the cost of developing and operating energy collection and storage systems, and develops the life cycle cost of energy storage. The end result of this subprogram is a levelized unit cost of energy storage on a \$/MBtu basis. This stored energy is then "sold" to the distribution entity for input into the distribution system.

\section{The Distribution Submodel}

The distribution submodel develops a design for a hot (chilled) water distribution system and calculates annual capital, operating and maintenance costs for the system. Climate parameters are used to determine peak and average heat demands, load factors, and supplemental heat requirements (if any). The peak demand is then employed to design the fluid transmission lines: the pipe size and insulation thickness is automatically optimized to a lowest total cost based upon the mix of capital cost, thermal losses, and required pumping energy.

The input data consist of demand characteristics for a point demand, district heating system, or some combination. Materials and design options for piping, insulation, and casing are also input. If district heating is being modeled, the input data include city layout, characteristics of districts that constitute the city, and various options and adjustment factors.

The city is defined by its distance from the aquifer, climatic characteristics, and the number and type of districts within the city. Each district is a contiguous area consisting of buildings of similar heat demand and uniform 
density. Five district types, representing typical residential areas are defined; others can be added as necessary.

TECHNICAL AND ECONOMIC ASSUMPTIONS

The cost of aquifer heat storage was estimated using the technical and economic assumptions listed in Table 1. These assumptions are, in general, not optimistic, but rather reflect costs and conditions likely to exist in many parts of the nation. Additional cost information concerning specific ATES elements is given in Table 2 .

Nine base case configurations were generated in order to cover a range of potential conditions. These consisted of three source temperatures $\left(325^{\circ} \mathrm{F} /\right.$ $163^{\circ} \mathrm{C}, \quad 250^{\circ} \mathrm{F} / 121^{\circ} \mathrm{C}$, and $\left.175^{\circ} \mathrm{F} / 79^{\circ} \mathrm{C}\right)$, applied to each of three system sizes ( $3 \mathrm{MW}_{t}, 10 \mathrm{MW}_{t}$, and $50 \mathrm{MW}_{t}$ peak demand). These configurations were subsequently used as the base for parametric analysis to determine the importance of various economic and technical assumptions. 
TABLE 1. Modelling Assumptions

Economic Assumptions

System Startup

Start of Construction

Operating Life

Base Year for Cost Estimates

Cost Information

Electricity

Purchased Thermal Energy

Exploration Costs

Well Drilling and Casing

Price Escalation Information

General Inflation

Purchased Thermal Energy

Electricity

Capital Equipment

O\&M Expense

Financing Information

Mode

Interest Rate

Technical Assumptions

Energy Source

Availability

Supply Temperatures

Return Temperatures

Load Description

Peak Demand

Load Factor

Reject Temperature

Wellfield Description

We11 Depth

Well Spacing

Maximum We 11 Productivity

Supp ly Aquifer

Thermal Efficiency

Fluid Recovery Factor

Storage Aquifer

Thermal Efficiency

Fluid Recovery Factor

Transmission Systems

Pipe

Insulation

Storage System Construction

Distribution System Construction

Source-to-User Separation
January 1990

January 1987

30 years

January 1980

$\$ .05 / \mathrm{kWh}$

$\$ 2.00 / \mathrm{MBtu}$

$\$ 100,000-\$ 400,000 /$ site

$\$ 100 /$ foot

$6 \% /$ year

$7 \% /$ year

$7 \% /$ year

$6 \% /$ year

$6 \% /$ year

municipal financing (no taxes) $10 \% /$ year

120 days/year

$325 \mathrm{~F} / 163 \mathrm{C}$

$250 \mathrm{~F} / 121 \mathrm{C}$

$175 \mathrm{~F} / 79 \mathrm{C}$

90F-100F

3, 10, and $50 \mathrm{MW}$

$25 \%$

$100 \mathrm{~F} / 38 \mathrm{C}$

400 feet

25 acres

$150,000 \mathrm{lb} / \mathrm{hr}(300 \mathrm{gpm})$

$85 \%$

$112 \%$

$70 \%$ @ $175 \mathrm{~F}$

$63 \%$ \& 250F

$60 \%$ @ $325 \mathrm{~F}$

$90 \%$ for al1 temperatures

schedule 40 carbon steel

calcium silicate

above ground

buried

3000 meters, one way 
TABLE 2. Cost Ranges for Selected Elements of ATES Systems

ATES E lement

Carbon Steel Pipe

(material only)

Calcium Silicate Insulation

(material + installation)

Polyurethane Insulation

(material + installation)

PVC Casing

(material only)

Steel Casing

(material only)

Valves

(equipment + installation)

Downhole Pumps

(equipment + installation)

Shell and Tube Heat Exchanger
Description

4" sch 40

12 " sch 40

$24 "$ sch 40

2" insul., 6" pipe

3" insul., 12" pipe

4" insul., 18" pipe

2" insul., 6" pipe

3" insul., 12" pipe

4" insul., 18" pipe

6" casing

12 " casing

$18^{\prime \prime}$ casing

12 " casing

24 " casing

36" casing

4"

12 "

24"

$300 \mathrm{gpm}, 200 \mathrm{ft}$ head

$300 \mathrm{gpm}, 400 \mathrm{ft}$ head

$1000 \mathrm{gpm}, 400 \mathrm{ft}$ head

$1000 \mathrm{ft}_{2}^{2}$ HTA

$5000 \mathrm{ft}^{2}$ HTA

$25,000 \mathrm{ft}^{2}$ HTA
Cost-1980 Dollars

$\$ 4.20 / f t$

$\$ 21.50 / f t$

$\$ 60.00 / \mathrm{ft}$

$\$ 8.50 / f t$

$\$ 18.00 / \mathrm{ft}$

$\$ 33.00 / \mathrm{ft}$

$\$ 8.00 / \mathrm{ft}$

$\$ 25.50 / \mathrm{ft}$

$\$ 50.00 / \mathrm{ft}$

$\$ 5.10 / \mathrm{ft}$

$\$ 11.00 / \mathrm{ft}$

$\$ 24.00 / f t$

$\$ 10.00 / \mathrm{ft}$

$\$ 24.00 / f t$

$\$ 50.00 / f t$

$\$ 520$ ea

$\$ 2350$ ea

$\$ 13,450$ ea

$\$ 10,600$ ea

$\$ 13,000$ ea

$\$ 32,600$ ea

$\$ 27,200$

$\$ 95,600$

$\$ 335,400$ 


\section{POINT DEMAND COST ESTIMATES}

\section{BASE CASE RESULTS}

In this section of the report cost estimates are developed for energy delivered from an ATES storage installation to a point demand. The system modelled is depicted in Figure 4. The ATES installation consists of a pair of well fields (in the same aquifer), two heat exchangers, and transmission piping that connects the four major elements. All piping is assumed to be composed of carbon steel pipe, with calcium silicate insulation and aluminum casing, constructed above ground. All of the energy available from the initial source is assumed to be stored in the aquifer during a 120-day period. This energy is then recovered from the aquifer during the period of a full year, at a 25\% load factor (annual average-to-peak flow ratio of .25). No distribution or end-use costs are included in the estimates.

The results of this analys is are presented in Figure 5, which shows how the cost of ATES storage varies with system size at three source temperatures. ATES is highly dependent upon economies of scale for cost-effective implementation: the cost curve is fairly flat beyond $8 \mathrm{MW}$, and tends to rise steeply for system sizes below $5 \mathrm{MW}$. As a figure of comparison, a $5 \mathrm{MW}$ system demand is approximately equal to the peak system demand of 350 single family houses in the Minneapolis-St Paul climate.

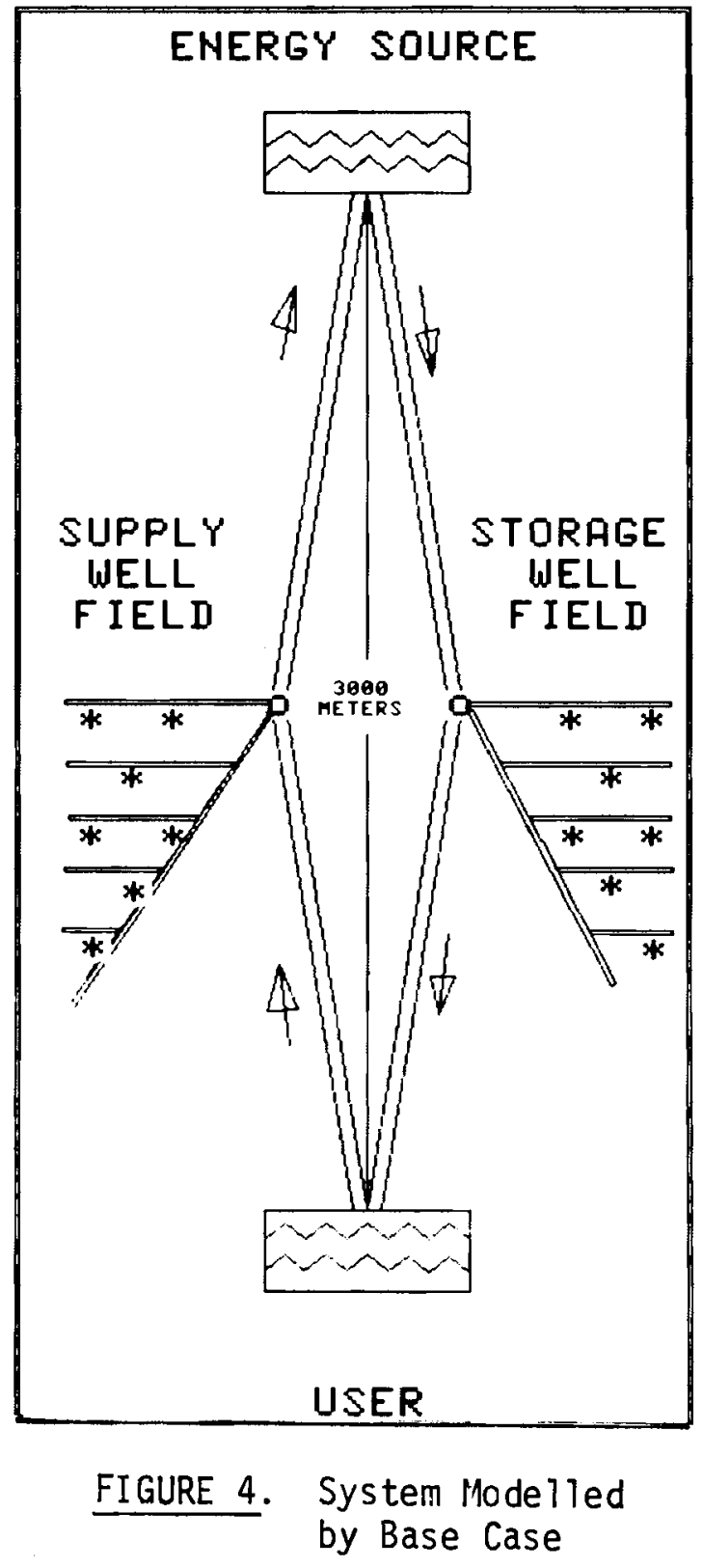




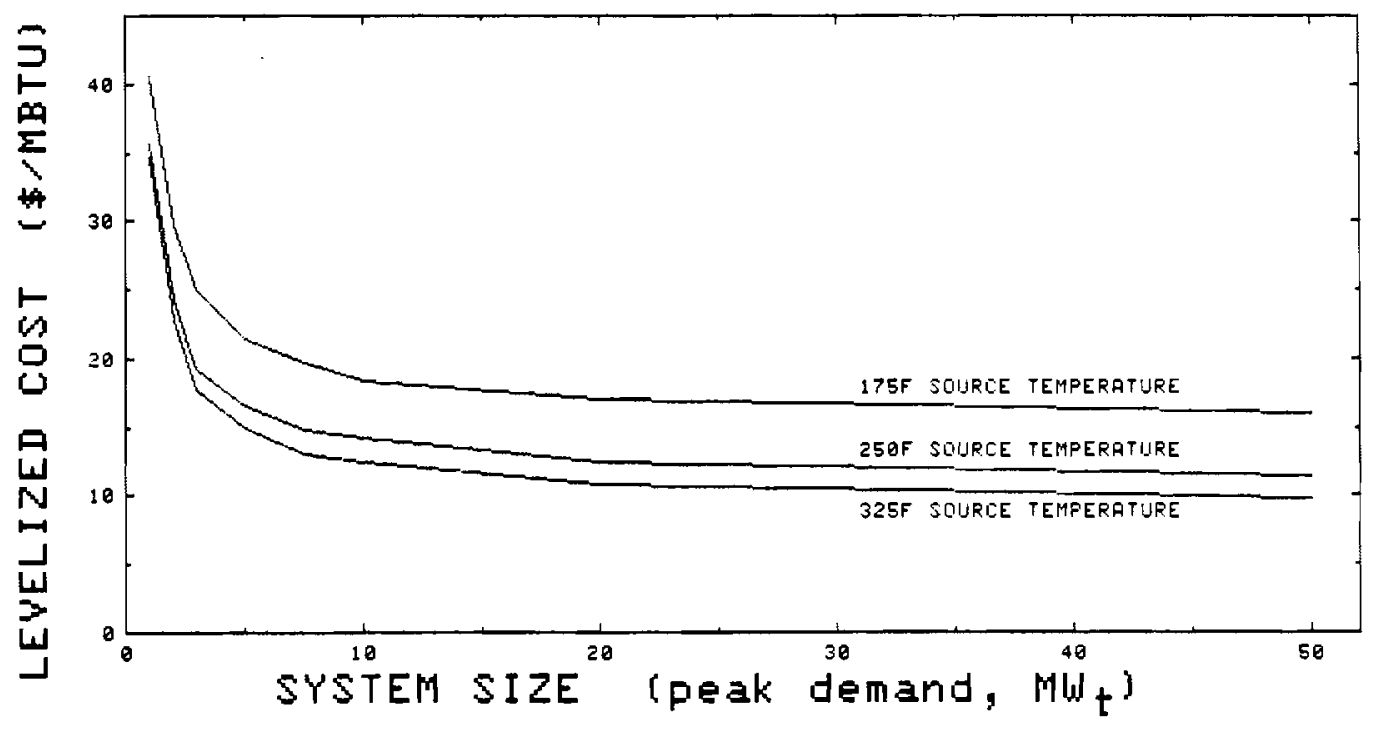

FIGURE 5. Energy Cost as a Function of System Size.

\section{COMPONENT COST BREAKDOWN FOR ATES}

The cost of ATES energy is broken down by components for the $10 \mathrm{MW} 325^{\circ} \mathrm{F}$ base case configuration in Figure 6 . The unit energy cost is $\$ 12.39 / \mathrm{MBtu}$ in January, 1980 dollars. The electrical (pumping energy) component of this levelized cost is $\$ .67$, or $5.4 \%$ of the total cost. This low percentage would increase as well depth (pumping head) increases, but would never become a dominating portion of total cost.

The levelized cost of purchased thermal energy is $\$ 5.41 / \mathrm{MBtu}$, or $43.6 \%$ of the total cost, even though the purchase cost is only $\$ 2.00 / \mathrm{MBtu}$. This difference reflects the cost of energy lost in the aquifer and pipelines, and also the effect of price escalation. Since the delivered cost of ATES energy increases by $\$ 2.70 / \mathrm{MBtu}$

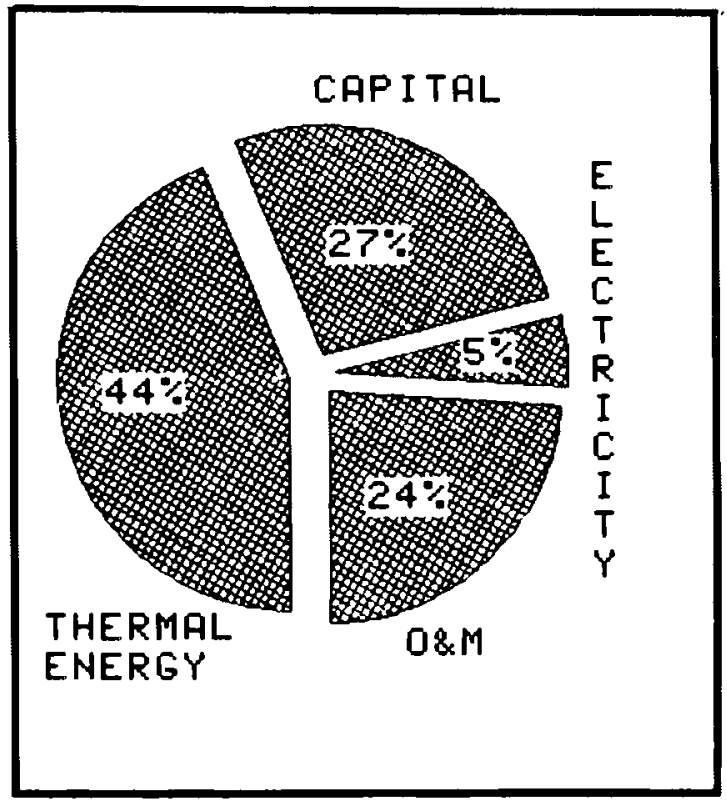

FIGURE 6. Cost Breakdown for the $325^{\circ}, 10 \mathrm{MW}$ ATES base case 
for every $\$ 1.00 /$ MBtu paid for purchased thermal energy, it is obvious that the cost of thermal energy is the most important controllable factor determining the economic performance of an ATES system.

The relationship between fixed and variable costs change, of course, as the input assumptions change. As system size increases, the proportion of fixed cost decreases, and variable costs (such as purchased thermal energy) become relatively more important. As an example, if we examine the component cost breakdown for the $3 \mathrm{MW}$ base case at $325^{\circ}$, we find that thermal energy constitutes $30.8 \%$ of the total levelized cost, and capital accounts for $33.5 \%$. At $50 \mathrm{MW}$, capital contributes only $21.0 \%$, whereas purchased thermal energy is a full $55.1 \%$ of the total levelized cost.

\section{THE COST OF CONVENTIONAL HEAT DELIVERY}

In order to place the cost of ATES-delivered energy in perspective, comparable cost estimates were made for hot water generated from conventional technologies. If hot water were to be supplied by an electric boiler ( $\Theta 5 \$ / \mathrm{kWh}$ and $7 \%$ escalation), then the levelized cost of energy production would be $\$ 18.90 /$ MBtu. If an oil-fired furnace were employed (@ $\$ 1.00 /$ gallon and $8 \%$ escalation), then the levelized cost would be $\$ 15.95 / \mathrm{MBtu}$. A comparison of these conventional technologies to the cost of ATES-delivered energy (base case, $10 \mathrm{MW}$, $325^{\circ} \mathrm{F}$ source) is made in Figure 7 , where the cost of ATES is shown as a

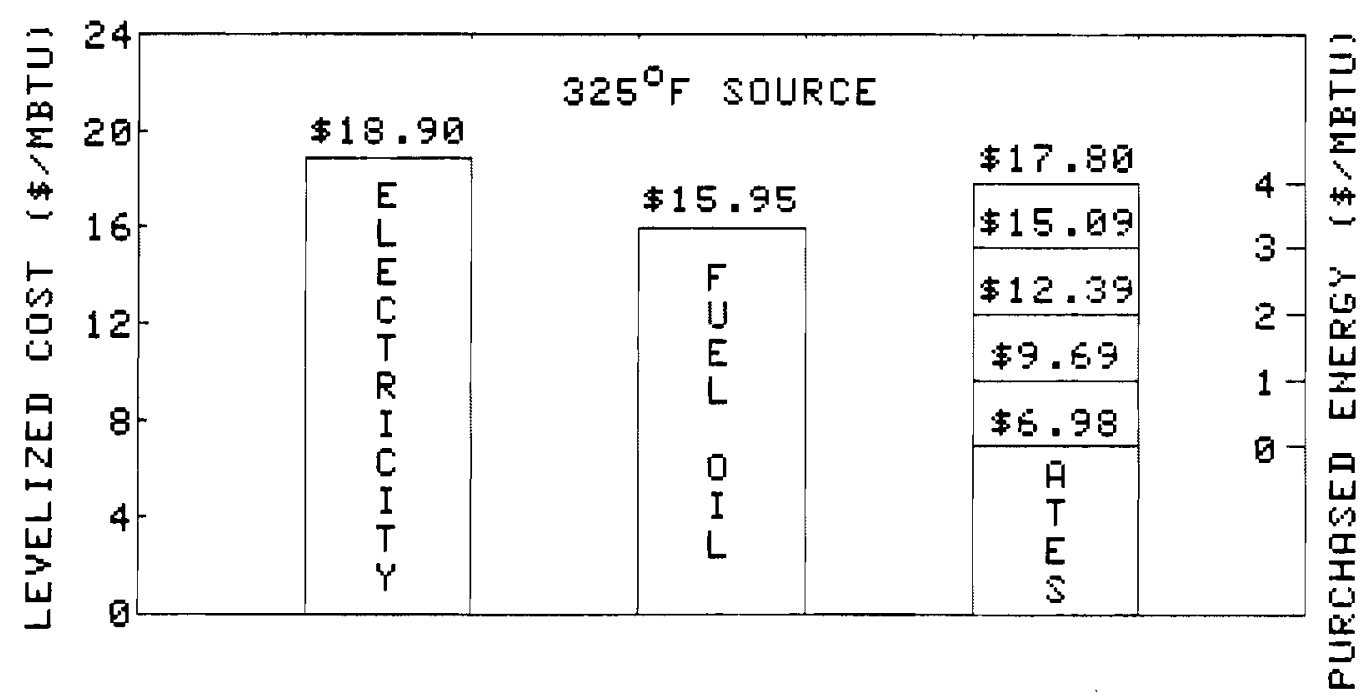

FIGURE 7. A Comparison of the cost of ATES Against Conventional Technology 
function of the cost of purchased thermal energy. The costs listed for ATES are based upon a system design that is optimized to a $\$ 2.00 / \mathrm{MBtu}$ cost for purchased thermal energy. This is a simplification, as system design (amount of insulation, etc.) would change as the cost of input energy changes.

\section{PARAMETRIC ANALYSES}

Parametric analyses were conducted to investigate the effects of varying technical and economic assumptions upon the cost of ATES development and operation. These results are presented in graphs similar to Figure 3 , with the levelized unit cost of energy presented on the ordinate, and the independent variable being investigated on the abscissa. (The levelized unit cost of energy includes capital (including owner's expense), purchased thermal energy, pumping energy, and operation and maintenance. Each graph presents the results for three system sizes: $3 \mathrm{MW}, 10 \mathrm{MW}$, and $50 \mathrm{MW}$ peak demand. Only the results from the $325^{\circ} \mathrm{F}$ source are presented in the body of the report. Results for the $250^{\circ} \mathrm{F}$ and $175^{\circ} \mathrm{F}$ sources are included in Appendix $\mathrm{A}$. In general, the curves for these lower temperatures are identical to those for the $325^{\circ} \mathrm{F}$ source, but shifted higher on the vertical (cost) axis.

Source Availability

One of the major capital components of an ATES system is the cost of well drilling and development. Since all ATES wells serve as both injection and withdrawal wells, the total number of wells required is determined by the peak system flow, either into or out of the aquifer. Peak flow into the aquifer is determined by the need to store enough energy during the available storage period to satisfy total annual demand. Peak flow out of the aquifer is determined by the peak demand of the users. The number of wells required is determined by the maximum of these two rates. (The injection capacity of a well can differ markedly from its withdrawal capacity, thereby changing the ratio of input-to-withdrawal wells, and ultimately affecting the total number of system wells required. In this investigation, however, we have assumed equal withdrawal and injection capacities.)

Figure 8 presents the relationship of source availability and levelized cost. In the base case, the energy was assumed to be available continuously 


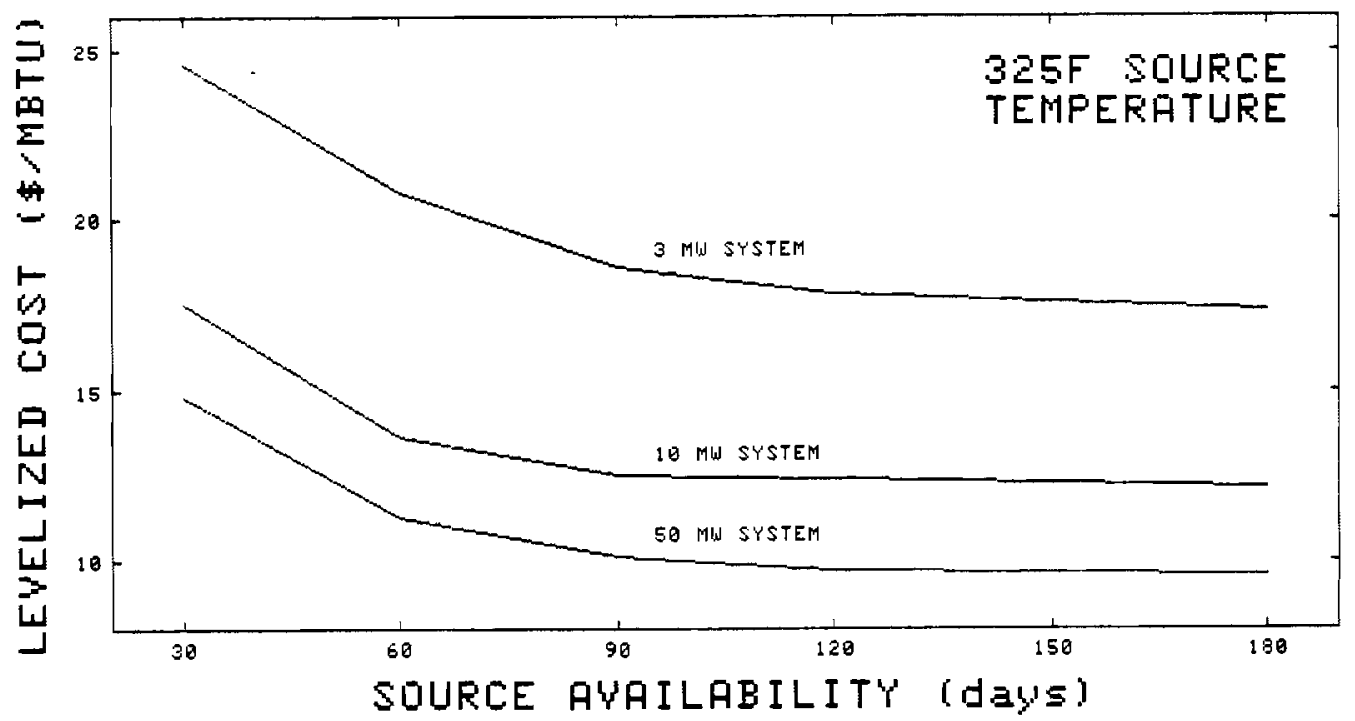

FIGURE 8. Energy Cost as a Function of Source Availability

over a 120-day period (24 hours per day). For source availabilities above 104 days, the number of wells is controlled by demand parameters, and so the curve is relatively flat. In this region the number of wells does not change with increasing source availability, and the decreased energy cost reflects only decreasing heat exchanger and pipe sizes. At availabilities of less than 104 days, the number of wells is dependent upon supply availability, and total cost rises more quickly with decreasing source availability.

\section{Well Parameters}

\section{Well Productivity.}

The relationship between maximum well productivity and levelized cost is a step function, since cost does not increase with reduced well capacity until another pair of wells is required by the system. An additional well adds not only drilling cost, but also an additional pump and the pipeline necessary to connect the well to the existing manifold system. The results of varying well productivity are presented in Figure 9. In the base case, a maximum well production of $150,000 \mathrm{lb} / \mathrm{hr}$ was assumed (about $300 \mathrm{gpm}$ ). This is not highly productive for water or geothermal wells, but it is probably reasonable for the aquifer transmissivities that will be required for economic thermal efficiencies. (Some geothermal wells are rated at over 1,000,000 1b/hr.) 


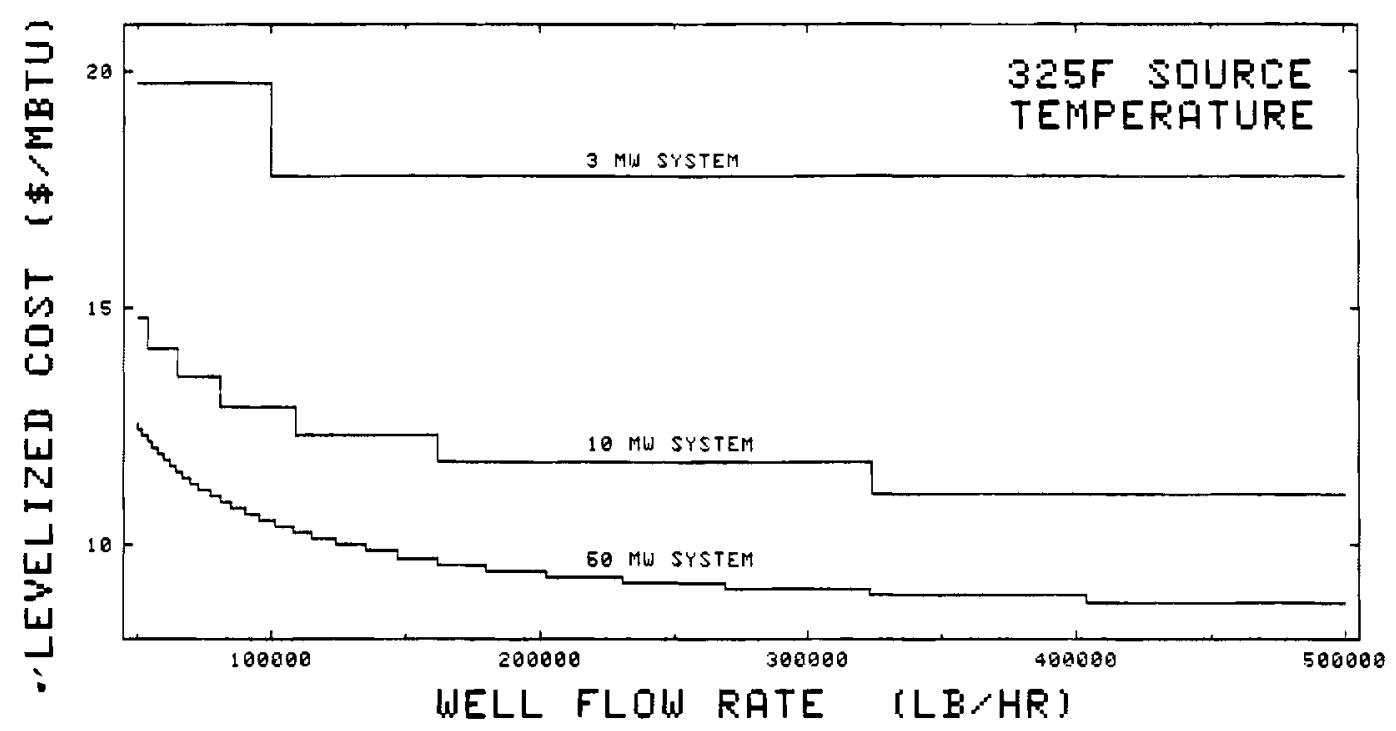

FIGURE 9. Energy Cost as a Function of Well Productivity

\section{Well cost.}

The effect of well cost on the levelized cost of energy delivery is depicted in Figure 10. Well cost includes drilling, casing, and well development, but not the cost of the downhole pump. The relationship is linear and rather flat, since wells constitute only a portion of the capital cost, which (for the base case) is itself only $27 \%$ of the total levelized cost. In the base case,

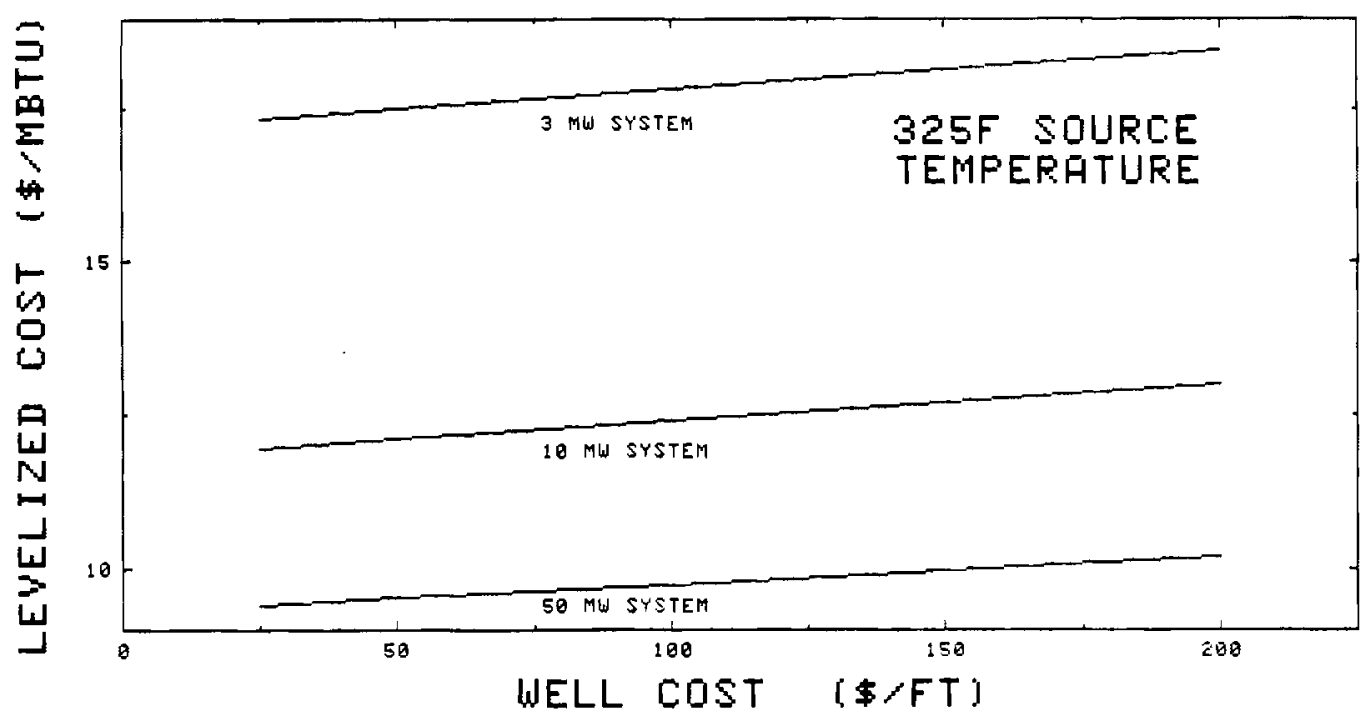

FIGURE 10. Energy Cost as a Function of Well cost 
wells were assumed to cost $\$ 100 /$ foot. Well drillers in many parts of the nation regularly drill suitable wells for under $\$ 20 /$ foot. In other parts of the nation (notably Alaska), well drilling costs can exceed $\$ 200 /$ foot.

We 11 productivity and we 11 cost are interdependent parameters, and are, to some extent, controllable by the developer. Economic tradeoffs exist that depend upon drilling and aquifer parameters. These need to be optimized in the design of the well field.

3. Well Life.

The effect of well life on levelized cost is similar to that of well cost, since as the average well life decreases, the total cost of wells increases. As indicated by Figure 11, there is not much effect on the levelized cost of energy until the average system well life falls below 5 years. And, since most water-well experience indicates an economic life of greater than ten years, well life will probably not be a major cost concern for ATES systems.

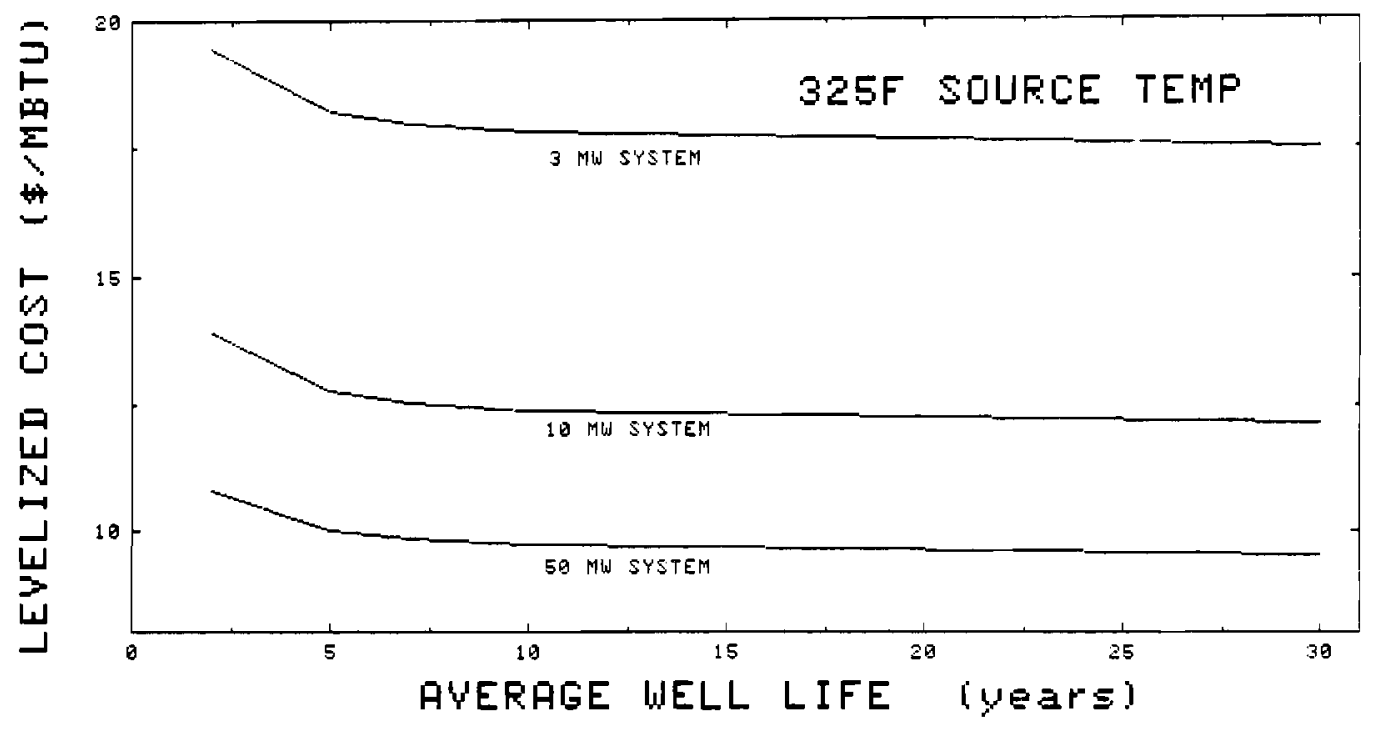

FIGURE 11. Energy Cost as a Function of Well Life 
Aquifer Parameters

1. Aquifer Depth.

Increased aquifer depth can increase the cost of delivered energy in two ways. First, it increases the capital cost of well drilling and completion. Second, it may increase the size (capital cost) of the pump required, and also the work (electricity) required to pump water to the surface heat exchanger. Pumping head is determined by the static water level in the well and well drawdown, factors that may not directly relate to well depth. In this investigation it is conservatively assumed that the pump must overcome a head equal to the well depth. Such conservatism should not grossly effect the total cost of ATES delivered energy, as electricity is only a small component of total cost. In the base case 400-foot wells are assumed. If well depth is increased to 1500 feet, then there is a significant increase in storage cost, as depicted in Figure 12 .

\section{Aquifer Thermal Efficiency.}

Aquifer thermal efficiency (the ratio of energy recovered from the aquifer to the initial input energy) is dependent upon a large number of geologic and operational parameters, many of which are not fully understood at this time.

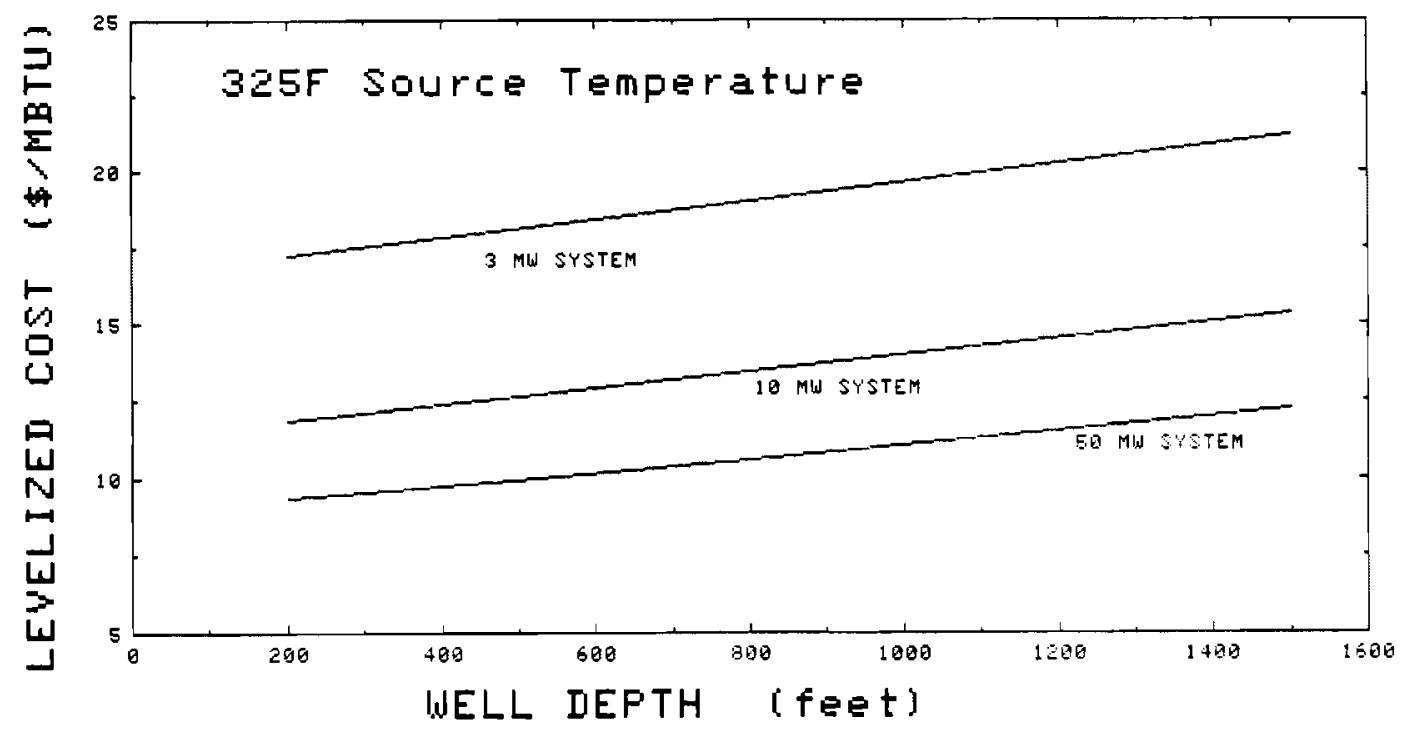

FIGURE 12. Energy Cost as a Function of Aquifer Depth 
In general, the most efficient ATES systems will have the following characteristics:

- Large amounts of energy will be stored. Thermal energy is lost at the bubble surface, which grows as the square of the radius. The volume stored grows as the cube of the radius. Since the fraction of heat loss is a function of the ratio of the surface area to volume, the larger the scale of injection, the smaller will be this ratio, and hence, the more efficient will be the ATES system.

- The aquifer will be confined - bounded below and above by impervious layers (aquitards) that minimize heat and fluid transfer to the neighboring formations. The overlying aquitard will also prevent dilution of the thermal energy by infiltration of cooler water from an overlying aquifer or from a surface source.

- The regional flow rate within the aquifer will be negligible. A substantial natural flow would sweep the injected thermal energy "downstream" before the heat could be withdrawn in the recovery cycle.

- The aquifer will be thick enough to permit a compact storage geometry. A thin aquifer, for instance, would result in a long, flat bubble with a high surface-to-volume ratio, and a correspondingly lower efficiency.

- The storage temperature differential will be minimal. The greater the difference between the discovery temperature and the injection temperature, the greater will be the proportional heat loss. There are at least two causes: One is the greater heat transfer rate to the surrounding water caused by the greater temperature differential. The second (and perhaps more important) cause is the "tilting" effect caused by the greater buoyancy of the hot storage bubble. The hot water is less dense and less viscous than the surrounding groundwater, causing the boundary (or thermocline) to tilt away from the vertical. In the recovery cycle, cold water at the bottom of the well is recovered before all of the heat energy can be recovered from near the top of the well, causing a cooler mixture to be recovered, and reducing aquifer thermal efficiency. This discussion does not suggest that cooler systems will be most cost effective, however. Rather, the hotter the source water, the more economic will be the storage function because savings in capital and operating expenses will more than compensate for any decreased aquifer thermal efficiency.

- The end-user will have flexible flow and temperature requirements. Towards the latter part of the withdrawal operation, the water temperature will tend to drop, slowly at first, and then more quickly as the mixed water at the edge of the storage bubble is recovered. If the system design (end user) is flexible enough to use this lower temperature water (e.g., a heating system with oversized piping and radiators), then the total amount of energy recovered will be greater than if the system must cease operation immediately when the water temperature drops a few degrees. 
Computer models and experimental field data indicate that initial aquifer thermal efficiencies may exceed $70 \%$ for confined aquifers. More heat will be lost to the aquifer during early cycles of injection and withdrawal than during the later cycles when the aquifer has been "conditioned" by lost thermal energy. Some investigators indicate that $80 \%$ to more than $90 \%$ efficiencies are possible after a number of cycles. (5)

In this investigation, only the steady state condition is modelled, and aquifer thermal efficiency is assumed constant over time. The model employs two input parameters to simulate aquifer efficiency: aquifer thermal storage efficiency (ratio of annual energy recovery to annual energy injection - both with respect to the aquifer discovery temperature), and aquifer fluid recovery fraction (ratio of annual water volume recovery to annual volume injected). For the base case we have assumed that $90 \%$ of the injected water was recovered before the water became too cold to use, and that $60 \%$ of the injected heat was recovered in this water volume $\left(0325^{\circ} \mathrm{F}\right)$. For the lower temperatures, we assumed a better aquifer thermal efficiency (63\% a the $250^{\circ}$ source, and $70 \%$ a the $175^{\circ}$ source), and the same $90 \%$ fluid recovery fraction.

In Figure 13 the relationship of energy cost to overall aquifer efficiency is investigated. Both fluid recovery fraction (top) and aquifer thermal efficiency (bottom) were varied continuously so as to deliver the same average temperature water during the recovery cycle. At the left side of the curves, a very poor aquifer is modelled. The fluid recovery factor is $50 \%$ and the thermal efficiency is only 34\%: only half of the injected water is recovered, containing only $34 \%$ of the total input energy. The right edge of the curves is the base case, representing a good aquifer.

Figure 13 represents the change in energy cost as overall aquifer performance changes. ATES systems can deliver thermal energy at a reasonable cost even with moderately poor aquifer performance. It is important to note, however, that the cost of purchased thermal energy is assumed to be only $\$ 2 / \mathrm{MBtu}$ in this case. If purchased thermal energy were more expensive, then the effect of aquifer performance would be more pronounced. 


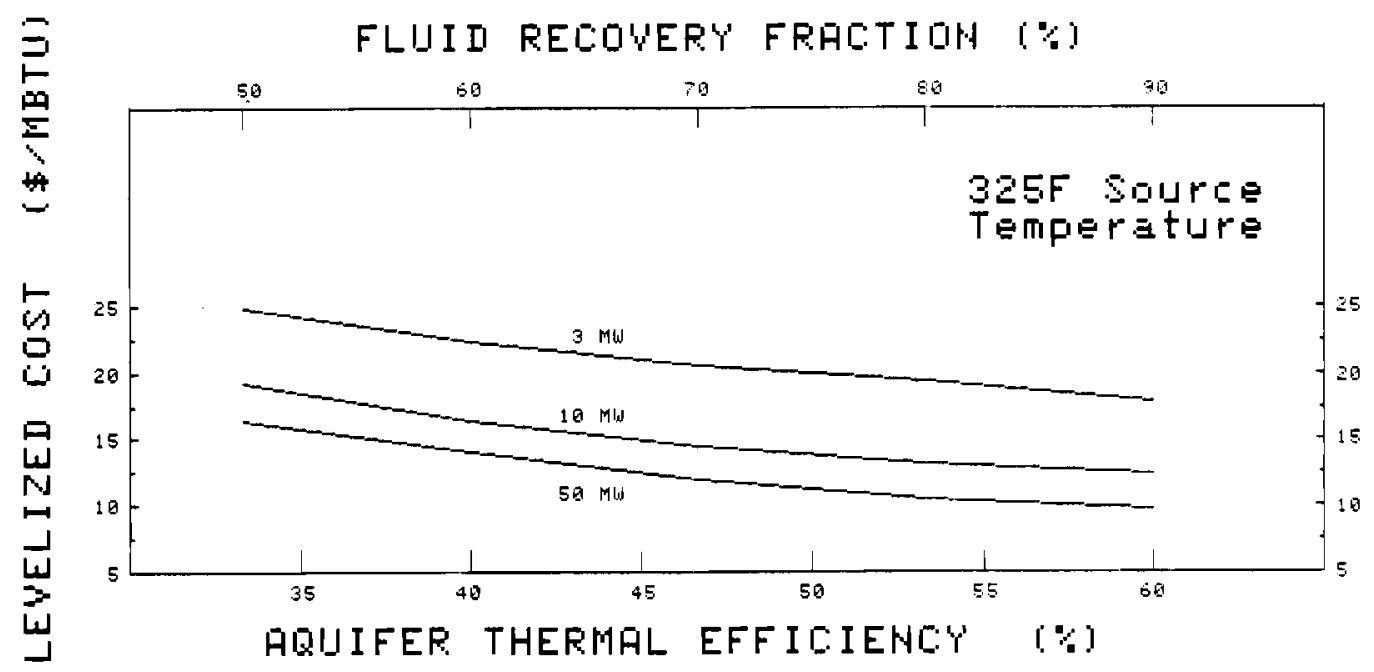

FIGURE 13. Energy Cost as a Function of Aquifer Performance

\section{Demand Parameters}

\section{Load Factor.}

The load factor is defined as the ratio of average annual hourly demand to peak hourly demand, and is one of the most important parameters affecting the unit cost of energy. The fixed portions of the unit energy cost are inversely proportional to the load factor, and fixed costs are predominant for an ATES system (if we ignore the cost of purchased thermal energy). The variable portions of the unit cost of energy do not vary with changes in load factor.

In this analysis (Figure 14), a greater load factor is equivalent to a larger annual rate of energy storage, since peak demand is maintained constant as load factor is increased. The base case load factor is 25\%, about equal to that expected for a heating system for a city in a moderately cool climate. Load factors of $50 \%$ or greater are not unusual for process heat users.

Unfortunately, there is little that the ATES developer can do to increase the load factor for a particular application, since load factor is a property of the user's needs. One approach often taken with district heating systems is to undersize system components. This increases the load factor, but it also results in an unserved peak demand that must be filled through a supplemental source (such as an oil-fired heater). As another approach, the developer can increase the system load factor by combining non-coincident users on a single system. 


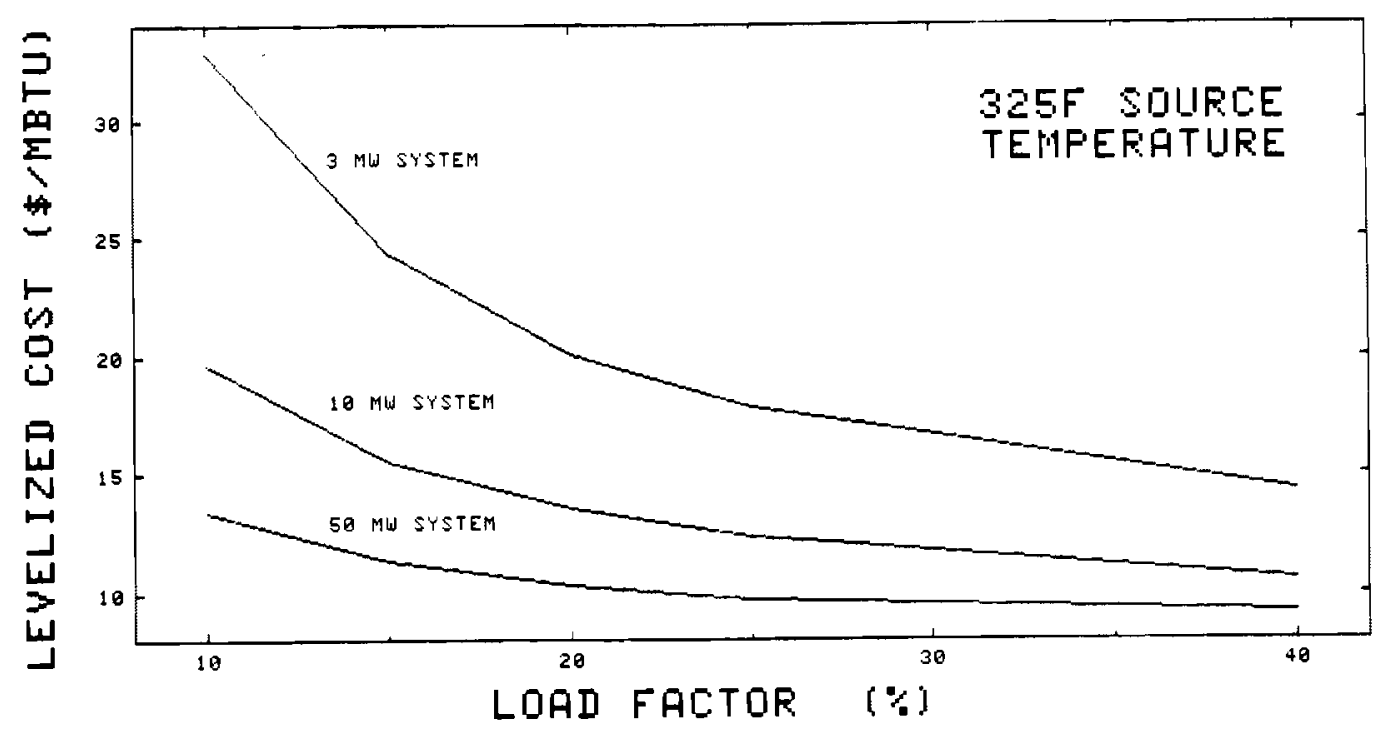

FIGURE 14. Energy Cost as a Function of Demand Load Factor

\section{Transmission Distance.}

The cost of ATES-delivered energy is dependent upon the total distance over which the fluid must be transmitted. In the base case, each of the four legs is modelled at 1500 meters, giving a source-to-user separation of 3000 meters (about 2 miles) and a total pumping distance (excluding the wellfield manifolding) of 6000 meters. In the analys is of source-user separation distance (Figure 15), we see that the relationship between transmission distance and energy cost is essentially linear. Economic transmission distance is strongly a function of system size. For the $50 \mathrm{MW}$ systems, energy can be economically transported over long distances. For the $3 \mathrm{MW}$ systems, the cost of energy quickly becomes prohibitive with increasing transmission distance.

Transmission cost is highly dependent on fluid temperature (see Appendix A), since the energy content of each pound of fluid increases with temperature. Pipe size, casing size, and insulation volume can all be reduced with increased temperature. Economic transmission distance is also highly dependent upon load factor: most of the cost is related to construction of the pipeline (and thus is a fixed cost), and only minimal costs result from the pumping operations (variable costs). 


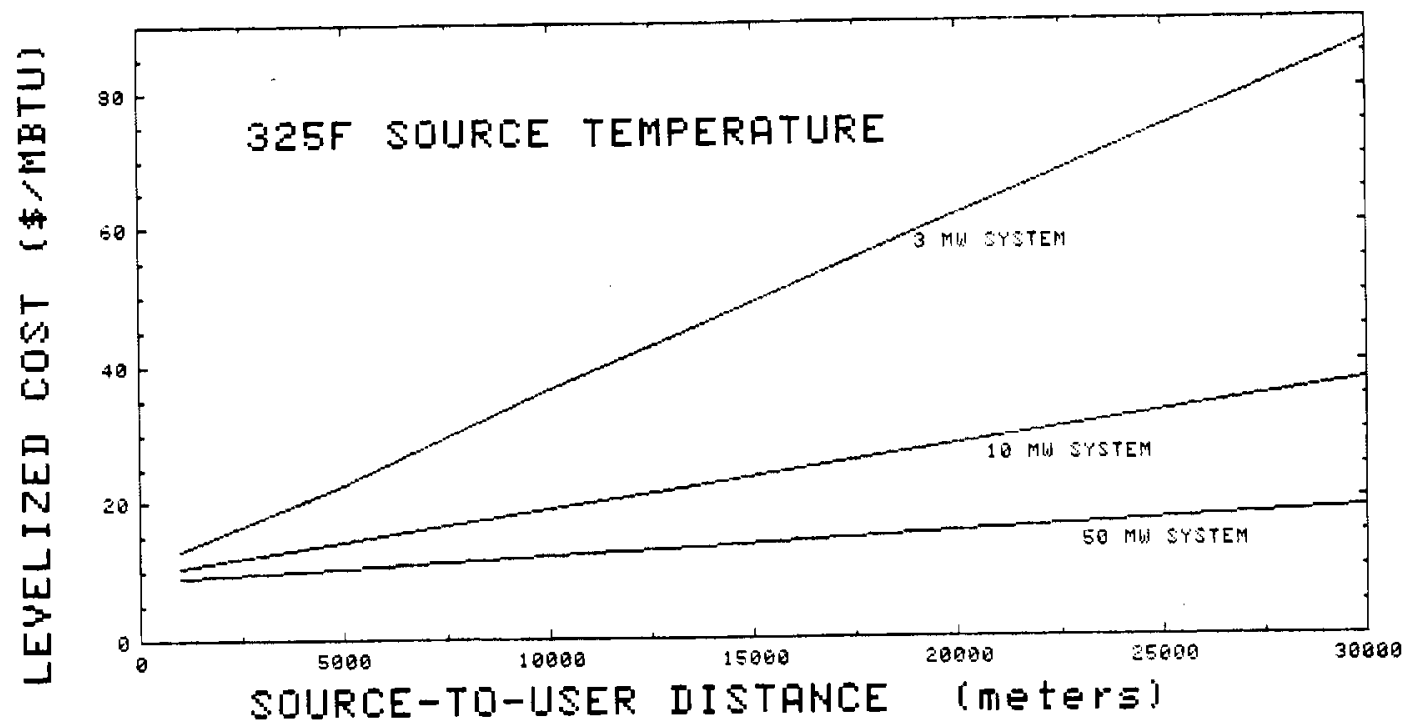

FIGURE 15. Energy Cost as a Function of Transmission Distance

3. No User Heat Exchanger Option.

In general, it is necessary to isolate the water stored in the aquifer from the hot water distribution system by means of a heat exchanger, both to protect the aquifer from environmental damage, and to protect the expensive distribution systems from corrosion. This requirement imposes severe penalties upon the cost of ATES-delivered energy: the added capital and operating costs of a heat exchanger, and the reduced temperature of the fluid delivered to the distribution system. In some situations (when using a non-potable, but noncorrosive aquifer water, for instance) the heat exchanger may no longer be required for protecting the aquifer and distribution system. Figure 16 provides a comparison of the economic performance of an ATES system with no user heat exchanger to the base case ATES configuration.

Economic Parameters

1. Cost of Electricity.

The unit cost of energy is rather insensitive to the cost of electricity, as reflected in Figure 17. Electricity is used only for pumping energy, and is only about $5 \%$ of the total levelized cost for the $325^{\circ} \mathrm{F}$ source. 


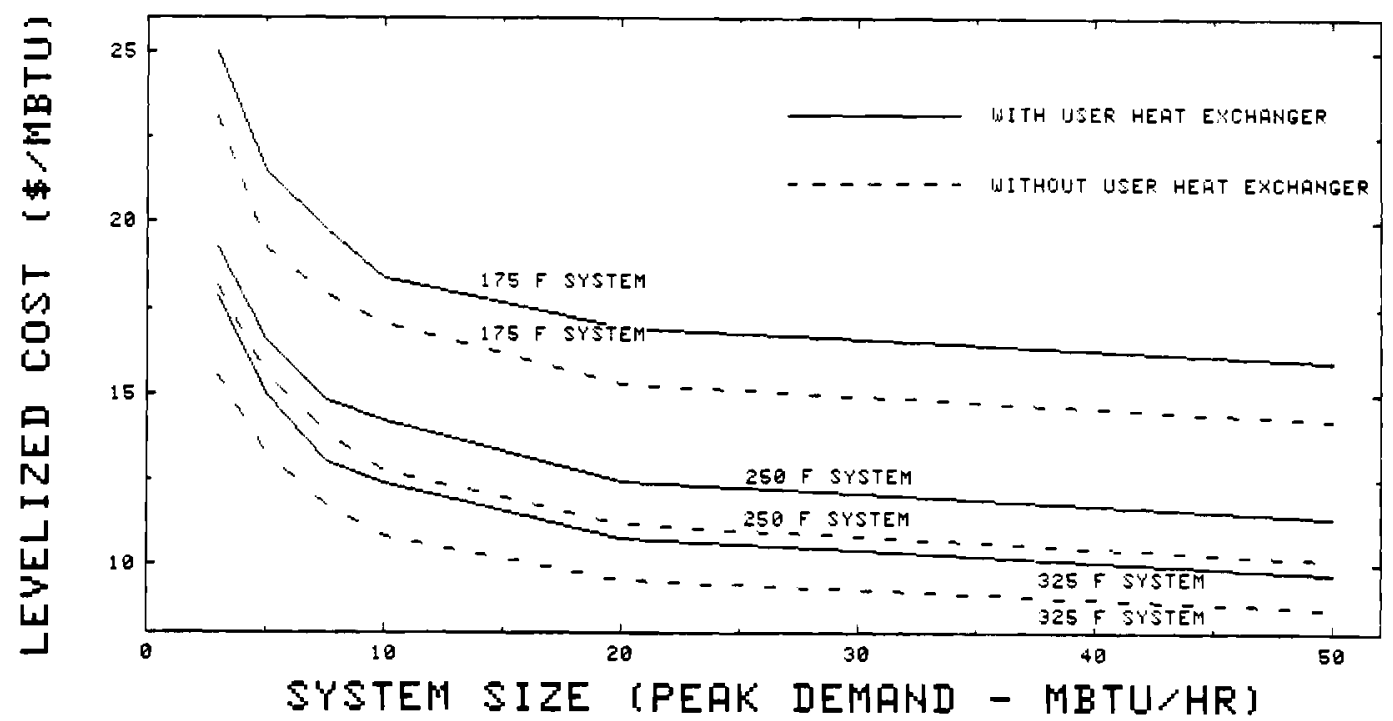

FIGURE 16. Energy Cost for a System with No User Heat Exchanger

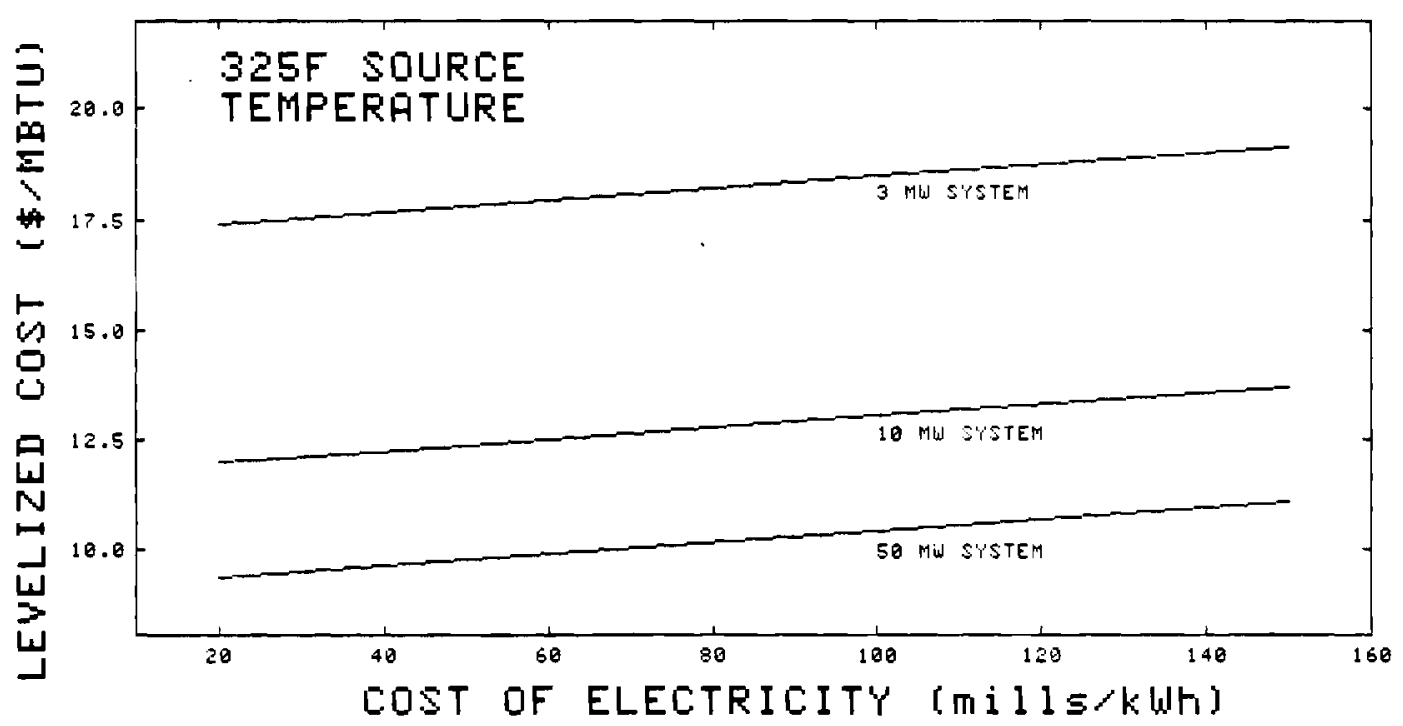

FIGURE 17. Energy Cost as a Function of the Cost of Electricity

\section{Cost of Purchased Thermal Energy.}

The cost of purchased thermal energy is critical to the cost-effective use of ATES systems and of ten dominates other ATES component costs. The purchase cost of thermal energy is magnified by system thermal losses and price escalation. 
For the base case system (at a source temperature of $325^{\circ} \mathrm{F}$ ) 2.2 Btus are purchased for every 1.0 Btu that is delivered to the end user. As a result, the cost of ATES rises quickly with increasing cost of purchased thermal energy (Figure 18).

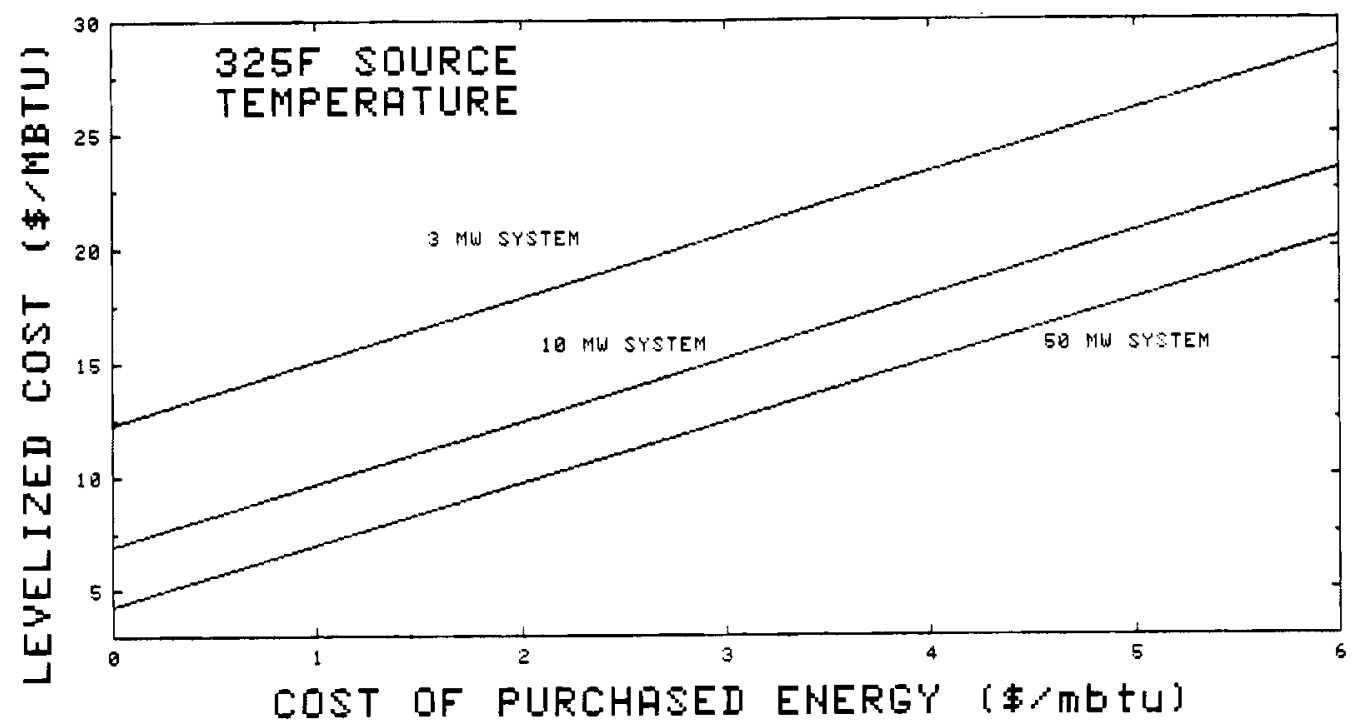

FIGURE 18. Energy Cost as a Function of the Cost of Purchased Thermal Energy

3. Cost of Capital.

The effect of financing mode is investigated in Figure 19. Both municipal (100\% tax-free bonds) and private (after-tax rate, $50 \%$ bond $/ 50 \%$ equity) financing are investigated. For the private financing cases, a 10\% investment tax credit was assumed, and double-declining depreciation was used. These curves do not reflect the reduced plant depreciable lives available under the Economic Recovery Tax Act of 1981.

\section{$\underline{\text { SUMMARY }}$}

It is apparent from the above analyses that the economic performance of an ATES system is dependent upon a large number of system and economic parameters. The most important controllable cost is the cost of purchased thermal energy (Figure 18). System size (Figure 5) is very important, as costeffective use of technology is heavily dependent upon economies of scale. Other 


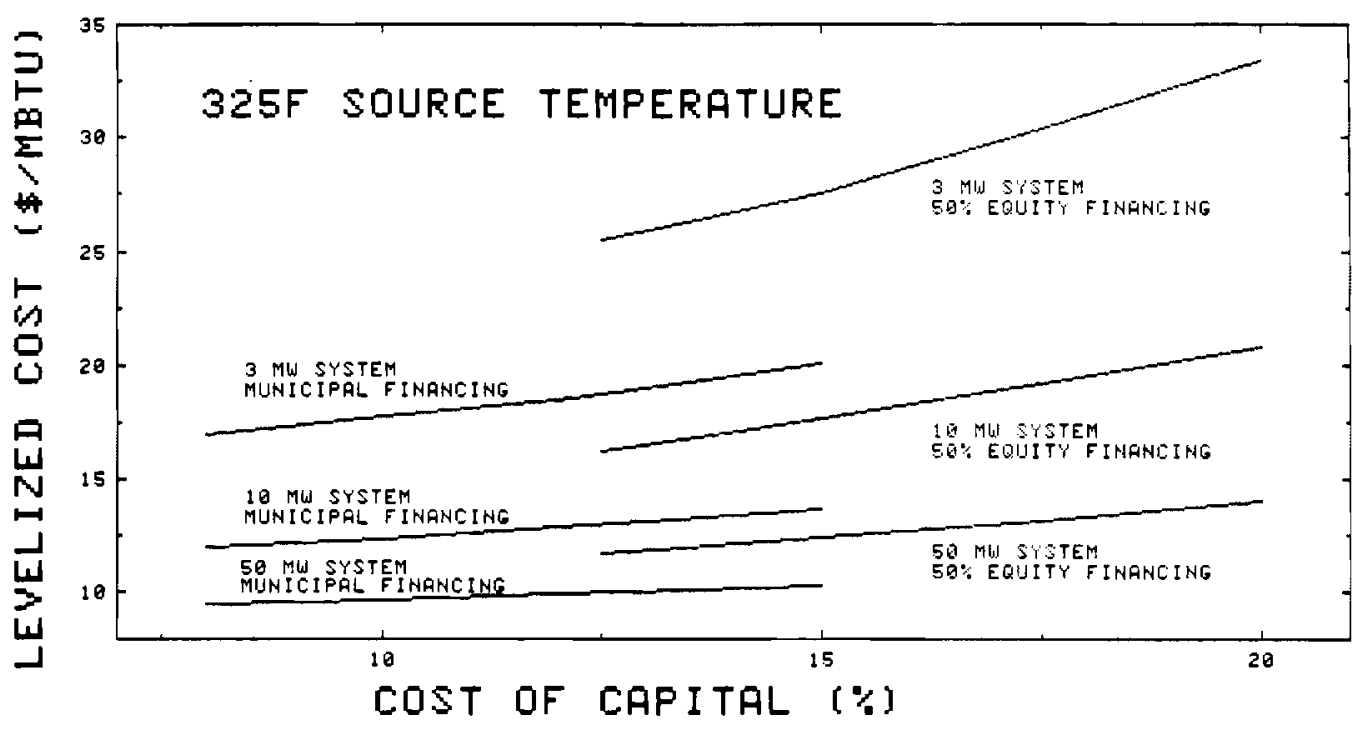

FIGURE 19. Energy Cost as a Function of Cost of Capital

important parameters include source temperature (Figure 5 and Appendix A), load factor (Figure 14), transmission distance (Figure 15), and aquifer thermal efficiency (Figure 13). 


\section{RESIDENTIAL DEVELOPMENT COST ESTIMATES}

The cost of supplying ATES energy to residential developments for space heating and domestic hot water is estimated in this section of the report. As in the point-demand section, three source temperatures are investigated: $325^{\circ} \mathrm{F}, 250^{\circ} \mathrm{F}$, and $175^{\circ} \mathrm{F}$. Only the results for $325^{\circ} \mathrm{F}$ are given here, the results for the lower temperatures are included as Appendix $B$.

Costs are estimated for two climates. A cold climate (Minneapolis, Minnesota) is characterized by a 9000 degree-day heating season, and a system design temperature of $-20^{\circ} \mathrm{F}$. A moderately cool climate (Seattle, Washington) is characterized by 4500 heating degree-days and a system design temperature of $+15^{0} \mathrm{~F}$.

Two types of residential development are investigated for each climate: single-family houses and high-rise apartment buildings. The single-family houses simulated have 1620 square feet on one level, and are of typical preenergy-crisis construction. They have an assumed density of four houses per acre, and a daily hot water demand of 60 gallons per day per unit. The apartment houses are nine-story buildings of 72 units each, with an assumed building density of 1.67 acres per building. Each unit contains 780 square feet, and each apartment house has a daily hot water demand of $5400 \mathrm{gallons}$.

The residential cost estimates employ the same system design and base-case assumptions as in the point-demand analysis, with one major difference. These include the cost of constructing and operating a distribution system to transport the hot water from the user heat exchanger to the end user. As in the point-demand analysis, the cost of end-use equipment is not included in the cost estimates. The distribution systems modelled are assumed to be buried in a retrofit operation, with cost allowances made for trenching, pipelaying, backfilling, and repaving. The pipes themselves are schedule 40 carbon steel, with calcium silicate insulation in a steel casing.

In these residential cost analyses, the system peak is assumed to be less than the sum of the individual peaks, since the peak load for all units within the system will not occur simultaneously. A diversity factor of $72 \%$ is 
assumed, allowing for the downsizing of distribution system laterals and mains $(6)$.

\section{BASE CASE RESULTS}

The levelized cost of ATES-delivered energy for single-family houses and apartment houses in both the Seattle and Minneapolis climates is presented in Figure 20.

Several important features are evident. Most obvious is that apartment house systems are much less expensive to serve than single-family houses (if we assume that their internal distribution systems are already in-place, as we do here). This is because only a small distribution system is required to deliver energy to an apartment house, as compared to the extensive piping network necessary to service a single-family housing district of the same load.

Another salient feature is that the Seattle single-family houses are significantly more expensive to serve than the Minneapolis single-family houses. Two factors come into play here. One is that Minneapolis exhibits a better load factor $(40.2 \%$ versus $35.2 \%)$, and so utilization of capital equipment is more efficient. The second is, that because of Minneapolis's cold climate, less housing units are required to constitute the same peak demand,

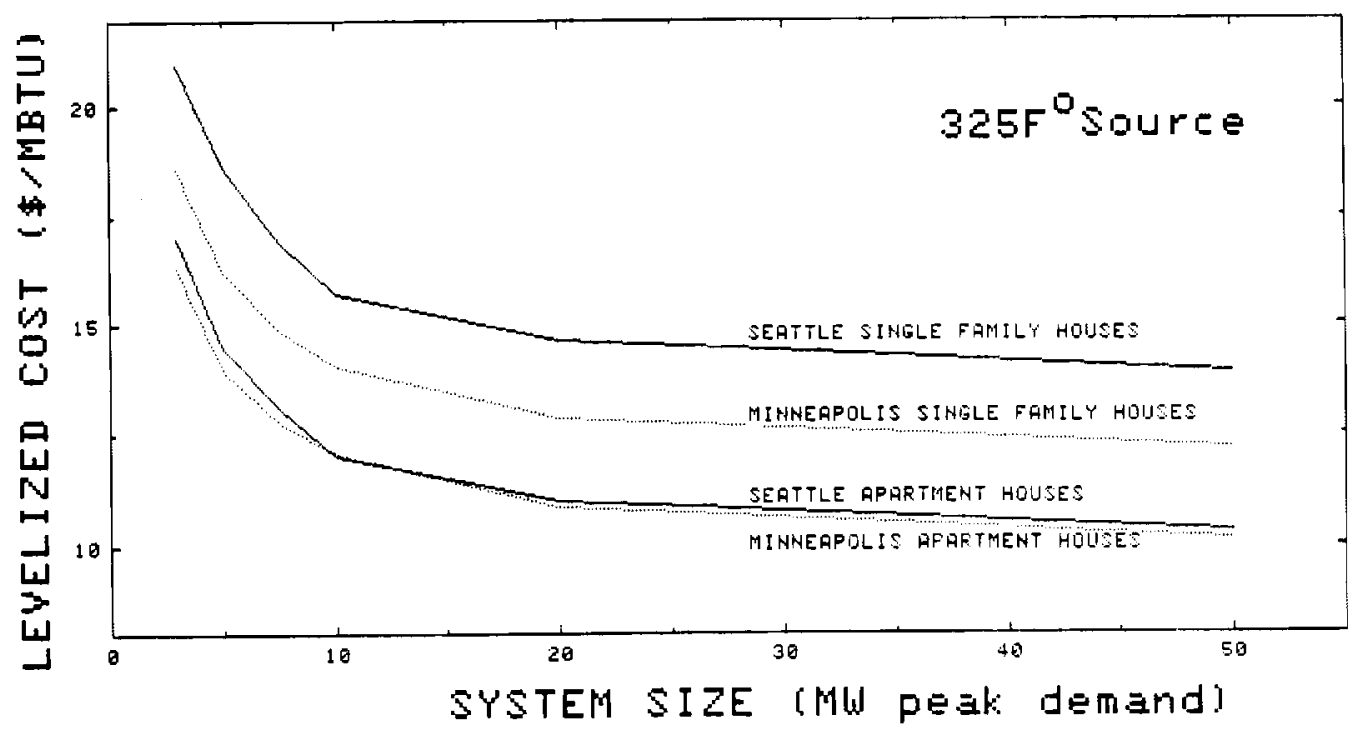

FIGURE 20. Base Case Results for Residential Developments 
and so the distribution system is less extensive. The same factors come into play with respect to the apartment buildings, but distribution costs are such a small portion of total cost that there is little difference between the two total cost estimates.

One important result of this investigation is that significant economies of scale are available. The cost curves flatten out only beyond $20 \mathrm{MW}$, and increase steeply for system demands under $10 \mathrm{MW}$. Almost all of the residential developments investigated are competitive with the cost of hot water from alternative sources, as indicated by the costs given in the point-demand investigation.

\section{COMPONENT COST BREAKDOWN FOR RESIDENTIAL DEVELOPMENTS}

The capital cost breakdown for each of the four residential developments (10 MW @ $325^{\circ} \mathrm{F}$ ) is presented in Figure 21. The added capital cost of the

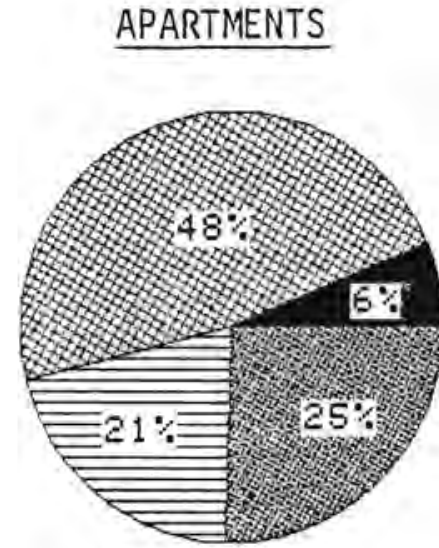

MINNEAPOLIS

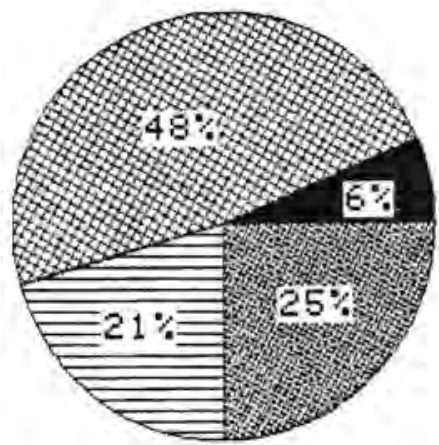

SEATTLE

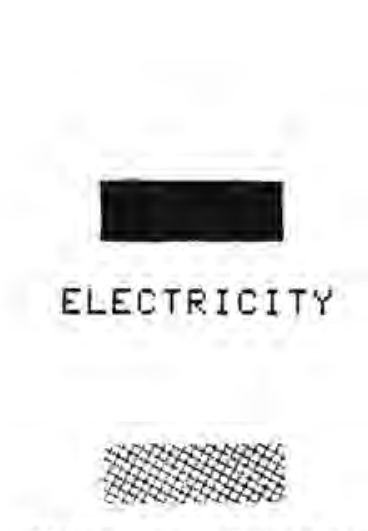

THERMAL ENERGY

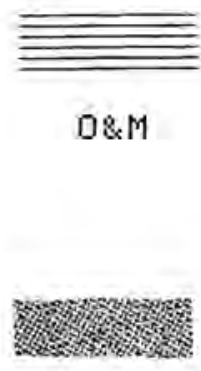

CAPITAL

\section{SINGLE FAMILY HOUSES}

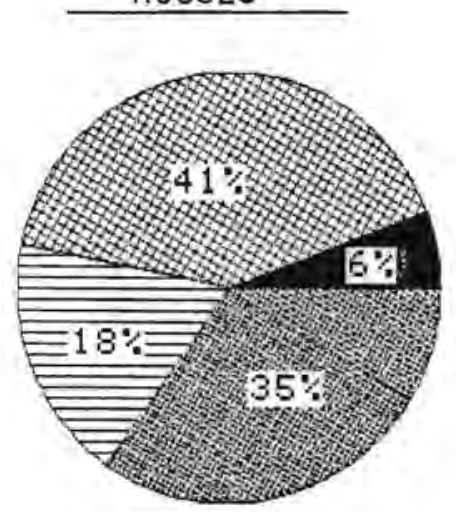

MINNEAFOLIS

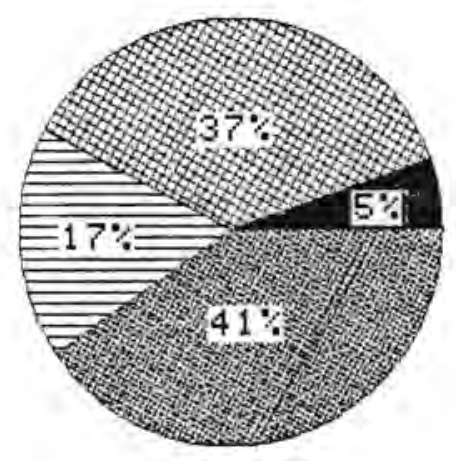

SEATTLE

FIGURE 21. Cost Component Breakdown for Residential Developments 
distribution systems has increased the capital cost component of the single family houses over the point demand situation. As a result, thermal energy has become a smaller component for single family houses. The capital component of the apartment houses has not increased, however, due to the relatively small distribution system required by apartment houses.

\section{PARAMETRIC ANALYSES}

The alternative system configurations investigated in the point-demand analysis are not reinvestigated here. A fair estimate of how those parameter variations affect the results presented in this section can (in many cases) be obtained by simply adding the cost difference between the point-demand base case and the selected parametric analys is to the relevent residential development cost. The effect of varying the cost of capital is re-estimated here, however, since the the major capital investment in the distribution systems greatly increases the capital portion of the total levelized cost. The financial and tax assumptions used for the point demand investigations are reemployed here.

The effect of varying the cost of capital is presented in Figures 22-25. Apartment house systems appear to be cost-effective, except at the 3 MN size

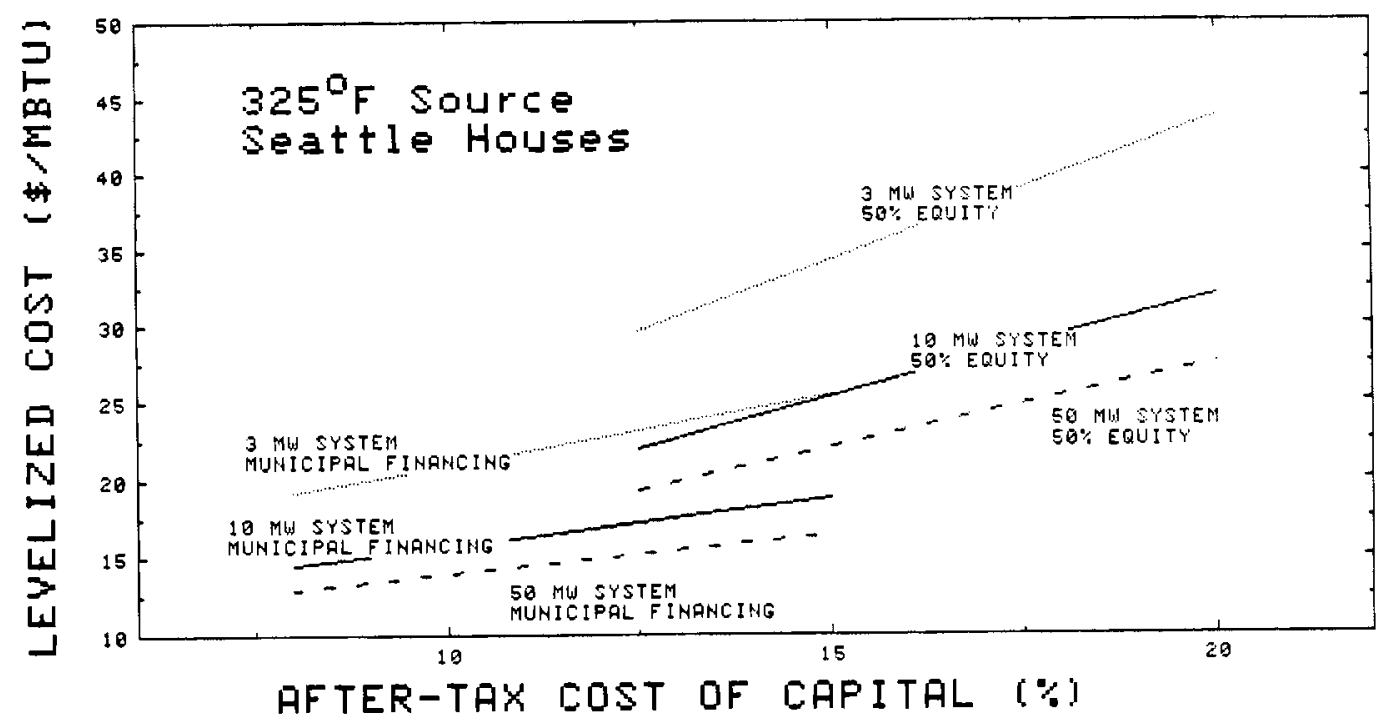

FIGURE 22. Effect of Financing on Residential ATES Systems Seatt le Single-Family Houses 


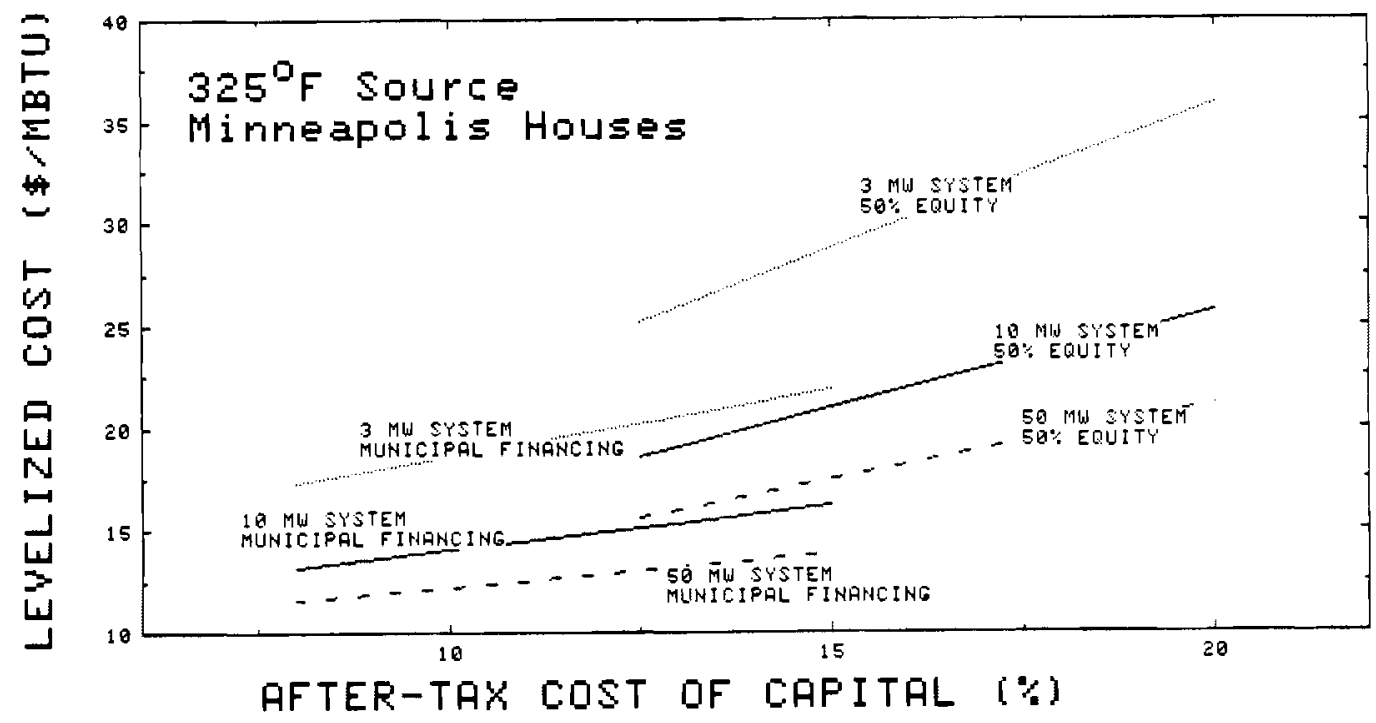

FIGURE 23. Effect of Financing on Residential ATES Systems Minneapolis Single-Family Houses

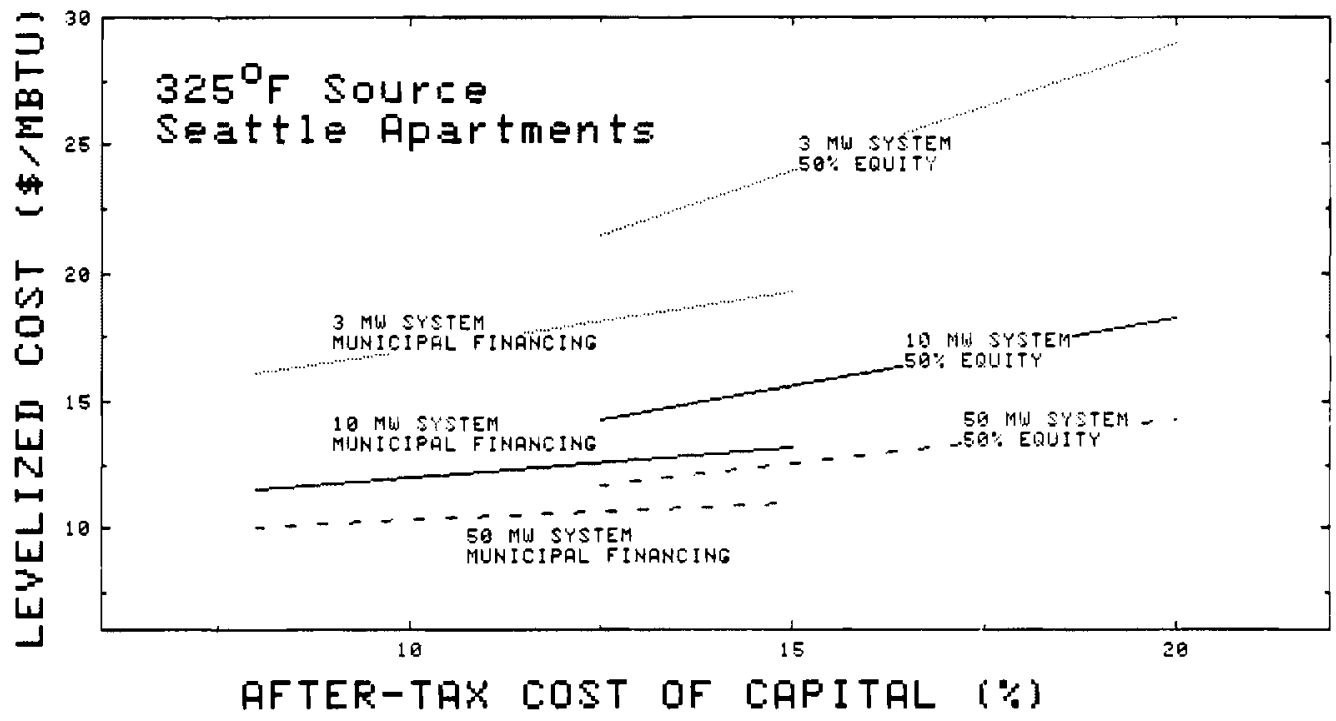

FIGURE 24. Effect of Financing on Residential ATES Systems Seattle Apartment Houses

under private financing. In general, single-family housing systems are not cost-effective for the private sector, and must be funded through a municipaltype funding. 


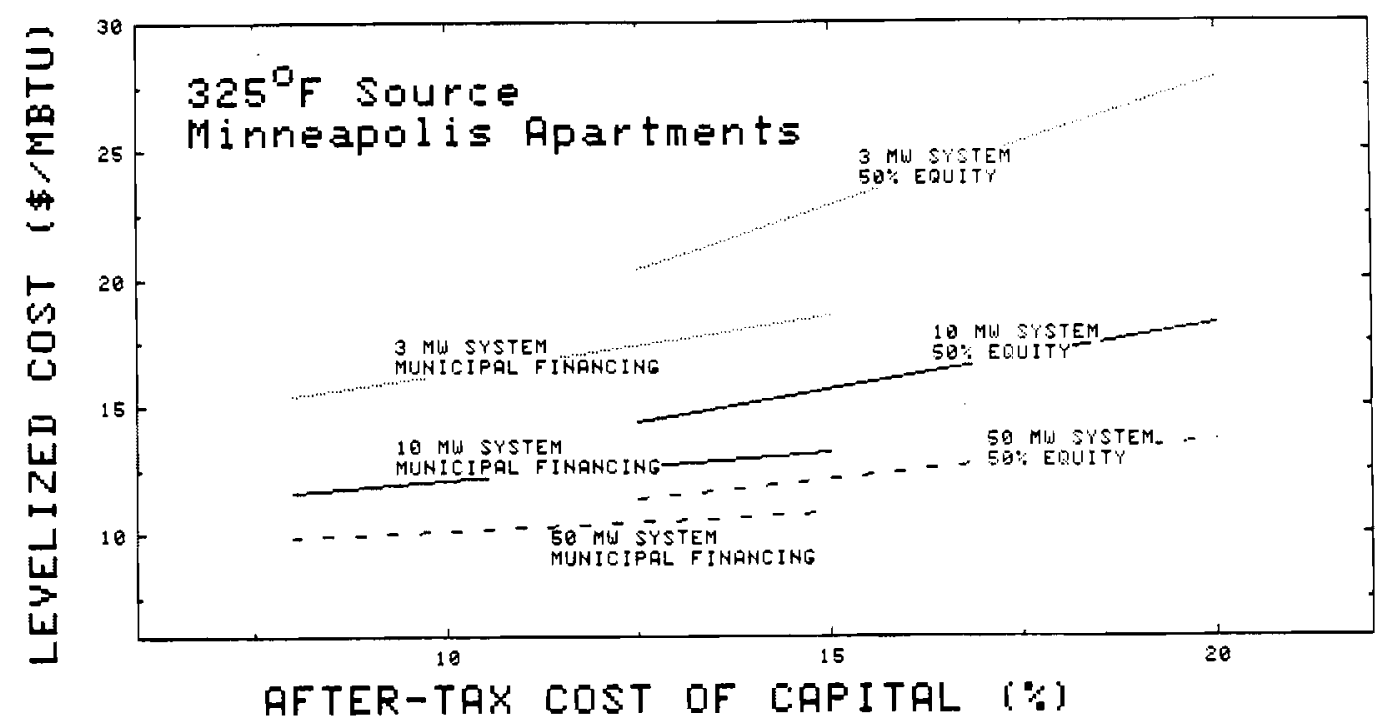

FIGURE 25. Effect of Financing on Residential ATES Systems Minneapolis Apartment Houses

\section{SUMMARY}

ATES economics for residential developments differ from point demand systems chiefly through inclusion of a distribution system. Distribution systems can add significantly to the cost of delivered energy where either the living unit density is low and/or the energy demand per unit is low. Financing options become more important because distribution systems are capital intensive. Systems of greater than $10 \mathrm{MW}$ size are required to gain the economies of scale available. 
In this third part of the investigation, a district heating/ATES system is modelled for the City of Richland, Washington, with a 5109 degree-day heating season, a system design temperature of $-5^{\circ} \mathrm{F}$, and a load factor of $30.4 \%$. The city is simulated by 18 different districts (Figure 26), a composite of trailer

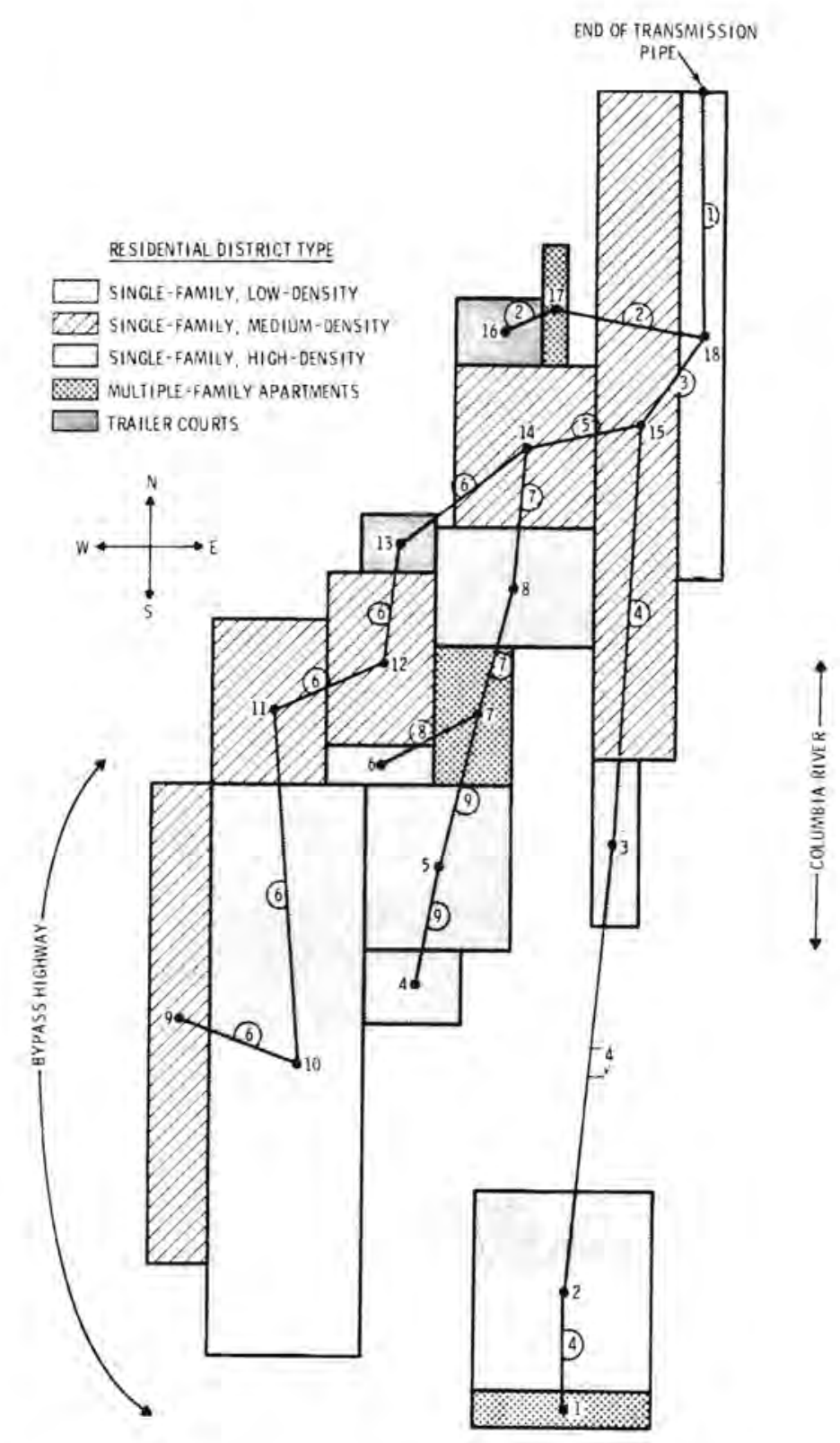

FIGURE 26. Layout of Heating Districts in Richland 
courts, garden apartments, and single family housing developments of varying density. Technical and economic assumptions are the same as employed in the preceding sections. End-use equipment is not considered in the cost estimates. The ATES user-heat exchanger is assumed to be at the northern edge of the city.

\section{BASE CASE RESULTS}

Figure 27 reports the estimated cost of ATES-supplied energy for the City of Richland under a range of financing costs. The $325^{\circ} \mathrm{F}$ and $250^{\circ} \mathrm{F}$ systems appear to be cost-effective for a range of municipal financing costs, but not for private financing. The $175^{\circ} \mathrm{F}$ system is questionable for all financing costs investigated.

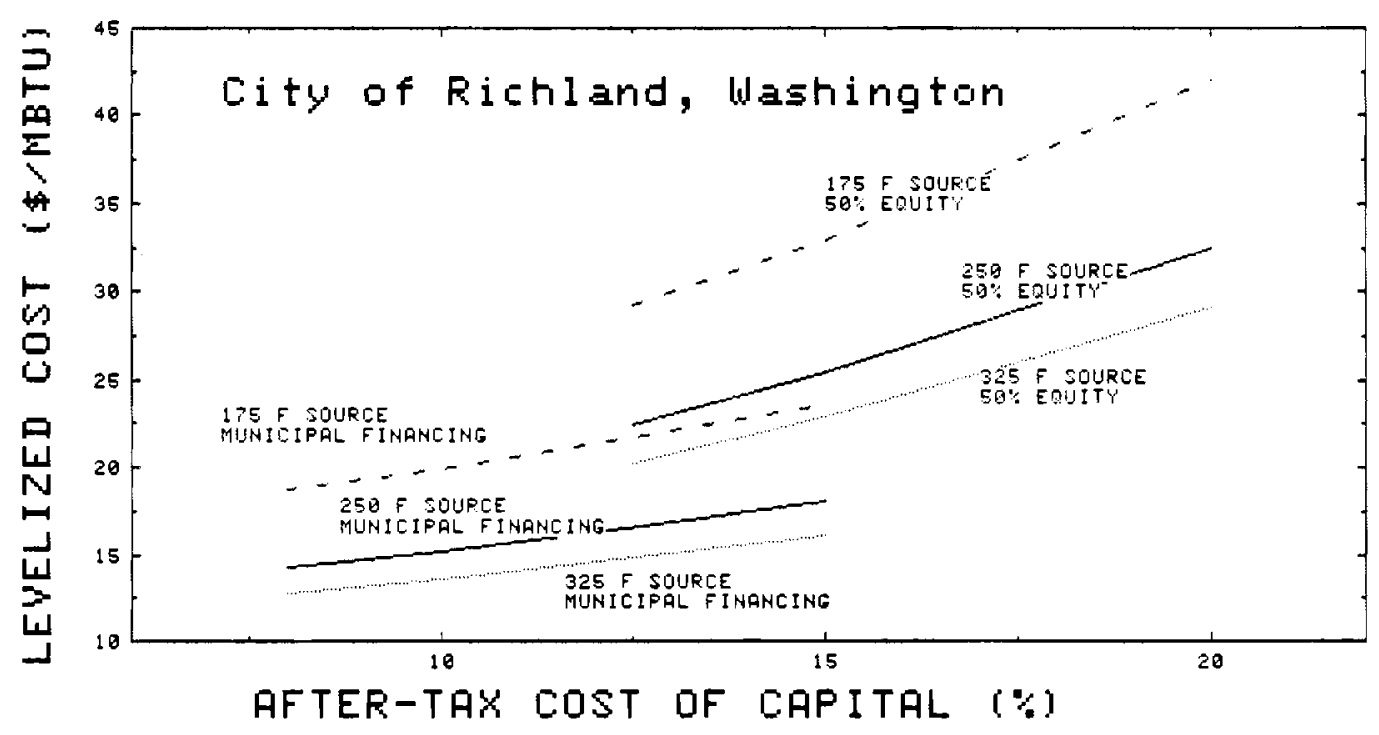

FIGURE 27. Energy Cost as a Function of Cost of Capital (City of Richland)

\section{COMPONENT COST BREAKDOWN FOR CITY-WIDE ATES}

Figure 28 depicts the component breakdown for the levelized cost of heating the City of Richland from an ATES facility. The capital fraction has increased significantly over that of the point demand systems, reflecting the high capital cost of the distribution system. The ratio of energy purchased to 


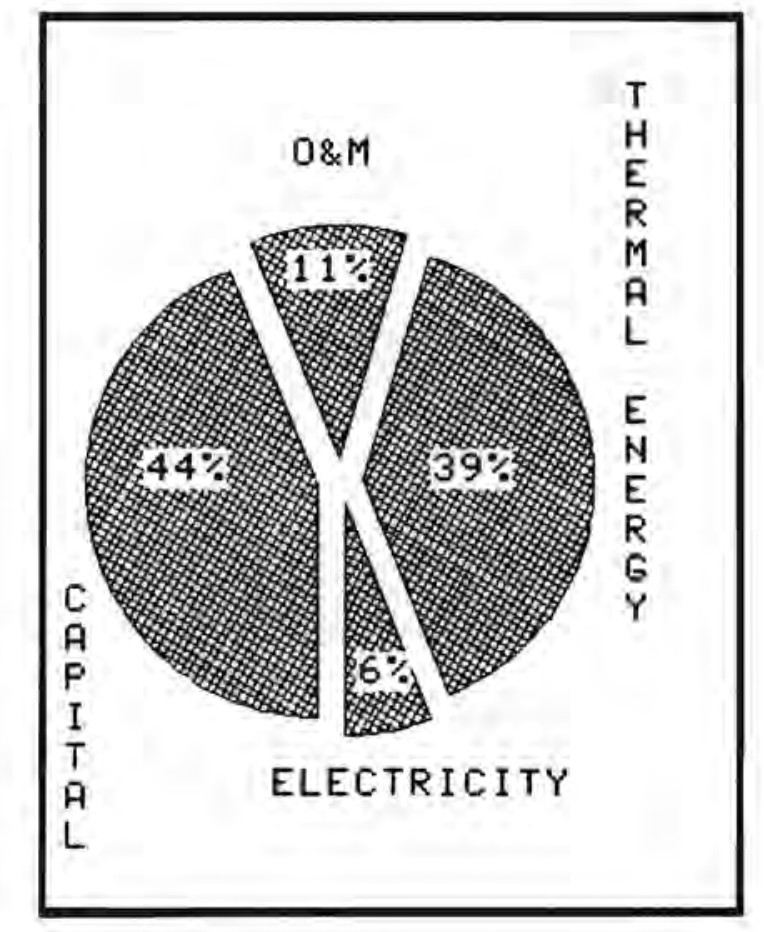

FIGURE 28. Component Cost Breakdown for ATES City of Richland

energy delivered has increased, because of the additional thermal losses in distribution system pipelines.

\section{PARAMETRIC ANALYSIS}

If we were to include retrofit costs for converting existing city dwelling units to district heating, then the cost of energy supply would be significantiy higher. Under the base-case assumptions, the levelized cost of heating rises $96 \$$ for each $\$ 1000$ of retrofit cost per unit. If we assume a $\$ 2500$ retrofit cost per unit in Richland, then (under base case conditions) the cost of heating is $\$ 15.96 / \mathrm{MBtu}$ for the $325^{\circ} \mathrm{F}$ system, and $\$ 17.55 / \mathrm{MBtu}$ for the $250^{\circ} \mathrm{F}$ system.

In Figure 29 the effect of transmission distance on the cost of energy supplied to the City of Richland is investigated. For a system the size of Richland (95 MW peak demand), hot water can be piped large distances with only sma11 cost increases. 


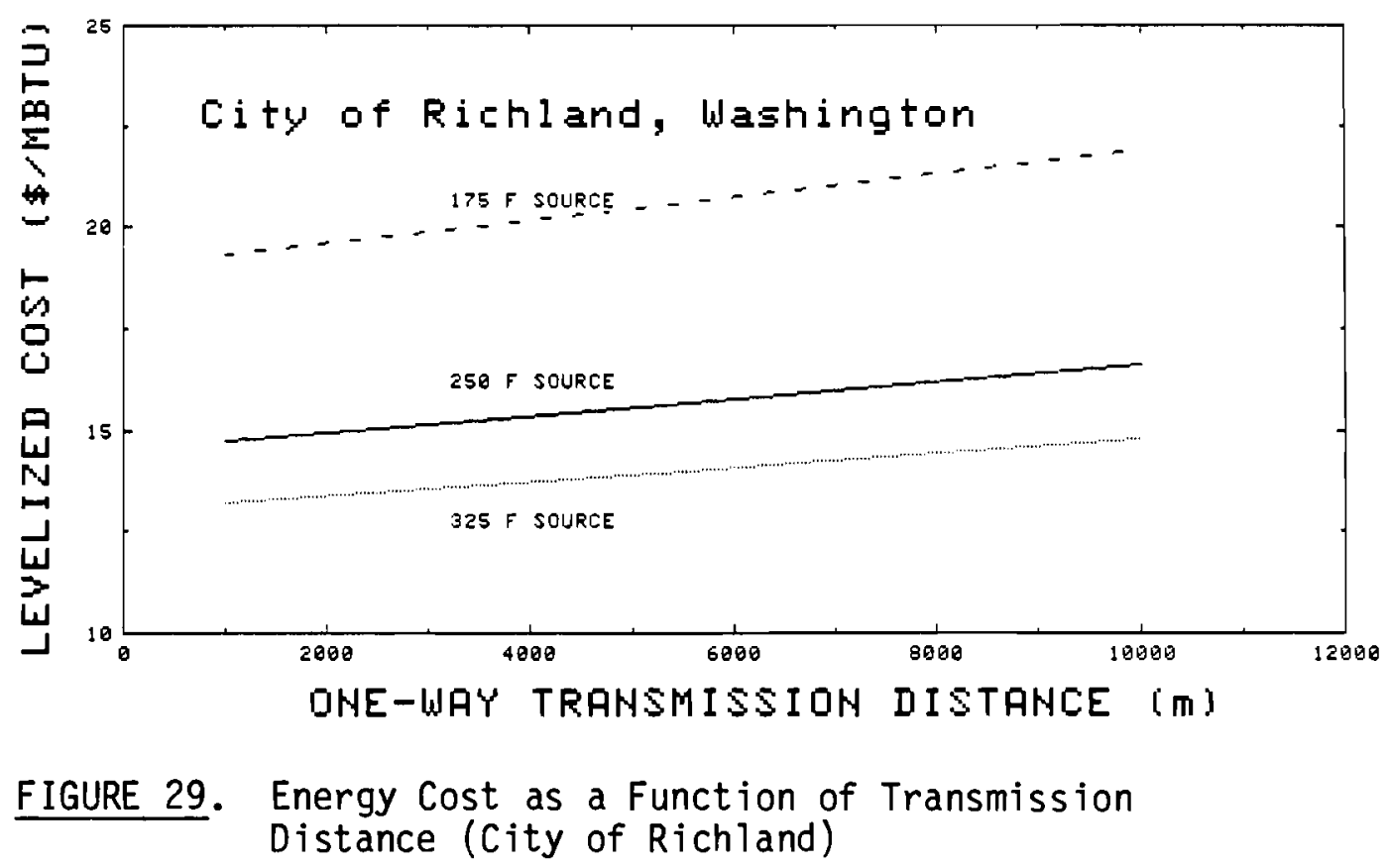

\section{SUMMARY}

Cost estimates for the City of Richland extend earlier discussions for point demand and residential development estimates. The extensive distribution system employed increases capital cost as a percentage of total cost. This magnifies the importance of acquiring inexpensive financing. 


\section{REFERENCES}

1. Meyer, C. F., Housz, W., Ayres, B. L., and Ingram, H. M., Role of the Heat Storage We 11 in Future U.S. Energy Systems, GE76TMP-27A, GE Tempo, Santa Barbara, CA, December, 1977.

2. Karkheck, J., E. Powe 11, and E. Beardsworth, "Prospects for District Heating in the United States," Science Vol. 195, March 1977.

3. Intertechnology Corporation, Analysis of the Economic Potential of Solar Thermal Energy to Provide Industrial Process Heat, Volume I, Warrentown, VA, February 1977.

4. Meyer, C. F., "Heat Storage Wells: Key to Large-Scale Cogeneration," Public Power, July-August, 1977.

5. Doughty, C., Hellstrom, G., Tsang, C. F., and Claesson, J., A Study of ATES Thermal Behavior Using a Steady Flow Model, LBL-11029, Lawrence Berkeley Laboratory, Berkeley, CA, January, 1981.

6. Huber, H. D., McDonald, C. L., Bloomster, C. H., and Schulte, S. C., User Manual for GEOCITY: A Computer Model for Geothermal District Heating Cost Analysis, PNL-2742, Pacific Northwest Laboratory, Richland, WA, October, 1978. 
.

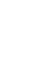

- 
APPENDIX A

POINT-DEMAND ATES COST ESTIMATES FOR $175^{\circ} \mathrm{F}, 250^{\circ} \mathrm{F}$, and $325^{\circ} \mathrm{F}$ SOURCES 

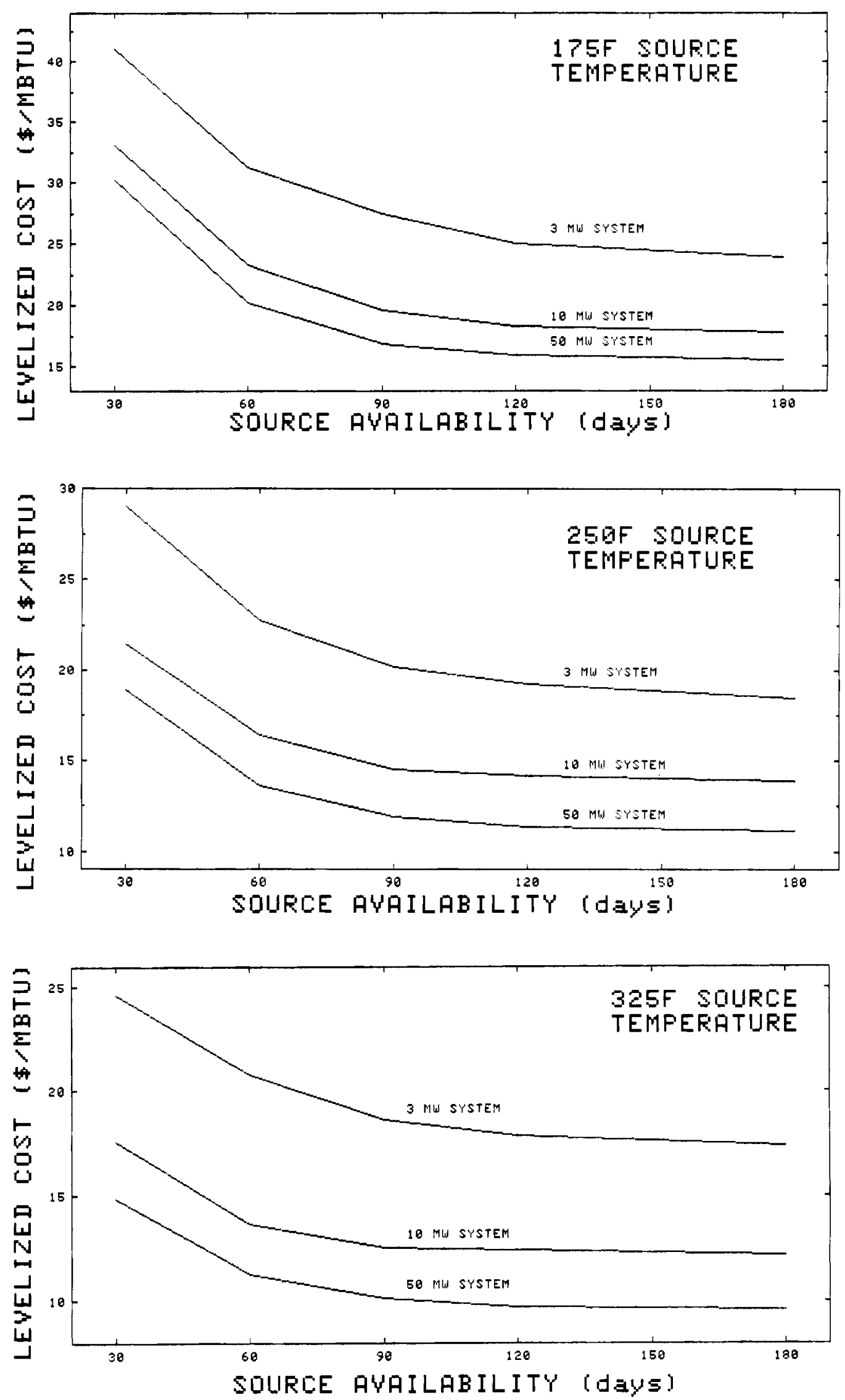

FIGURE A-1. Energy Cost as a Function of Source Availability 

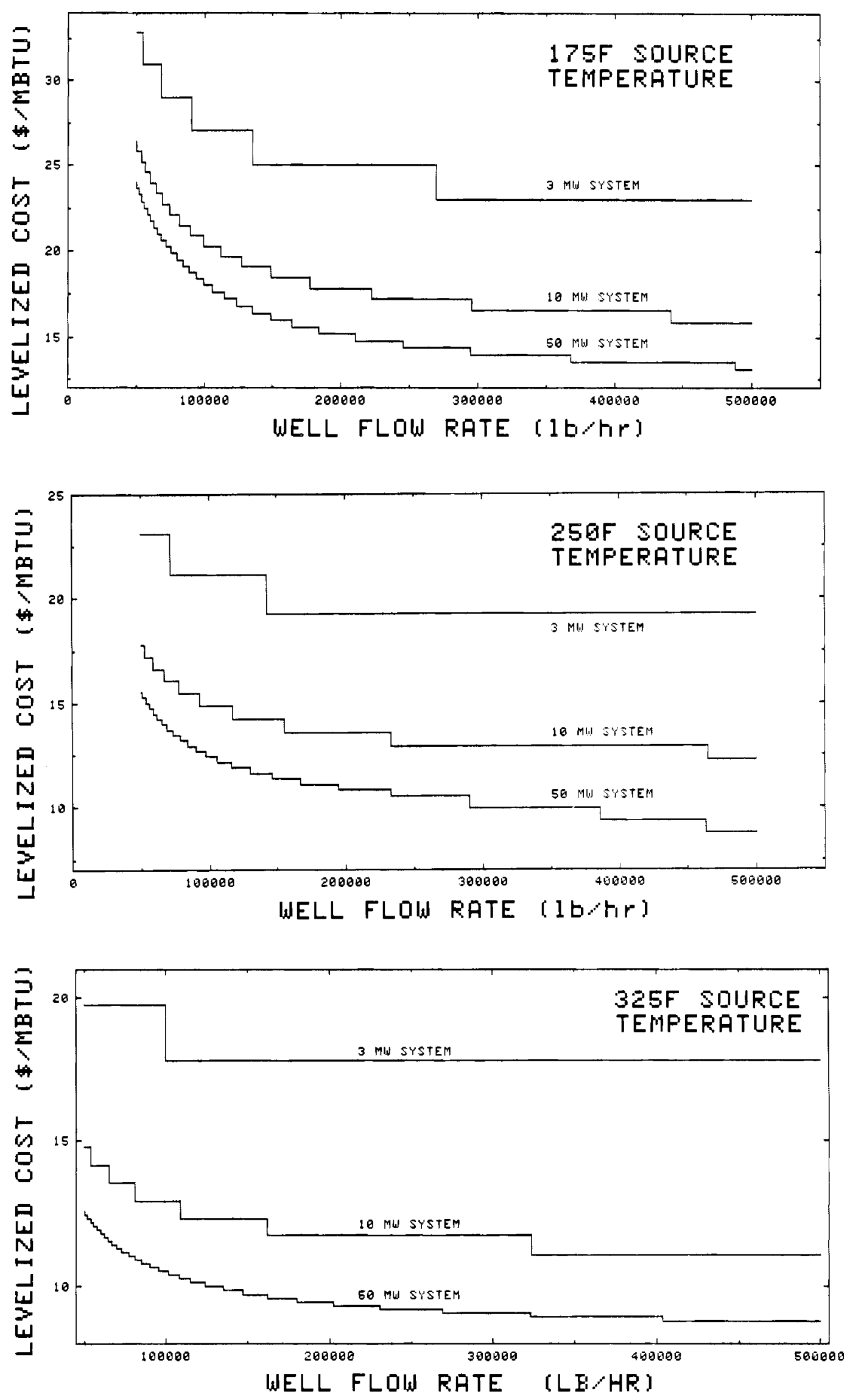

FIGURE A-2. Energy Cost as a Function of We11 Productivity 

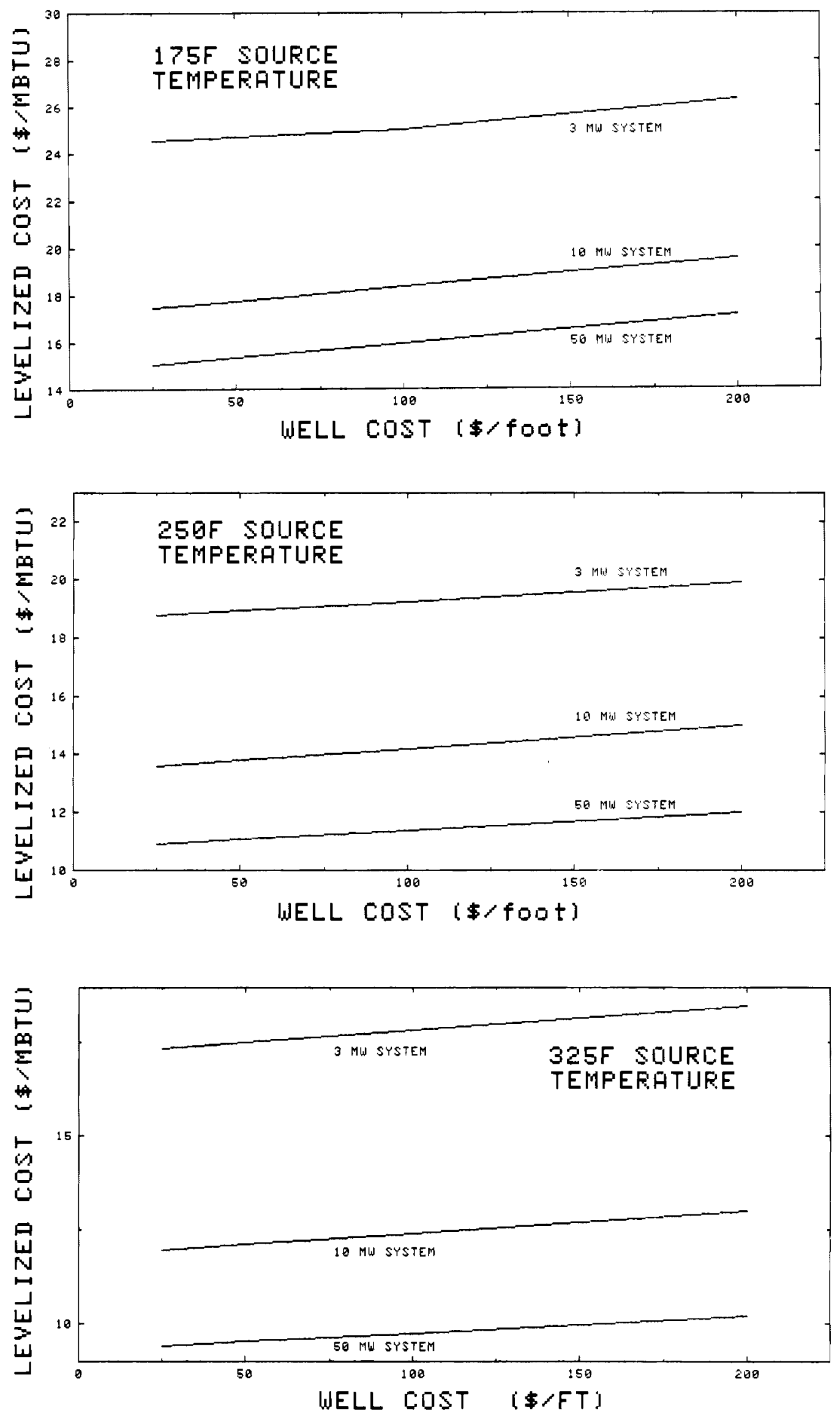

FIGURE A-3. Energy Cost as a Function of Well cost

A. 3 

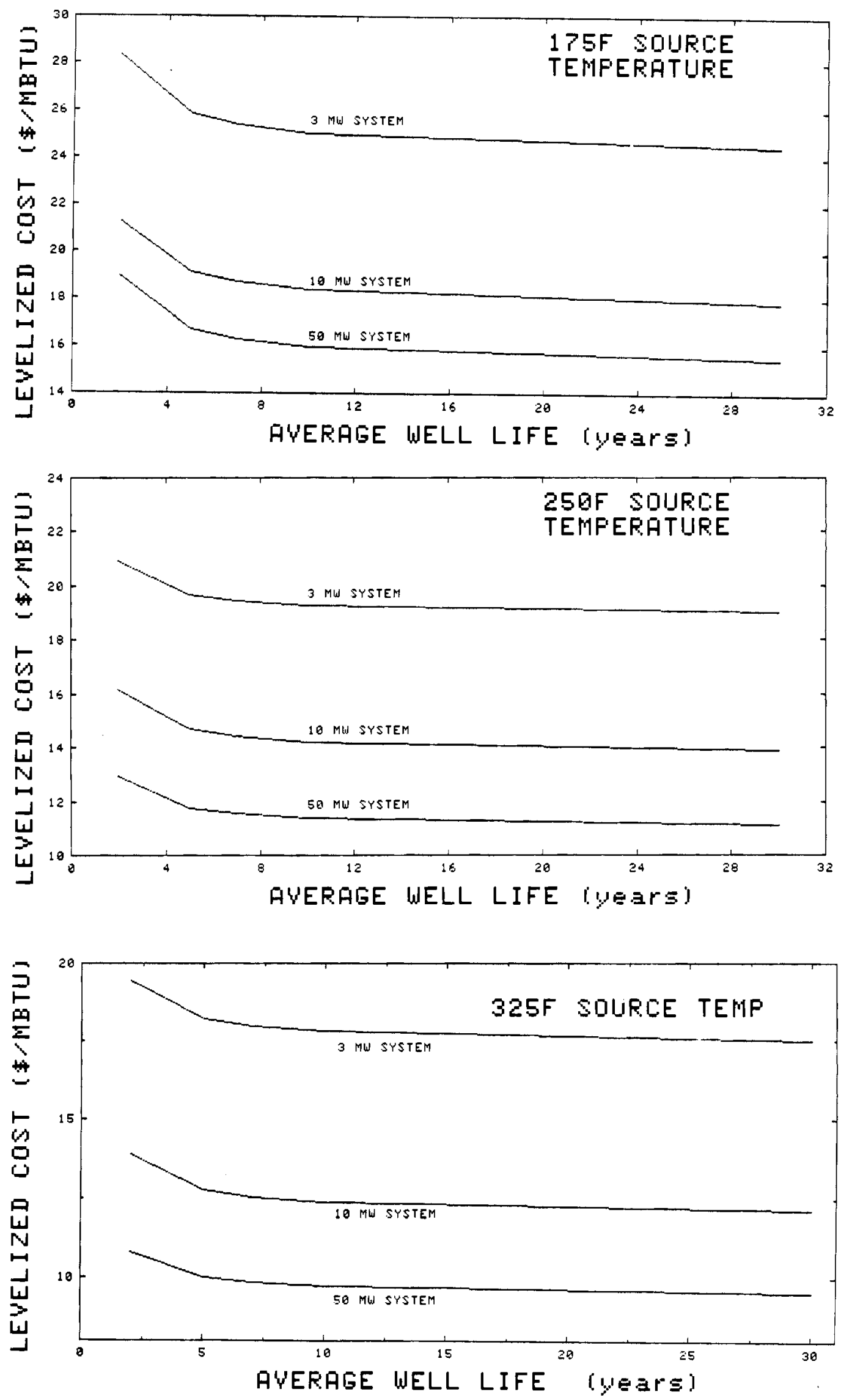

FIGURE A-4. Energy Cost as a Function of Well Life 

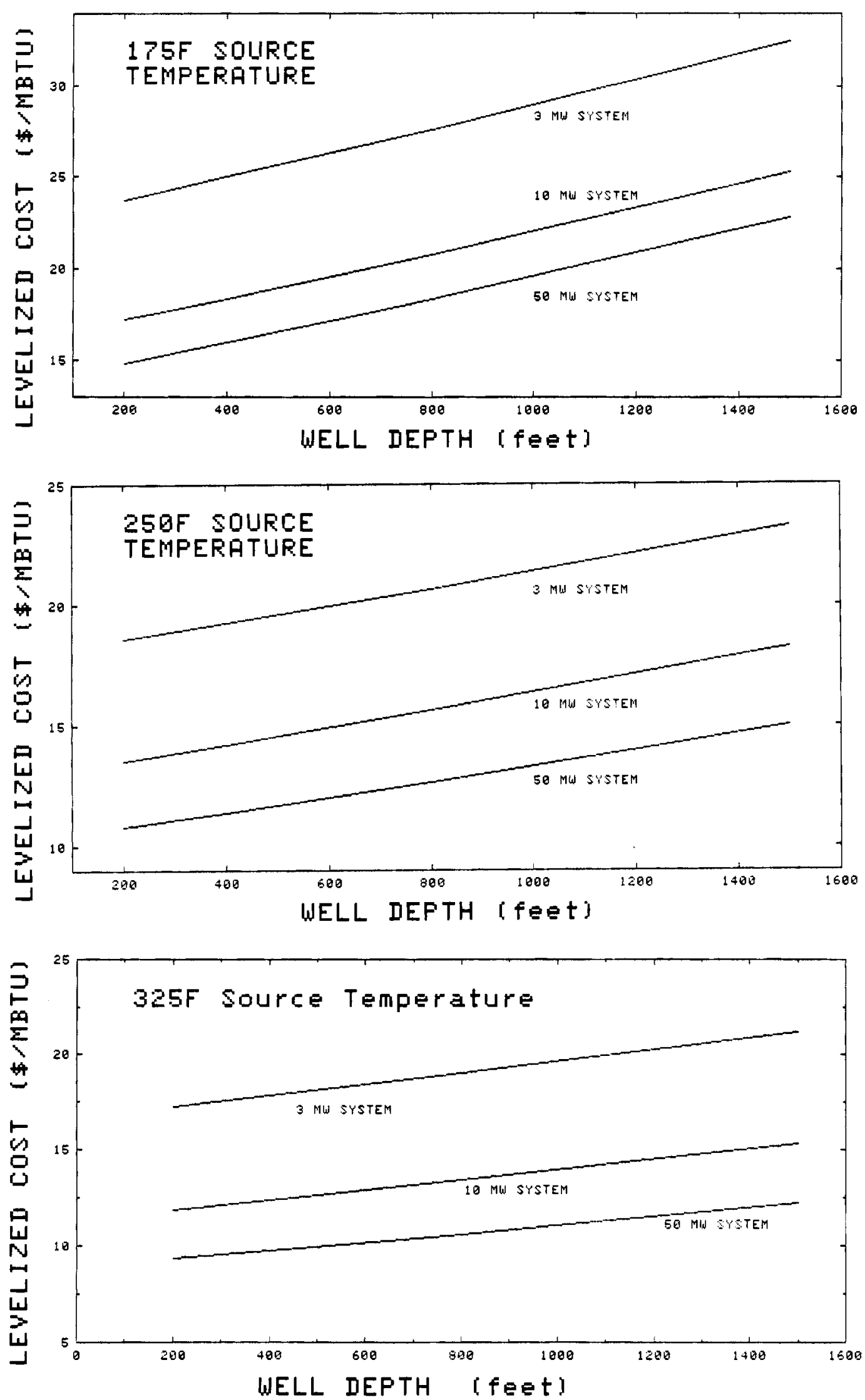

FIGURE A-5. Energy Cost as a Function of Aquifer Depth

A. 5 

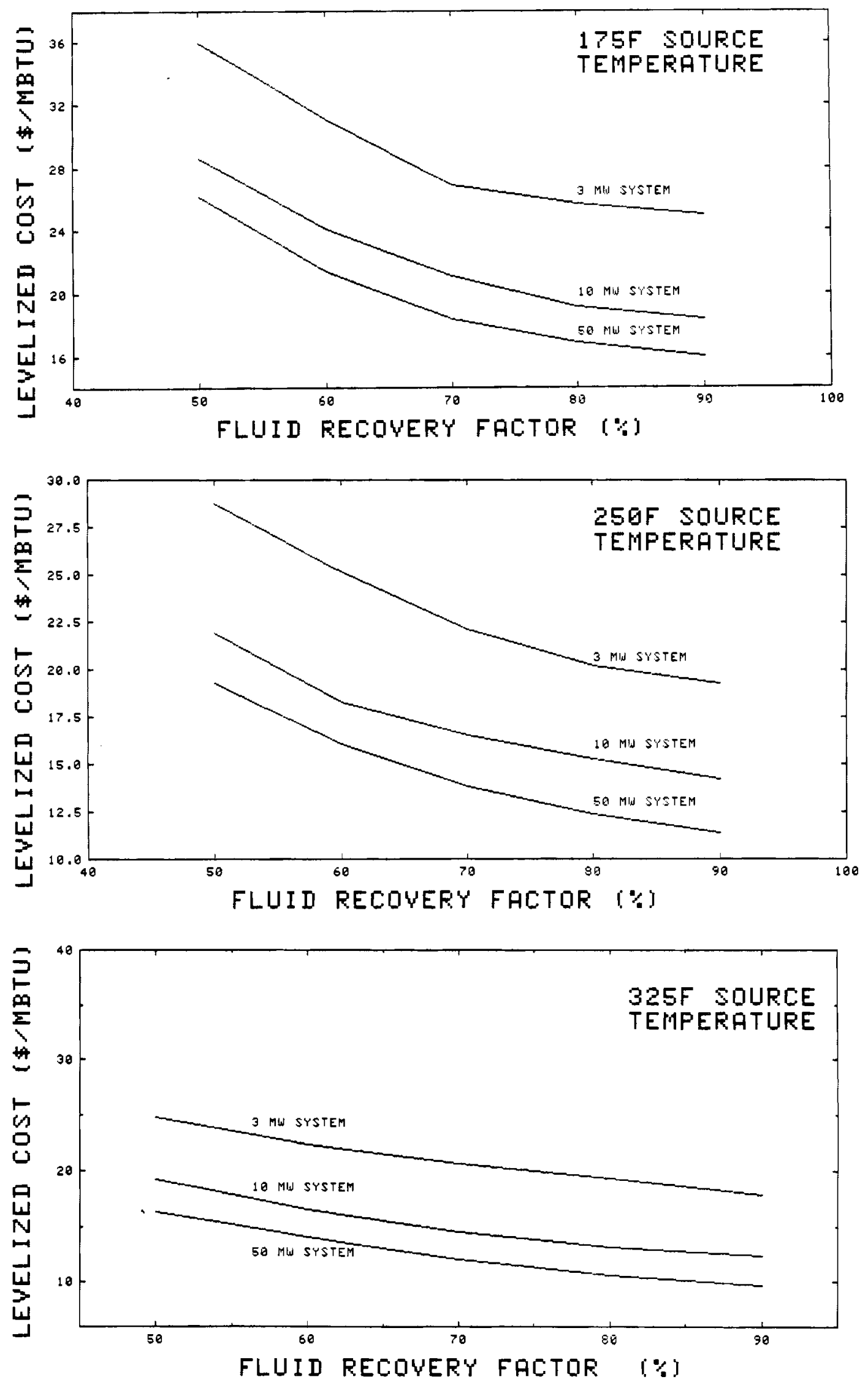

FIGURE A-6. Energy cost as a Function of Aquifer Performance 

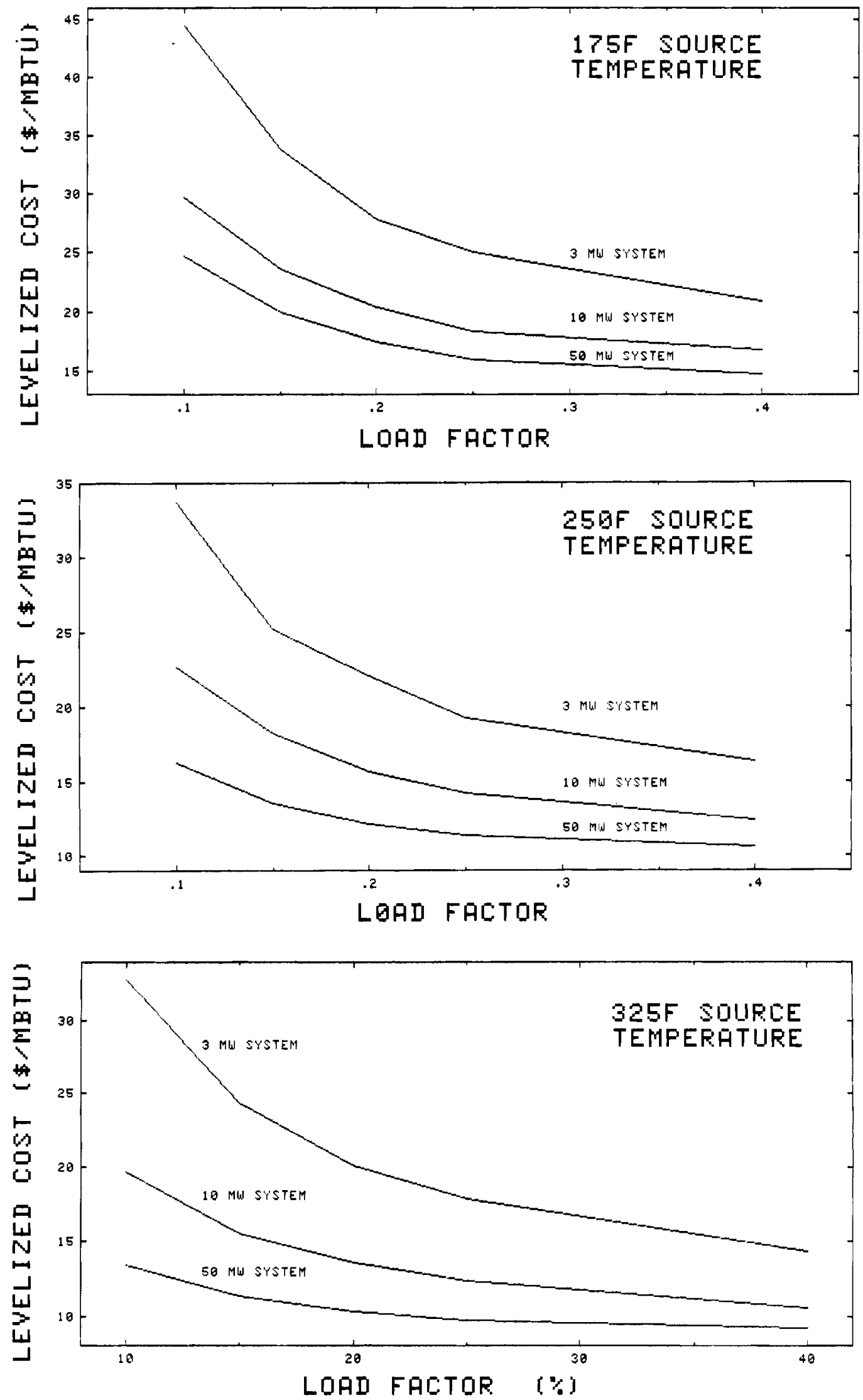

FIGURE A-7. Energy Cost as a Function of Demand Load Factor 

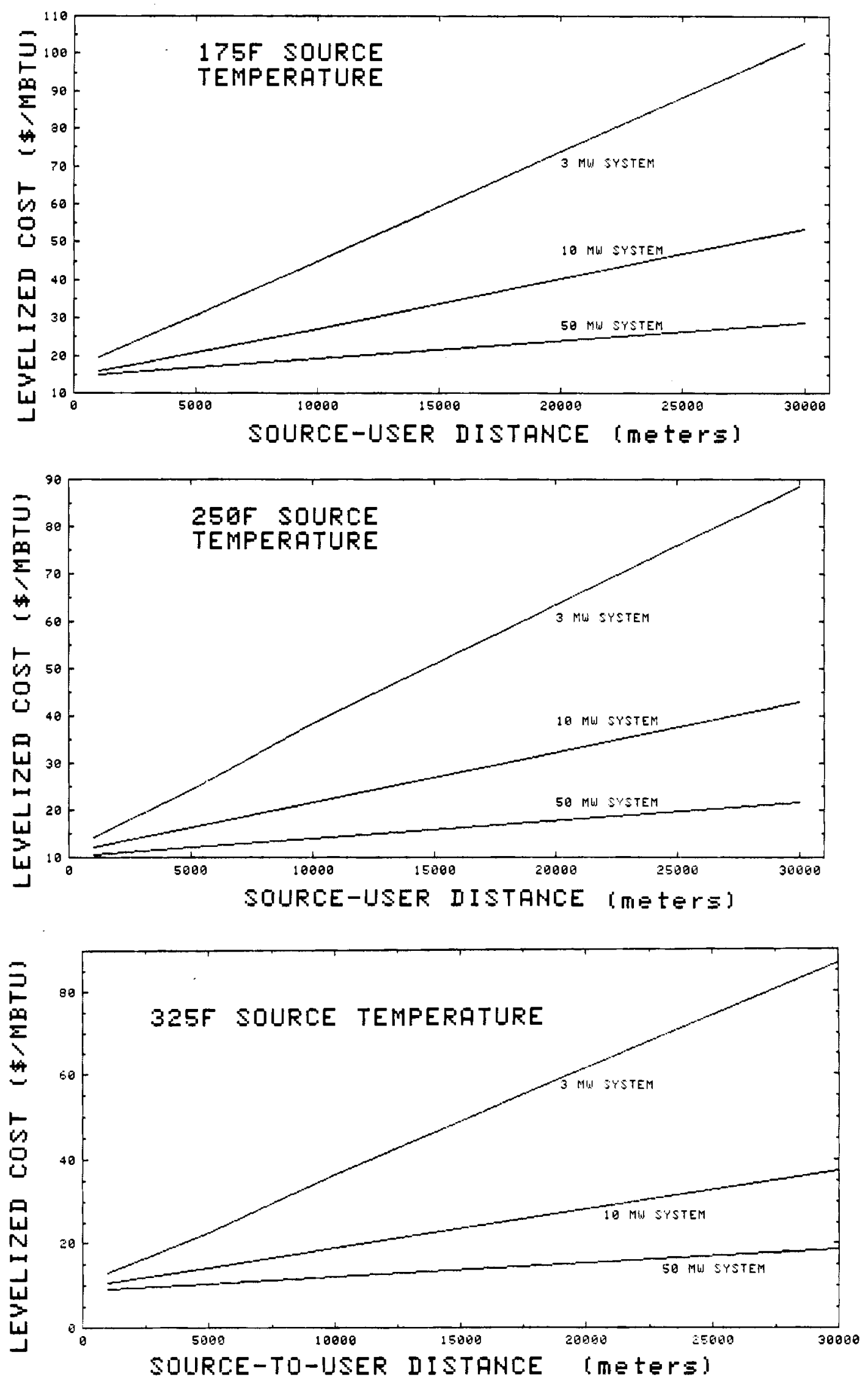

FIGURE A-8. Energy Cost as a Function of Transmission Distance 

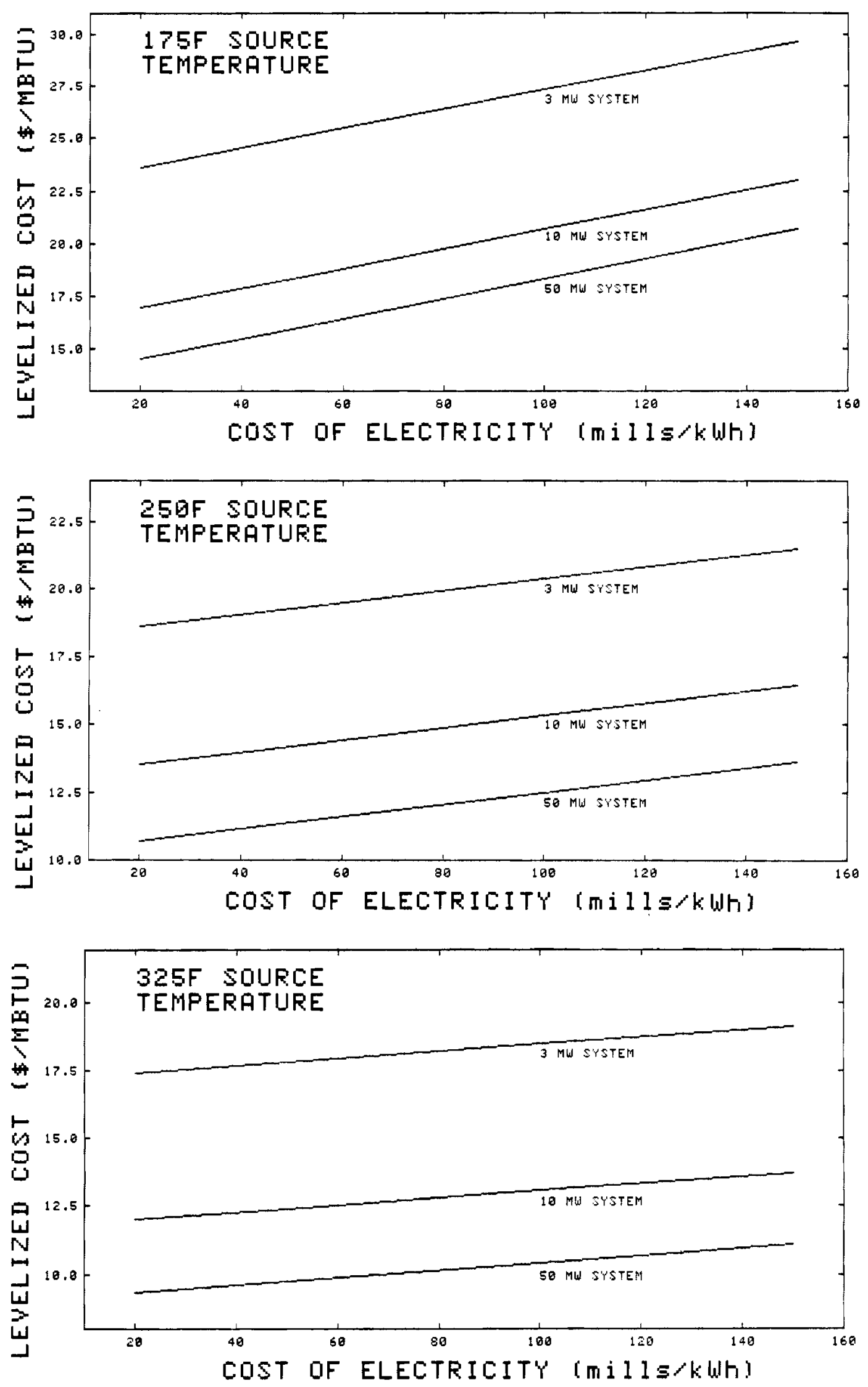

FIGURE A-9. Energy cost as a Function of Electricity cost 

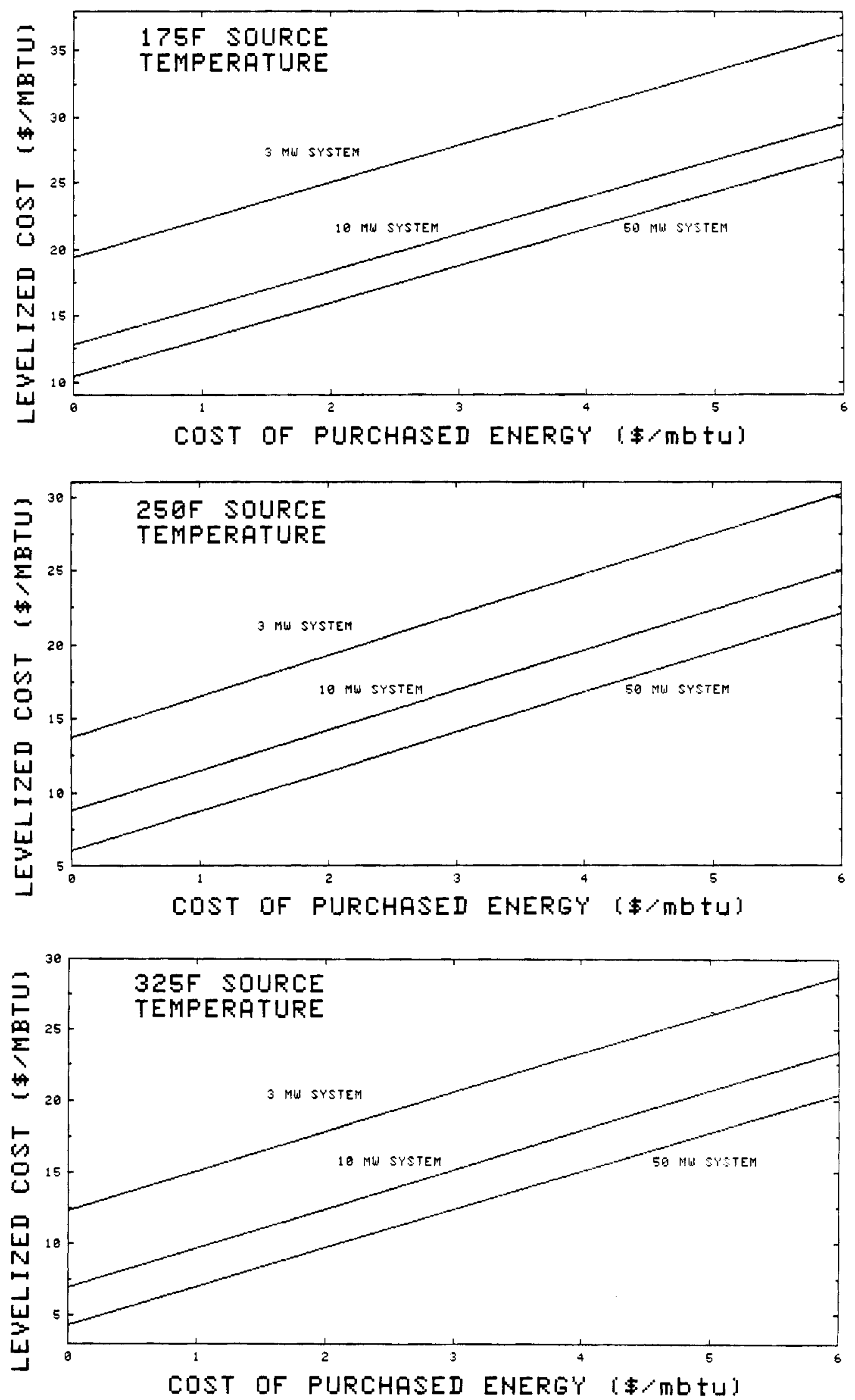

FIGURE A-10. Energy cost as a Function of the Price of Purchased Thermal Energy 

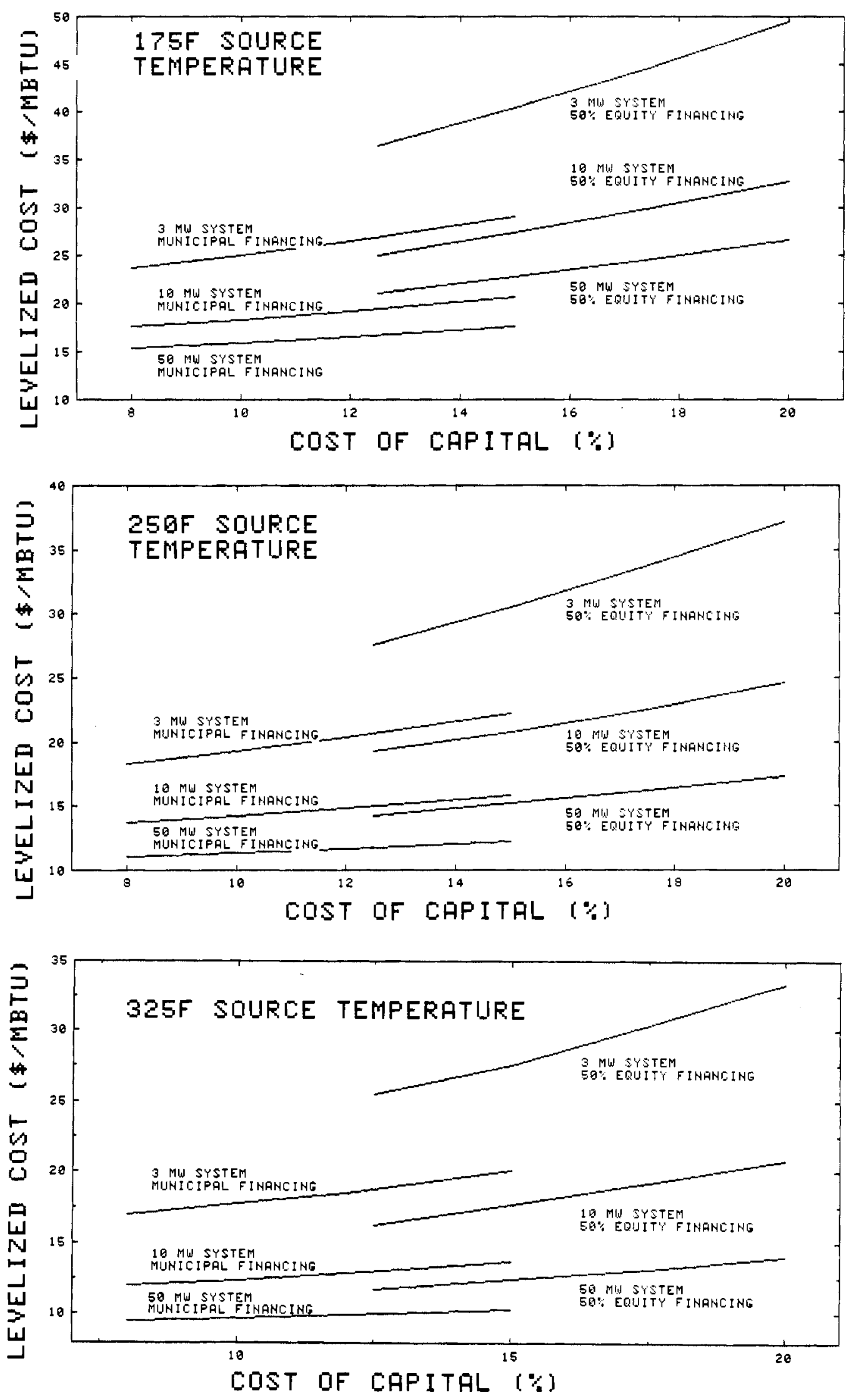

FIGURE A-11. Energy Cost as a Function of the cost of Capita? 

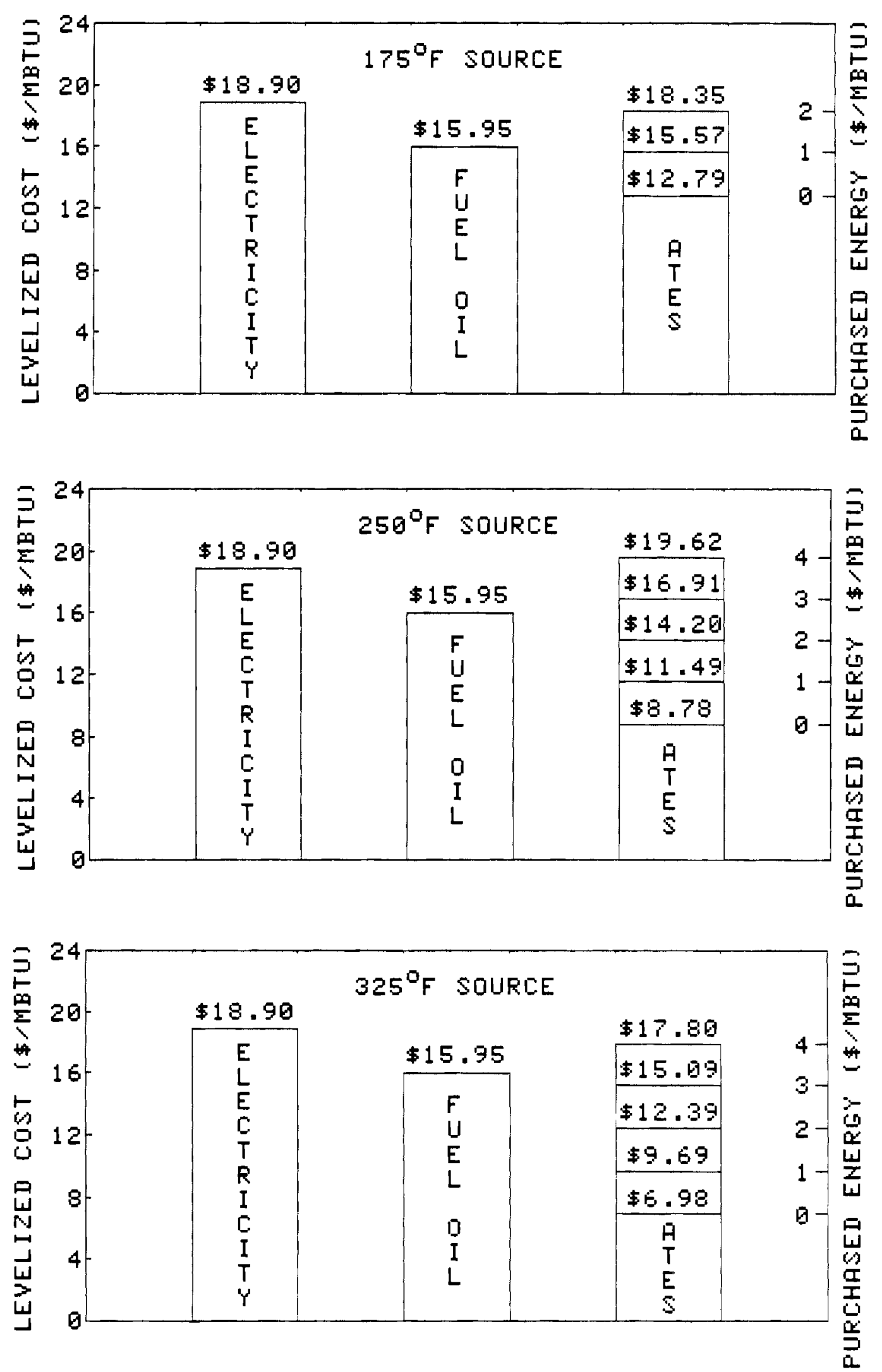

FIGURE A-12. A Comparison of the cost of ATES Against Conventional Technology 
APPENDIX B

RESIDENTIAL DEVELOPMENT ATES COST ESTIMATES FOR $175^{\circ} \mathrm{F}, 250^{\circ} \mathrm{F}$, and $325^{\circ} \mathrm{F}$ SOURCES 

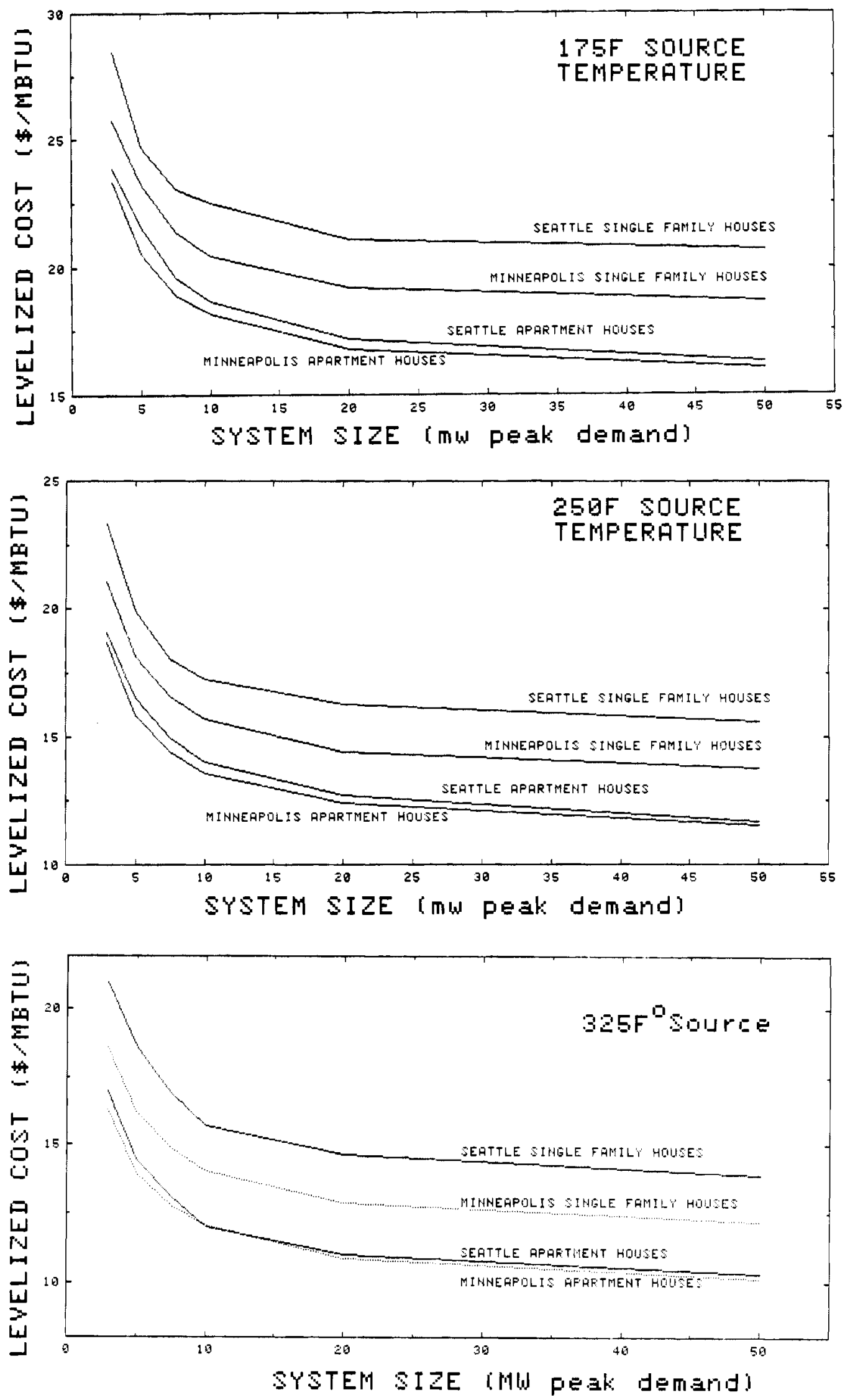

FIGURE B-1. Energy Cost as a Function of System Size (residential developments)

B. 1 

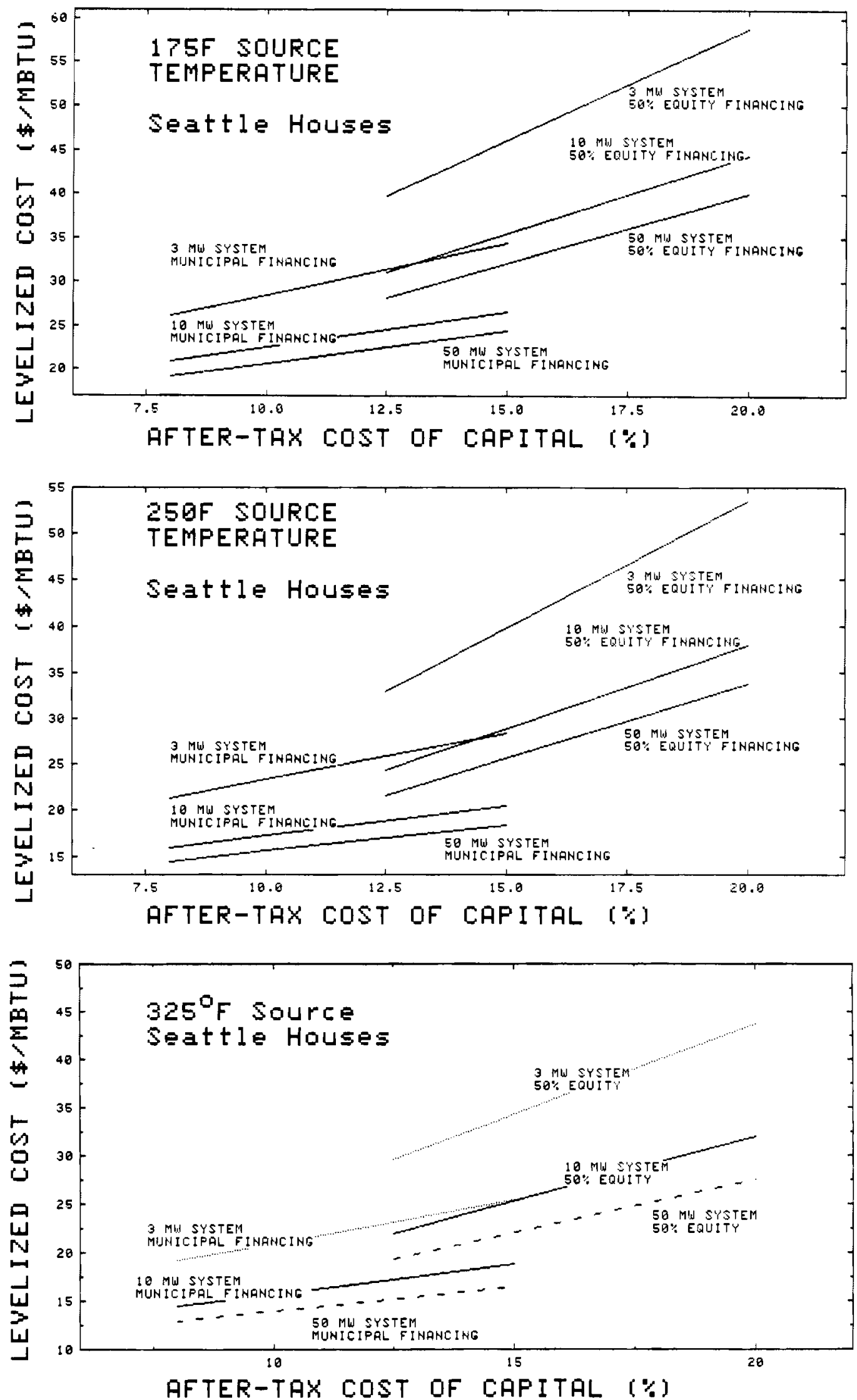

FIGURE B-2. Energy Cost as a Function of Cost of Capital (residential developments-Seattle houses) 

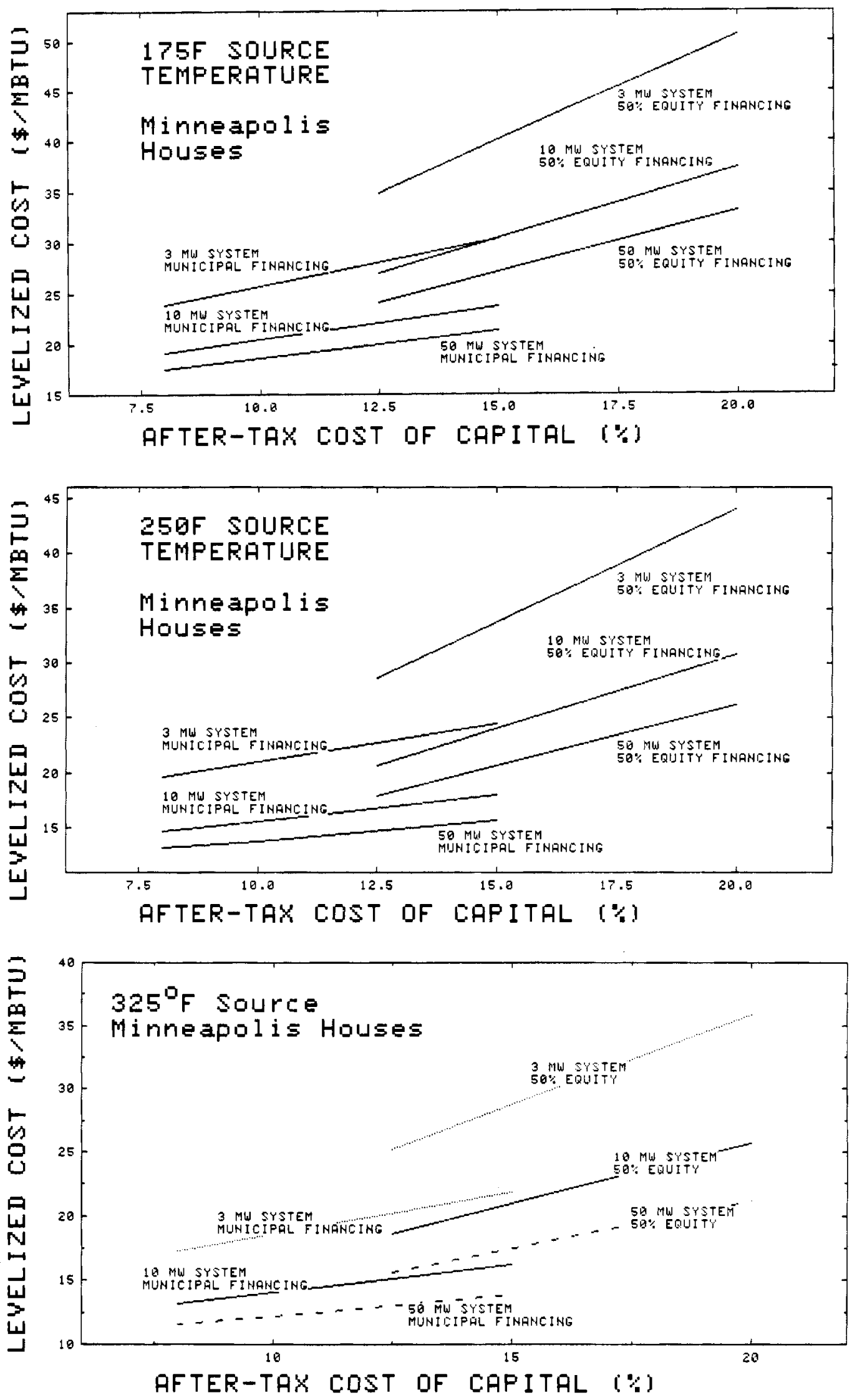

FIGURE B-3. Energy Cost as a Function of Cost of Capital (residential development-Minneapol is houses)

B. 3 

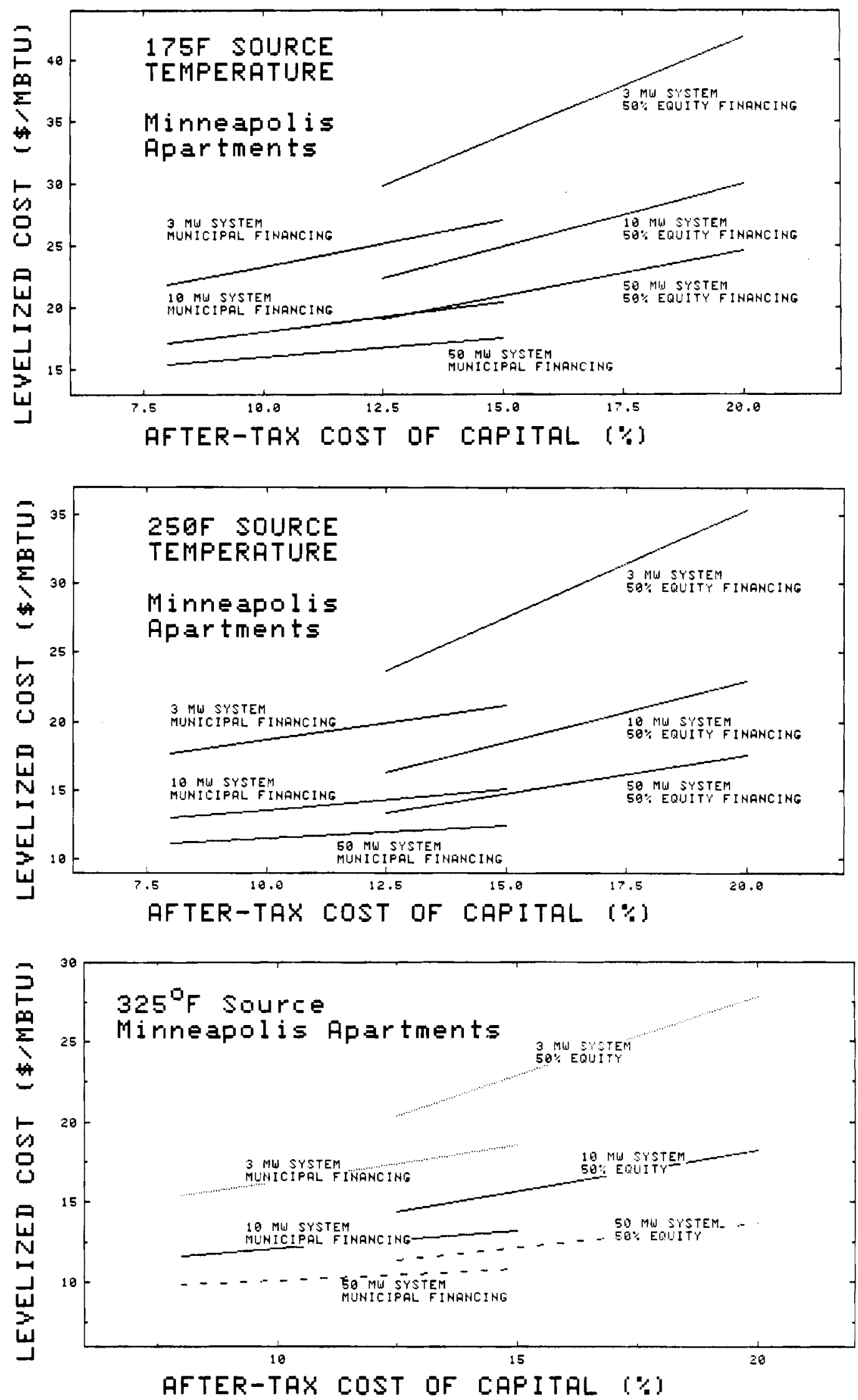

FIGURE B-4. Energy Cost as a Function of Cost of Capital (residential development-Minneapolis apartments)

B. 4 

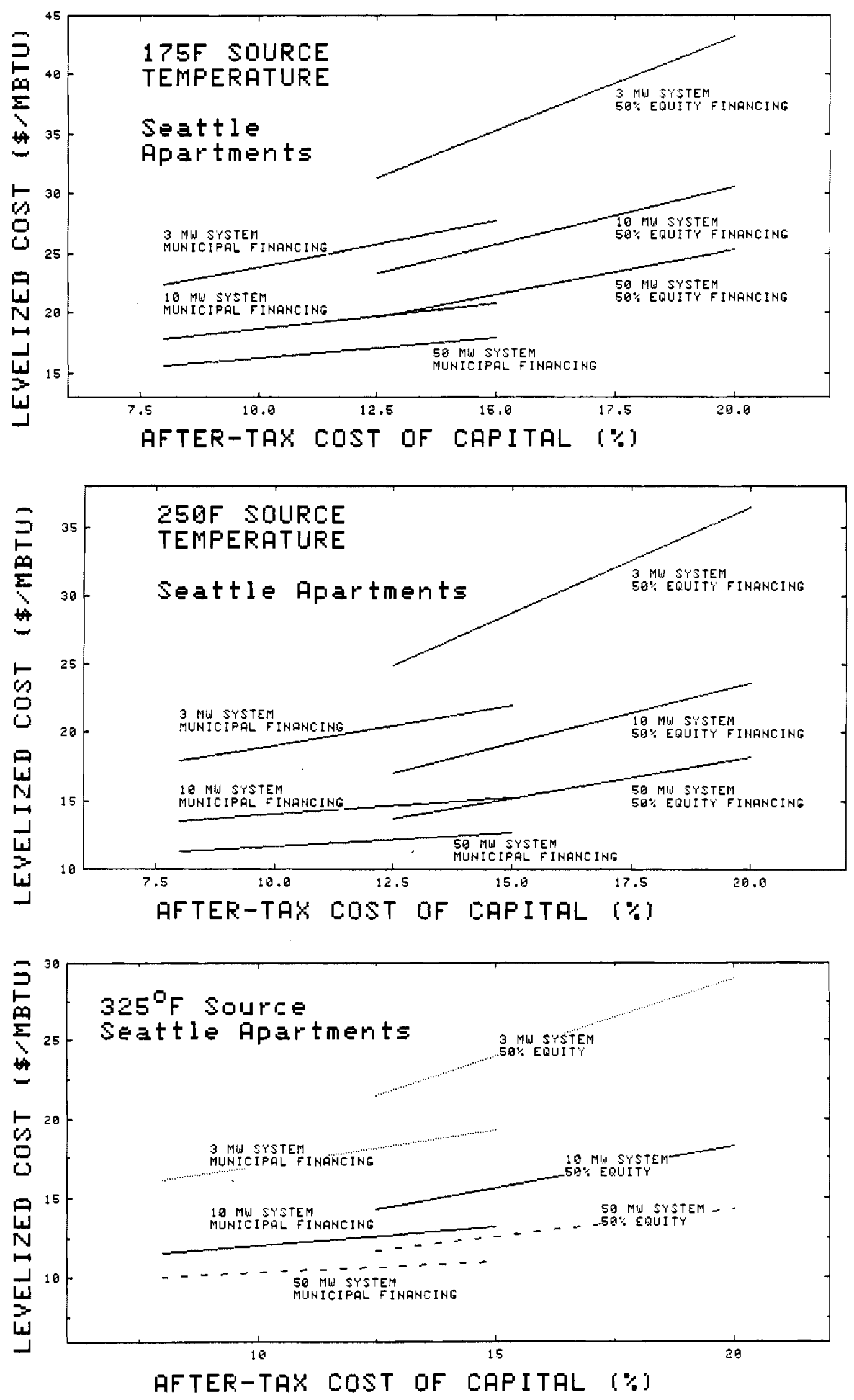

FIGURE B-5. Energy Cost as a Function of cost of Capital (residential development-Seattle apartments)

B. 5 


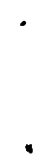




\section{DISTRIBUTION}

No. of

Copies

OFFSITE

A. A. Churm

DOE Patent Division

9800 S. Cass Avenue

Argonne, IL 60439

John J. Brogan

DOE Office of Energy

Systems Research

Washington, D.C. 20585

Arnold Epstein

Project Manager

CR-341, Forrestal Building

Department of Energy

Washington, D.C. 20585

T. Levinson

DOE Office of Energy

Systems Research

Washington, D.C. 20585

R. Shivers

DOE Office of Energy

Systems Research

Washington, D.C. 20585

Veronica Rabl

DOE Office of Energy

Systems Research

Washington, D.C. 20585

I. Gyuk

DOE Office of Energy

Systems Research

Washington, D.C. 20585

J. H. Swisher

DOE Office of Energy

Systems Research

Washington, D.C. 20585
No. of

Copies

Fred J. Molz

School of Engineering

Auburn University

Auburn, AL 36830

Donald Langmuir

Department of Chemistry and Geochemistry

Colorado School of Mines

Golden, C0 80401

Louis Stern

Dames \& Moore

6 Commerce Drive

Cranford, NJ 07016

Walter Hausz

$4520 \mathrm{Via} V$ istosa

Santa Barbara, CA 93110

Charles F. Meyer

1141 Cima Linda Lane

Santa Barbara, CA 93108

Chin Fu Tsang

Bldg. 90, Room 1012-H

University of California

Lawrence Berkeley Laboratory

1 Cyclotron Road

Berkeley, CA 94720

Victor E. Hampel

Integrated Information Systems

Computation Dept., L-275

University of California

Lawrence Livermore Laboratory

Livermore, CA 94550

L. Lorenz

Internorth

2223 Dodge Street

Omaha, NE 68102

27 Technical Information Center 
No. of

Copies

Matt Walton

Minnesota Geological Survey

319 15th Avenue, S.E.

Minneapolis, MN 55455

National Aeronautics and Space Administration

Asst. Adm. for Energy Programs

Washington, D.C. 20546

National Science Foundation

Division of Advanced Energy Research and Technology

Room 1140

1800 G Street, N.W.

Washington, D.C. 20550

Director

New York State Energy Research and Development Agency

Rockefeller Plaza

Albany, NY 12223

J. F. Martin

Oak Ridge National Laboratory

PO Box Y

Oak Ridge, TN 37830

Douglas D. Huxtable, Director

Energy R\&D

Rocket Research Company

York Center

Redmond, WA 98052

L. B. Katter

Rocket Research Center

York Center

Redmond, WA 98052

Craig Cooley

Terra Tek

University Research Park

400 Wakara Way

Salt Lake, UT 84108
No. of

Copies

W. G. Wilson

Sand ia Laboratories, Livermore PO Box 969

Livermore, CA 94550

Sandia Laboratories

Technical Library

Division 3141

Albuquerque, NM 87185

Charles Wyman

Solar Energy Research Institute

1516 Cole Boulevard

Golden, CO 80401

Allan Michaels

Solar Thermal Storage Programs

Argonne National Laboratory

Building 362

9700 South Cass Avenue

Argonne, IL 60439

John F. Spencer

Department of Ecology

State of Washington

Olympia, WA 98504

Jerry J. Phillips

Projects Manager

Tennessee Valley Authority

350 Commerce Union Bank Bldg.

Chattanooga, TN 37401

William Waldrop

Assistant Branch Chief

Water Systems Development Branch

Division of Water Management

Tennessee Valley Authority

PO Drawer E

Norris, TN 37828

L. Radosevich

Sandia Laboratories, Livermore

PO Box 969

Livermore, CA 94550 
No. of

Copies

Donald L. Reddell

Agricultural Enginering Dept. Texas A\&M University

College Station, TX 77843

U.S. Army Corps of Engineers

Attn: Library

PO Box 59

Louisville, KY 40202

U.S. Department of Energy

Attn: Chief, APMBR

Division of Energy Storage

Systems

Washington, D.C. 20545

U.S. Department of Energy

Attn: Director, Policy and Planning

Office of Conservation and

Solar Applications

Washington, D.C. 20545

U.S. Department of Interior

Attn: Natural Resources

Serials Branch (G/E)

Washington, D.C. 20240

Kevin Billings

Legislative Assistant

Office of Congressman

Sid Morrison

1330 Longworth Building

Washington, D.C. 20515

Robert D. MacNish

District Chief

Arizona District

U.S. Geological Survey

Federal Building

Tucson, AZ 85718

Union Carbide Corporation

Nuclear Division

Attn: Library

$Y-12$ Plant

PO Box $Y$

Oak Ridge, TN 37830
No. of

Copies

Stanley N. Davis

Department of Hydrology and

Water Research

University of Arizona

Tucson, AZ 85705

W. E. Soderberg

Program Director, ATES

University of Minnesota

200 Shops Bldg.

319 15th Avenue, S.E.

Minneapolis, MN 55455

James W. Crosby II I

Geology Department

Washington State University

Pul lman, WA 99164

David L. Schreiber, Ph.D., P.E. Consulting Hydraulic Engineer

PO Box 1087

(\% The Colony)

Coeur d'Alene, ID 83814

ONS ITE

DOE Richland Operations Office

H. E. Ransom

78 Pacific Northwest Laboratory

M. A. Beckwith

D. Blahnik

C. H. Bloomster

10 D. R. Brown

S. M. Brown

D. B. Cearlock

D. E. Deonigi

T. J. Doherty

P. J. Duetsch

J. R. Eliason

A. F. Gasperino

P. L. Hendrickson

$10 \mathrm{H}$. D. Huber

C. T. Kincaid

L. D. Kannberg

W. W. Laity 
No. of

Copies

W. V. Loscutoff

R. P. Marshall

D. A. Meyers

J. R. Raymond

10 R. W. Reilly

J. A. Stottlemyre

L. D. Williams

G. E. Wukelic STES Library (20)

Technical Information (5)

Publishing Coordination (2) 